\title{
Gratuitous supplement
}

Like many other situations in my life, I found myself in Leuven in September 2008 without even knowing how I got here! I vividly remember that before finishing my master's studies, I thought a lot about what could be the best decision; to continue my $\mathrm{PhD}$ studies in Iran or embark on a PhD project abroad. Eventually, I decided to do a $\mathrm{PhD}$ abroad. Was it the right decision? Perhaps! Well, I can never know how things would have turned out if I had chosen another path in my life. But did I like it? No doubts, Yes!

As always, I am indebted to many people.

I would like to thank the committee members, Professor Octave, Professor Baes, Professor Baekelandt (it was really sad to hear about your loss as we were preparing the thesis), and Professor Jossin, all of whom kindly accepted to read my thesis and send me very helpful suggestions.

Bart, it has been a great pleasure to work in your lab. Our interaction changed my views about science and I learned many different things from you. The one I like most is this: "first, I should be able to convince myself, and then I might have a chance to convince others as well." Among the various skills I acquired during my PhD studies, the one I appreciate most is "critical thinking". Sometimes, I assumed that because I understood "one", I could also understand "two", as one and one make two! Then, you reminded me that I must understand "and". Thank you for giving me the opportunity to work in such an amazing environment. In your lab, I enjoyed doing science as much as I had fun interacting with people from all around the world. It has been such a remarkable experience that I am almost sorry that I am finishing my $\mathrm{PhD}$ !

Bassem, I like to thank you for inviting me to Leuven for the interview five years ago and linking me to Bart. I learned from you that one should have at least one theory, preferably several, for every possible observation. I can just say that I am happy that I got to know a special Drosophila neurobiologist who has a picture of Che in his office and write about Middle East politics (I really think this is unique).Thanks a lot.

I could have never finished this work if I was not lucky enough to meet Carlos and Annette. Carlos, your constructive feedbacks and your positive attitude in difficult 
times was a great help. Your never ending smiles convinced me that the "happy scientist" is not just a myth. Annette, It was you who showed me how to combine planning and flexibility (and I guess a bit of diplomacy as well!) to succeed. I know that I was difficult to handle at times but you skillfully showed me what the best way to continue was. It was a great pleasure working with you and thanks for everything.

The first week of the $\mathrm{PhD}$ was one of the most confusing weeks in my life because of the new social and scientific surroundings ${ }^{1}$. Luckily, it did not take too long to meet Bruno. Bruno, you helped me to find my way around in the lab and become independent. I remember how quickly you showed me where and when different departmental seminars were, in particular the ones with free sandwiches! That was very useful. You are an amazing friend and I hope we get to travel to Iran together.

I have met so many nice friends and colleagues in the lab that it is actually difficult to have a concise acknowledgment! So expect a long list (stochastic ordering of names!). Lujia (it is never too late to open the grocery), Hugo (there are those letters that are neither written, nor pronounced), Pierre (don't worry, many roads to Monaco), Tilmann (I consider myself lucky to know you), Carlo (I am sure you will publish nice papers in my journal), Sam (I will thank you in the supplementary acknowledgment), Iryna (Bonjour mon amie!), Smaragda (nice to finish together and you saved my thesis), Anna, Fabrizio, Wim, Zeljko (no comment!), Alexandra, Tomasz, Ellen, Soraia, Liesbeth, Hermien (how is my good friend?), Amaia, Ina, Lucia, Francesc (for the unforgettable western blot of my life), Manuel (for lending me your "boos" card), Gerard (for trying to understand my jokes), Evgenia (really time to say "bye guys"), Samer (with you I realized I sometimes need to replace "why" with "why not"), Dominik, Nobuto (remember the analogy between Kebab and gamma secretase), Vanessa (do not forget, LIFE is like a watermelon!), Marco (the genius of all the time), Hilde (I could not even make it to Belgium without you), Eliane (thanks for helping me with the thesis), Isabel (for the battery of the laptop!), Sabine, Manasi (for the inspiring Ladoo movie), Sulieman (cheers man!), Katrien and Katleen (you knew almost everything), Gert, Zhiyong, Elke (we had a few in the lab, all very nice people), Tine (it was fun working with you), Veronique and Jonas (no $\mathrm{PhD}$ for me without you) and Lutgarde (one of my best friends!). Thank you all so

\footnotetext{
1. As I was preparing for the public defense, I realized that the last weeks can be as confusing as the first weeks.
} 
much. I almost forget to thank Pietro, Nadav, Yunhong and Sarah with whom I shared not only an office but also opinions (and gossip!). Amantha, not many people think I can be a good scientist and you are one of them. Thank you so much for helping me to continue in science, not to mention the biscuits! Eventually, a special mention in my thesis should go to my "alarm clock", without whom I may never have made it!

I would also like to thank the early morning people of the department who prepared everything before we arrive in the lab. Many of them I do not know by name but I truly appreciate their great help.

I would like to take this opportunity to thank the Iranian community of Leuven without whom I would have finished this work a couple of months earlier! In particular, Hamid o Nahid, Hassan o Tina, Omid o Elham and Ahmad o Maryam. Hamid, you rely too much on your brain, it is one of the most overrated organs! Hassan, I should be more respectful to you as a potential future colleague. Omid, I think everyone deserves some respect, even you (quote). Ahmad, if you had saved all those 5 minutes waiting for me, you would have finished your PhD by now. Thank you all.

I would like to thank my friends at Bon Yakhteh, in particular Ehasn, Yousof, Hamid and Shervin for generously helping me with my never ending paper works in Iran, not to mention the great Dizis that we had with Dr. Soleimani and Dr. Karimi in Darakeh.

I would like to thank my parents and my brothers who were there whenever I needed them. I am also really grateful to my parents-in-law and my sister-in-law who have always been very supportive of both Elham and me.

Words cannot thank you Elham. But you know it yourself that without you it would have been impossible. And the journey continues with you... 
SUMMARY

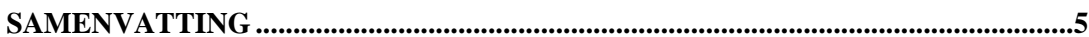

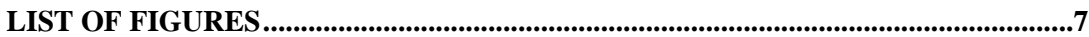

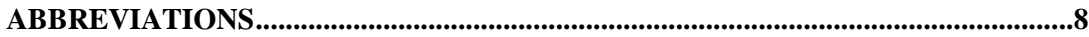

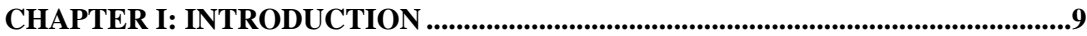

1.1 AMYLOID PRECURSOR PROTEIN DOMAIN STRUCTURE AND FUNCTION .....................10

1.2 EVOLUTION OF THE AMYLOID PRECURSOR PROTEIN FAMILY...................................15

1.3 PRoteOLYTIC PROCESSING OF AMYLOID PRECURSOR PROTEINS ...............................17

1.4 TEMPORALLY AND TISSUE SPECIFIC REGULATED EXPRESSION OF APP FAMILY

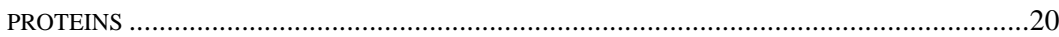

1.5 THE INTERACTION NETWORKS OF APP, APLP1 AND APLP2 SHOW SPECIFICITY .....21

1.6 VARIOUS ROLES OF THE APP MEMBERS IN THE NERVOUS SYSTEM ...........................22

1.6.1 The extracellular domain in development of $C$. elegans ....................................22

1.6.2 D. melanogaster's APPL in axonal wiring and synaptic function......................23

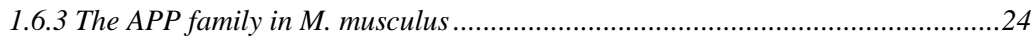

1.7 A ROLE OF APP AND APLPS IN CORTICAL DEVELOPMENT? .....................................28

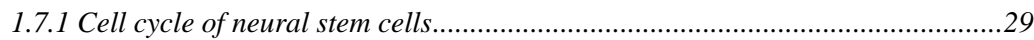

1.7.2 Radial migration and the role of APP proteins..................................................

CHAPTER II: RATIONALE, AIMS AND APPROACH ..............................................35

CHAPTER III: METHODS AND MATERIALS ..............................................................37

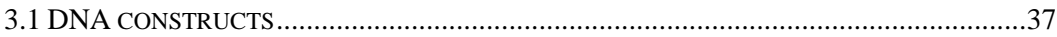

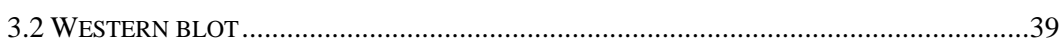

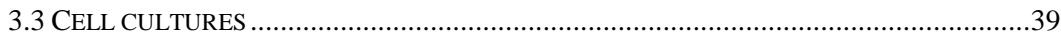

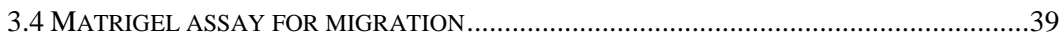

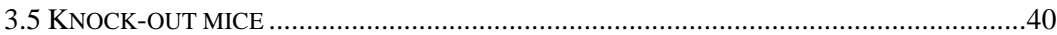

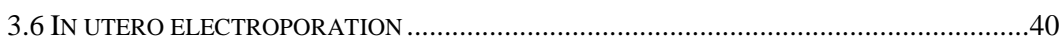

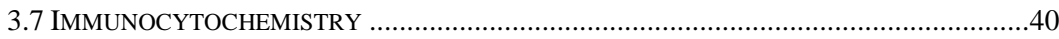

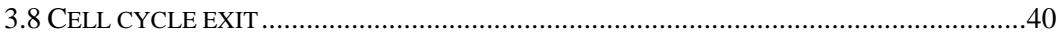

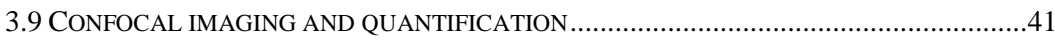

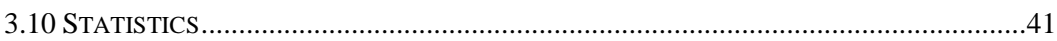

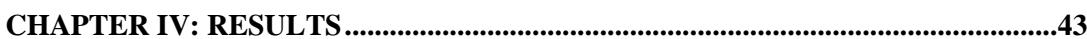

4.1 IDENTIFICATION OF FUNCTIONAL AND SPECIFIC SHRNAS TARGETING APLP2 2.........44 
4.2 DOWN-REGULATION OF APLP2 IN WT CORTICES DOES NOT CHANGE CORTICAL POSITIONING

4.3 DOWN-REGULATION OF APLP2 IN APP/APLP1 DKO CORTICES AFFECTS CORTICAL POSITIONING

4.4 MORPHOLOGY AND MIGRATORY BEHAVIOUR OF “TRIPLE KNOCK-OUT" CELLS REMAIN UNCHANGED .49

4.5 “TRIPLE KNOCK-OUT” CELLS REMAIN IN A PROLIFERATIVE PROGENITOR STATE ......51 4.6 APLP2 HAS A PROGENITOR SPECIFIC FUNCTION AND IS DISPENSABLE FOR RADIAL MIGRATION .53

4.7 CELL CYCLE VARIABLES ARE REGULATED By APLP2 56

CHAPTER V: GENERAL DISCUSSION AND PERSPECTIVES .61

5.1 HYPOTHESES ON APLP2 REGULATION OF NEURAL STEM CELL DIFFERENTIATION ....61 5.2 IN UTERO ELECTROPORATION TO STUDY NEURODEVELOPMENTAL PROCESSES: THE EXAMPLE OF APP PROTEINS . .62

5.3 CONTROVERSIES ON THE ROLE OF APP PROTEINS IN CORTICAL DEVELOPMENT ......64 5.4 PERSPECTIVE ON BIOLOGICAL FUNCTION OF APP PROTEIN FAMILY DURING CORTICAL DEVELOPMENT. .65

REFERENCES : . .69 


\section{Summary}

Human amyloid precursor protein (APP) belongs to a gene family that codes for type I trans-membrane proteins in different species, including fruit flies, roundworms and mice. Amyloid Precursor-like Protein1 and 2 (APLP1 and APLP2) are the two other mammalian members of this gene family. Like APP, APLP1 and APLP2 are transmembrane proteins with a large extracellular $\mathrm{N}$-terminal domain and short cytoplasmic $\mathrm{C}$-terminal fragment. Another common feature of APP/APLPs is their processing by enzymatic activities called secretases. Unlike APLP1 and APLP2, APP processing can generate amyloid beta peptides (Abeta) which precipitate in the brain of Alzheimer patients. Therefore, it is not surprising that APP has been extensively studied in the context of Alzheimer disease.

Nevertheless, APP and its two paralogues, APLP1 and APLP2, are expressed in early stages of brain development suggesting a physiological function for these proteins in early neurodevelopment. However, genetic knock-out and shRNA studies have led to contradictory conclusions about their role during embryonic brain development. In particular, down-regulation of APP in precursors and neurons of the developing cortex in vivo blocks the migration of neurons towards the cortical plate, while conversely, neurons in an APP/APLP1/APLP2 triple knock-out (ko) mouse over-migrate and accumulate ectopically in the marginal zone. The yet unexplained discrepancy between the overmigration effects in the triple ko and the blocked migration in the case of APP downregulation shows that the role of the APP family members in the course of cortical development is still unclear.

We hypothesized that APP and APLPs might regulate distinct processes in the developing cortex based on the differential mRNA expression profiles for APP gene family members. During cortical development: APP is found in the cortical plate $(\mathrm{CP})$ and ventricular zone (VZ), APLP2 in the VZ and subventricular zone (SVZ) and APLP1 in the CP only. The restriction of APLP2 expression to the proliferative zones (VZ/SVZ) of the developing cortex suggests a specific function for APLP2 in the development and specification of cortical progenitors. Therefore we focused our attention on the involvement of APLP2 in cortical development.

To this end, we interfered with APLP2 expression in developing cortices of wildtype (wt) mice using in utero electroporation. APLP2 down-regulation in wt cortices did not change cortical positioning of neurons. Next, we down-regulated APLP2 expression in APP/APLP1 dko mice reasoning that partial overlapping functions with APP and APLP1 might compensate for the absence of APLP2. While APP/APLP1 dko neurons migrated 
normally to the cortical plate, similar to their wt counterparts, further APLP2 downregulation in APP/APLP1 dko cells blocked cells predominantly in the proliferative zones of the developing cortex, leading to altered cortical positioning. We will use the term "triple ko" in the rest of the thesis to refer to these APP/APLP1dko cells that express APLP2shRNA. Our analysis shows that arrested cells remain undifferentiated as demonstrated by the continuous expression of progenitor and mitotic markers. We find that the morphology of "APP/APLP1/APLP2 triple ko" migrating neurons and "triple ko" radial glia fibers, a major substrate for neuronal migration, is normal. Furthermore, the migration of triple ko neurons in vitro seems not affected. Further investigation of the properties of neuronal progenitors showed delayed neuronal differentiation and decreased cell cycle exit of the triple deficient cells.

In summary, our data reveal a novel function of APLP2 in the regulation of proper cell cycle exit of neuronal progenitors. 


\section{Samenvatting}

Humaan amyloid voorlopereiwit (Amyloid Precursor Protein of APP) behoort tot een genfamilie die codeert voor type I transmembranaire proteïnen in verschillende diersoorten, waaronder fruitvliegen, rondwormen en muizen. Amyloid Precursor-like Proteïne 1 en 2 (APLP1 en APLP2) zijn de 2 andere leden van deze genfamilie in zoogdieren. Zoals APP zijn APLP1 en APLP2 transmembranaire proteïnen met een groot extracellulair Nterminaal domein en een kort cytoplasmatisch C-terminaal fragment. Een andere gemeenschappelijke eigenschap van APP/APLPs is hun klieving door enzymen, de secretasen. Anders dan APLP1 en APLP2, kan het verwerken van APP amyloïd beta peptiden (Abeta) genereren die neerslaan in de hersenen van Alzheimer patiënten. Daarom is het niet verrassend dat APP uitgebreid bestudeerd is in de context van de ziekte van Alzheimer.

APP en zijn 2 paralogen, APLP1 en APLP2, komen al tot expressie in vroege stadia van hersenontwikkeling, wat een fysiologische functie voor deze proteïnen suggereert in prille neuronale ontwikkeling. Genetische knock-out en shRNA studies hebben echter geleid tot contradictorische conclusies betreffende hun rol tijdens embryonale hersenontwikkeling. Meer bepaald down-regulatie van APP in voorlopers en neuronen van de ontwikkelende cortex in vivo blokkeert de migratie van neuronen naar de corticale plaat, terwijl omgekeerd, neuronen in een App/Aplp1/Aplp2 drievoudige knock-out (ko) muis overmigreren en ectopisch accumuleren in de marginale zone. De tot nog toe onverklaarde discrepantie tussen de over-migratie effecten in de drievoudige ko en de geblokkeerde migratie in het geval van App down-regulatie toont dat de rol van APP familieleden in het verloop van corticale ontwikkeling nog onduidelijk is.

We veronderstelden dat App en Aplps verschillende processen in de zich ontwikkelende cortex zouden kunnen regelen, gebaseerd op de verschillende mRNA expressie profielen voor leden van de APP genfamilie. Tijdens corticale ontwikkeling komt App tot expressie in de corticale plaat (CP) en de ventriculaire zone (VZ), Aplp2 in de VZ en subventriculaire zone (SVZ) en Aplp1 enkel in de CP. De beperking van Aplp2 expressie tot de proliferatieve zones (VZ/SVZ) van de ontwikkelende cortex suggereert een specifieke functie voor APLP2 in de ontwikkeling en specificatie van corticale voorlopers. Daarom hebben we onze aandacht gericht op de betrokkenheid van Aplp2 in corticale ontwikkeling.

Hiertoe interfereerden we met Aplp2 expressie in de ontwikkelende cortex van wildtype (wt) muizen door middel van in utero elektroporatie. Onderdrukken van Aplp2 expressie in 
wt cortex veranderde de corticale positionering van neuronen niet. Vervolgens onderdrukten we Aplp2 expressie in App/Aplp1 dubbele ko muizen, met de achterliggende gedachte dat gedeeltelijk overlappende functies van App en Aplp1 zouden kunnen compenseren voor de afwezigheid van Aplp2. Terwijl App/Aplp1 dko neuronen normaal migreren naar de corticale plaat, vergelijkbaar met hun wt tegenhangers, leidt verdere onderdrukking van Aplp2 in App/Aplp1 dko cellen tot stopzetting van hun migratie hoofdzakelijk in de proliferatieve zones van de ontwikkelende cortex. Dit veroorzaakt verandering van hun corticale positionering. Onze analyse toont aan dat afgestopte cellen ongedifferentieerd blijven zoals aangetoond door de continue expressie van voorloper en mitotische markers. We observeerden dat de morfologie van "App/Aplp1/Aplp2" drievoudige ko" migrerende neuronen en "drievoudige ko" radiale glia-vezels, een belangrijk substraat voor neuronale migratie, normaal is. Bovendien lijkt de migratie van drievoudige ko neuronen in vitro niet angetast. Verder onderzoek van de eigenschappen van neuronale voorlopers toont vertraagde neuronale differentiatie en verlaten de cel cyclus van de drievoudig deficiënte cellen minder.

Samengevat brengen onze data een nieuwe functie van Aplp2 in de regulatie van correcte cel cyclus uitgang van neuronale voorlopers aan het licht. 


\section{List of Figures}

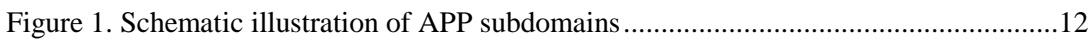

Figure 2. Examples of conserved and diverged motifs in the APP protein family ...............14

Figure 3 Simplified dendrogram of APP protein family ..................................................16

Figure 4. Cell cycle network and schematic representation of the developing cortex.........29

Figure 5. The experimental approaches used to study different neuronal processes. ...........44

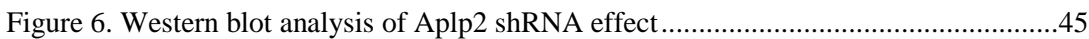

Figure 7. APLP2 down-regulation in wt cortices does not change cortical positioning of

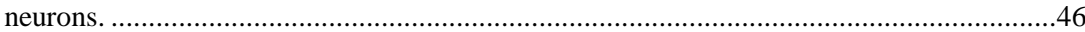

Figure 8. APLP2 down-regulation in dko cortices change cortical positioning of neurons. 48 Figure 9. Confocal images (left) and quantification (right) of the effect of a second Aplp2

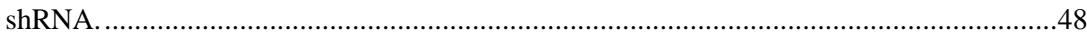

Figure 10. Morphology and in vitro migration of migrating neurons are not altered ..........50

Figure 11.The morphology of radial glia cells remains unchanged. ...................................51

Figure 12. The arrested "triple ko" EGFP positive cells express progenitor and mitotic marker. .52

Figure 13. Cell specific construct for Aplp2 down-regulation ..........................................53

Figure 14. Down-regulation of Aplp2 by shRNAmir change the cortical positioning ........54

Figure 15. Neuronal Aplp2 shRNAmir does not alter cortical positioning .........................55

Figure 16. Progenitor specific expression of Aplp2 shRNA is sufficient to retain cells in the

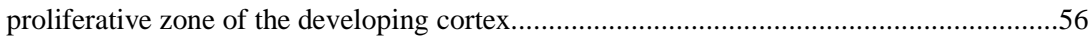

Figure 17. Decreased cell cycle exit rate after Aplp2 down-regulation .............................58

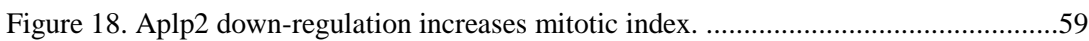

Figure 19. Aplp2 down-regulation increases the proportion of two major classes of cortical progenitors. 


\section{Abbreviations}

\begin{tabular}{|l|l|}
\hline APP & amyloid precursor protein \\
\hline APLP & amyloid precursor like protein \\
\hline APBA1 & amyloid precursor protein binding, family A \\
\hline Arc & Activity regulated cytoskeleton-associated protein \\
\hline ApoeR2 & apolipoprotein E receptor 2 \\
\hline CR & Cajal-Retzius \\
\hline CASK & calcium/calmodulin-dependent serine protein kinase \\
\hline CP & cortical plate \\
\hline CuBD & Copper Binding Domain \\
\hline Cux1 & Cut like homeobox 1 \\
\hline Dab1 & Disabled-1 \\
\hline dko & double knock-out \\
\hline GFAP & glial fibrillary acidic protein \\
\hline GSK-3 & Glycogen synthase kinase 3 \\
\hline FOS & FBJ murine osteosarcoma viral oncogene homolog \\
\hline GFLD & Growth factor like domain \\
\hline Ko & Knock-out \\
\hline LTP & long term potentiation \\
\hline MAP2 & Microtubule-associated protein 2 \\
\hline PCP & planar polarity pathway \\
\hline PS & Presenilin \\
\hline KCNH6 & Potassium voltage-gated channel, subfamily H loated) \\
\hline SVZ & Subventricular zone \\
\hline Tbr2 (Eomes) & T box brain protein 2 (eomesodermin homolog) \\
\hline VZ & ventricular zone \\
\hline Vldlr & very lensity lipoprotein receptor \\
\hline & Winge MMTV integration site family, member 5A. \\
\hline & \\
\hline
\end{tabular}




\section{Chapter I: Introduction}

Large parts of this chapter have been published in:

S. Ali M. Shariati and Bart De Strooper, Redundancy and divergence in the amyloid precursor protein family, FEBS letters, Volume 587, Issue 13, Pages 2036-2045, 2013.

In 1987, Amyloid Precursor Protein (APP) gene was identified when different research groups were searching for a putative precursor of the Abeta peptide. Amyloid beta peptide was known to be a major component of the amyloid plaques that are found in brains of people with Alzheimer's disease (AD) (Goldgaber, Lerman et al. 1987; Kang, Lemaire et al. 1987; Tanzi, Gusella et al. 1987). In the following years, homologues of APP were identified in human, mouse, as well as in Drosophila (Rosen, Martin-Morris et al. 1989; Coulson, Paliga et al. 2000). Although human APP was originally identified and named because of its link to AD, the conservation of the APP genes in the genomes suggests an advantage for the organisms. Therefore, parallel to the effort in understanding the pathogenic role of the human APP in AD, several groups are investigating the physiological function of APP proteins with a particular focus on the nervous system. The work presented in this thesis also aim to address the role of APP proteins in the mouse nervous system.

APP is the most-studied member of the APP protein family. I start the introduction by explaining the features of subdomains of APP as a well-studied member of the family. However, the APP gene family in mammals has two other members named APLPI and APLP2 (amyloid precursor-like protein). The interaction between the three genes and potential overlapping functions are complicating factors in analyzing the function of APP proteins in loss of function studies. Therefore, explaining evolution of APP gene family would help to understand the common and distinct features of APP proteins among different species.

One of the common features of the APP proteins from different species is their proteolytic processing by membrane proteases called secretases. Secretases cleave APP proteins into different fragments with functions potentially distinct from the full-length APP molecule suggesting different mechanism of action for APP proteins. On the other hand, the expression pattern and interaction network of APP and APLPs seems to be distinct for each member. Insight from knock-out models of $A P P$ genes in different species shows both distinct and overlapping phenotypes for each member. In the case of murine cortical development, deficiency of App proteins (In the text, mouse proteins are indicated with first capital letter followed by lower cases and human proteins are all capital letters. Genes 
follow the same rule but are italicized.) leads to apparently opposite outcomes in neuronal migration. We hypothesized that different members of App proteins can regulate distinct processes during cortical development. In particular, we focused on the role of Aplp2 in the regulation of neural stem cell differentiation.

\subsection{Amyloid Precursor Protein domain structure and function}

APP is a type I transmembrane protein that has a large N-terminal domain and a short Cterminal fragment. The N-terminal domain of APP is divided into two regions: so called E1- and E2- regions together with two unstructured parts called the acidic and linker regions (Fig. 1). The N-terminal-part of APP starts with the E1 domain which encompasses Growth-factor like domain (GFLD) and a Copper binding domain (CuBD). The crystal structure of GFLD showed that this domain is composed of $9 \beta$ stands and $1 \alpha$ helix which together form a globular compact domain (Rossjohn, Cappai et al. 1999). There are three disulfide bonds in this domains; Cys38-Cys62, Cys37-Cys117, Cys98-Cys105. The Cys98Cys 105 disulfide bond is at the center of a highly charged surface between amino acid 96110 patch (Rossjohn, Cappai et al. 1999). This sequence was previously shown to form a positively charged surface for heparin binding (negatively charged polysaccharide glycosaminoglycan) that regulates neurite outgrowth in primary neurons (Small, Nurcombe et al. 1994). In fact, combination of APP and heparan sulfate proteoglycan significantly potentiated the neurite outgrowth in primary neurons in vitro, whereas separately they did not (Small, Nurcombe et al. 1994). This is particularly interesting because it has been shown that the E1 domain of APP forms dimers upon binding to heparin (Dahms, Hoefgen et al. 2010) suggesting that the dimerization of APP can lead to the generation of a binding site for signaling factors that modulate neurite outgrowth. Alternatively, one can hypothesize that secreted GFLD binds to heparan sulfate proteoglycan in ligand-receptor mode of action, a mechanism that separates the function of soluble APP and membrane anchored APP. However, the functional importance of this interaction and the definitive putative receptor for soluble APP remain unidentified. The GFLD is followed by the CuBD which has $3 \beta$ strands and $1 \alpha$ helix which are connected by two disulfide bonds (Barnham, McKinstry et al. 2003; Kong, Adams et al. 2007). His147, His151 and Tyr168 are the residues that participate in copper binding by the CuBD (Barnham, McKinstry et al. 2003; Kong, Adams et al. 2007). These three residues are conserved in human APLP2 and mouse Aplp2 suggesting a possible conservation of this copper binding between APP and APLP2. 
This might provide neurons with a defense system against copper toxicity caused by high concentration of copper. Supporting this hypothesis, App knock-out (ko) neurons are more sensitive to neuronal death caused by copper toxicity. Unlike App ko neurons, Aplp2 ko neurons behave similar to the wt in response to high concentration of copper suggesting that the App protein regulates indeed copper homeostasis (White, Multhaup et al. 1999). The GFLD and CuBD are linked by an interdomain region that constitutes an interface for the interaction of the two subdomains. Many of the residues that participate in this interaction are conserved between APP and APLP2 but not APLP1 (Dahms, Hoefgen et al. 2010). In addition, Kaden et al showed that a synthetic peptide corresponding to the wt sequence of this loop region reduced dimerization of APP in vitro. This reduction was accompanied by a selective decreased $\beta$-cleavage of APP suggesting a role for dimerization in the regulation of APP processing (Kaden, Munter et al. 2008). In a cellular context, APP and APLPs promote cellular adhesion by dimerization in COS7 (Fibroblast-like Kidney Cells from monkey) (Soba, Eggert et al. 2005). Soba et al showed that APP and APLPs can form homo- and heteromeric complexes which are dependent on the E1 domain. These interactions at the cell surface increased cell clustering, supporting the intercellular adhesion role for APP and APLPs. Using a cell aggregation assay, App ko mouse embryonic fibroblasts formed similar number of aggregates when compared to wt. However, double ko of App/Aplp1 or single Aplp2 ko fibroblasts reduced the number of aggregates raising the possibility that App/Aplp1 and Aplp2 do not equally contribute to the fibroblasts adhesion and Aplp2 plays a more significant role (Soba, Eggert et al. 2005). 


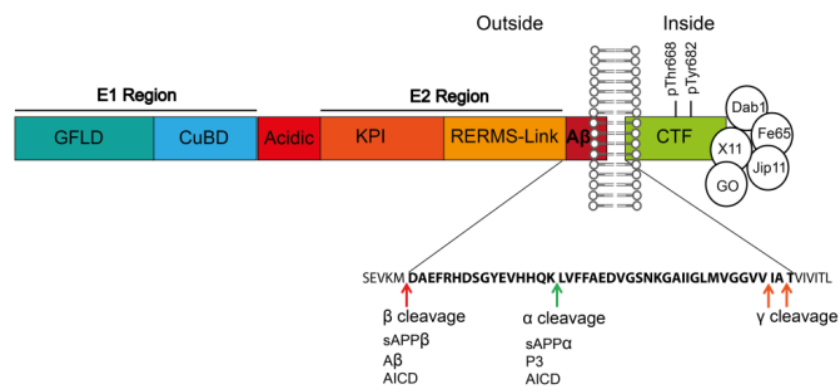

\section{Figure 1. Schematic illustration of APP subdomains}

Schematic representation of subdomains of APP. large extracellular domain of APP can be divided into E1 and E2 regions which are two structural subdomains of the APP n-terminal linked by a stretch of acidic amino acid. The E1 region contains growth-factor like domain (GFLD) and a copper binding domain (CuBD). The E1 and the E2 regions are linked by a short stretch of acidic amino acids. Two important features of E2 region are Kunitz protease inhibitor (KPI) and RERMS sequence which may contribute to APP signaling. APP is cleaved next to Abeta region (in red) by $\beta$ secretase activity (red arrow) leading to production of soluble APP $\beta$. Next APP stub is further processed by $\gamma$ secretase activity (orange arrows) leading to production of A $\beta$ and APP intracellular domain (AICD). Alternatively, the cleavage of APP can start with $\alpha$ secretase activity (green arrow) which will generate soluble APP $\alpha$, and P3 and AICD by $\gamma$ secretase activity. The short C-Terminal of APP is where APP binds to its intracellular interactors which are further discussed in the text. Two well-studied phosphorylation sites are also indicated and further discussed in the text.

An unstructured acidic region links the E1 with the E2 domain. Earlier studies showed that a distinct sequence of five amino acid residues known as the RERMS sequence resides in E2 region which possibly contributes to the growth promoting properties of APP such as fibroblast proliferation, neuronal survival and neurite outgrowth (Fig.1) (Ninomiya, Roch et al. 1993; Jin, Ninomiya et al. 1994; Ninomiya, Roch et al. 1994; Yamamoto, Miyoshi et al. 1994). The crystal structure of E2 domain revealed $6 \alpha$ helices forming a coiled-coiled structure. The overall structure of E2 domain of APLP1 is similar to APP meaning it can form dimers and bind to heparin (Lee, Xue et al. 2011; Xue, Lee et al. 2011). Analysis of the crystal structure showed that E2 domain dimers can form in anti-parallel orientation. Dimerization of the E2 domain creates a groove of positively charged amino acids that is a binding site for heparin. Unlike the heparin binding site in the E1 domains, the heparin binding residues in the E2 domain are conserved (Wang and Ha 2004). Interestingly, heparin binding induced dimerization of E2 domains (Wang and Ha 2004). Therefore, it is 
very likely that these two heparin binding domains regulate the dimerization and binding properties of full-length and soluble APP and APLPs. A third region that can mediate APP dimerization is located at the boundary of transmembrane and juxtamembrane domain of APP where three GxxxG motifs are located. These motifs are situated close to the cleavage sites of APP and therefore might regulate APP processing and function (Kienlen-Campard, Tasiaux et al. 2008; Sato, Tang et al. 2009; Khalifa, Van Hees et al. 2010). Indeed, this GxxxG motif was shown to be required for Abeta production but not APP Intracellular Domain (AICD) release which is the product of $\gamma$-cleavage of the APP C-terminal fragment. Changing the glycine pair to leucine significantly decreased the production of Abeta in CHO cells (Kienlen-Campard, Tasiaux et al. 2008). Overall, these data suggest that APP has adhesion properties and may be involved in cell-cell or cell-substrate adhesion and (or) signaling at the surface of the cell (Reinhard, Hebert et al. 2005).

In analogy with Notch signaling, the processing of the APP C-terminal fragment can release AICD which is postulated to form a multi-meric complex with transcriptional activity of cytoplasmic fragment of the APP (Cao and Südhof 2001; Cupers, Orlans et al. 2001). Initially, when intracellular domain of APP was fused to Gal4 transcription factor, this fusion protein alone did not activate the Gal4-dependent reporter. Searching for possible interactors that can boost AICD mediated transcription, over-expression of Fe65 turned out to be a potent stimulator of transcription. Finally, the authors proposed that AICD-Fe65 bind to Tip60, a histone acetyltransferase, to form a nuclear ternary complex that directly regulates transcription (Cao and Südhof 2001). Later, it was shown that cytoplasmic fragment of the APP has a short half life (less than $5 \mathrm{~min}$ ) and is partially distributed to the nucleus (Cupers, Orlans et al. 2001). More recently, a similar Gal4 assay showed that transcriptional activity of AICD depends on Med12 which is a RNA polymerase II regulator, suggesting a direct link between AICD of APP and the transcriptional machinery. In addition, a physical interaction between AICD and Med12 supported the role of AICD in gene regulation (Xu, Zhou et al. 2011). Until now, many endogenous AICD target genes such as APP itself, BACE1, GSK-3 $\beta$, KAI1 and Neprilysin were reported using exogenous expression of the AICD (Nalivaeva and Turner 2013). In contrast, complete deficiency of APP/APLPs did not influence the expression of the proposed target genes such as APP, KAI1, GSK-3 $\beta$ and Neprilysin, suggesting that intracellular domains of APP/APLPs are not potently involved in gene regulation at basal level (Hebert, Serneels et al. 2006). Therefore, the reports are conflicting on the transcriptional role and the identity of AICD target genes (Hebert, Serneels et al. 2006; Waldron, Isbert et al. 2008; Huysseune, Kienlen-Campard et al. 2009; Xu, Zhou et al. 2011). 
Currently, the experimental data are not available to compare the structure of the APLP2 with APP and APLP1. As it was discussed, the crystal structure of the E2 domain of APLP1 is very similar to APP but the crystal structure of APLP2 or its subdomains are not available. At the level of protein sequence each one of these protein has unique motifs which potentially can confer specific structural features to each member. For example, the $\mathrm{N}$-terminal of APLP2 homologues contains a unique GTGFAVAE motif with unknown function (Fig. 2). On the contrary, the C-terminal YENPTY motif is universally conserved in all members of the APP protein family, providing a common site for intracellular interactors of APP and APLPs (Fig.1,2). Experimental structural data for APLP2 will be valuable in understanding similarities and differences between APLP2 and APP or APLP1.

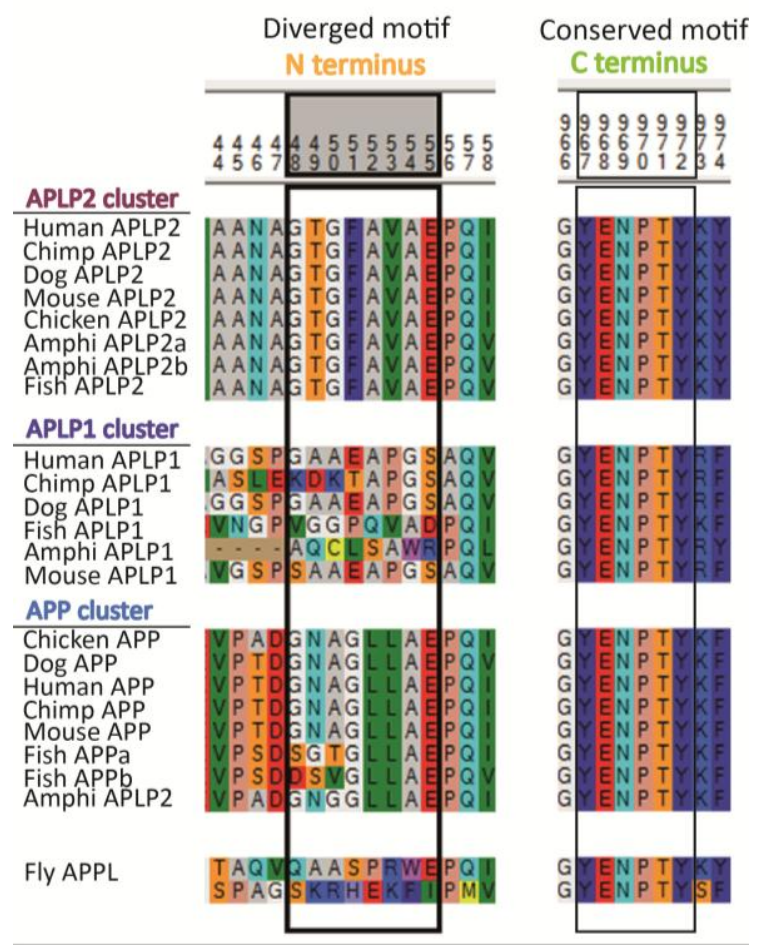

Figure 2. Examples of conserved and diverged motifs in the APP protein family

Alignment of APP protein family shows that the YENPTY motif at the c-terminal of this gene family is a universally conserved motif. The numbers above the figures indicate the alignment position of amino acids from $\mathrm{N}$ terminal to $\mathrm{C}$ terminal. 


\subsection{Evolution of the Amyloid Precursor Protein Family}

Genes encoding for the APP protein family have experienced several twists and turns during evolution. APP-like proteins have not been identified in prokaryotes, yeasts and plants (Fig. 3). The simplest and earliest branches of the evolutionary tree in which APPlike genes have been identified contain insects such as the fruit fly (D.melanogaster) and roundworms (C.elegans) each carrying one gene encoding for an APP-like protein. It is intriguing that APP-like proteins first emerge in Bilaterians with an early nervous system with functional synapses (Emes, Pocklington et al. 2008; Ryan and Grant 2009). Indeed, the extracellular domains of APP molecules have cell adhesion properties and can promote cell-cell adhesion (Soba, Eggert et al. 2005). Such intercellular interaction is important in early evolution for the generation of the synaptic junction (Emes, Pocklington et al. 2008; Emes and Grant 2012). Strikingly, when over-expressed in HEK cells, APP can potently induce synaptogenesis in the contacting axon and this activity requires the extracellular domain as well as the intracellular part of APP. The latter associates with presynaptic molecules such as APP binding family A (APBA1) and Calcium/calmodulin-dependent serine protein kinase (CASK) (Wang, Wang et al. 2009). Interestingly, APP is required both at pre- and postsynaptic compartments to induce synaptogenesis (Wang, Wang et al. 2009) which suggests that ancestral APP indeed might have evolved as a transmembrane protein responsible for homophilic interactions at the synaptic junction.

Five nodes of duplications are observed in the phylogenetic tree of the APP protein family when using Ensemble comparative genomics tools (simplified in Figure 3). For example, zebra fish (D.rerio) has in total four genes encoding APP proteins: two homologues for the human APP gene (appa and appb) plus aplp1 and aplp2 (Fig. 3). Similar to fishes, amphibians (Xenopus laevis) carry four app genes in their genome but they have two homologues for the human APLP2 gene: aplp2a, aplp2b plus app and aplp1 (Fig. 3). Instead, birds (G. Gallus) have lost the APLP1 gene leaving them with APP and APLP2 genes (Fig. 3). The paradoxical expansion and contraction of the APP family suggest that the duplications of the encoding genes have been the subject of highly selective evolutionary forces. The complicated trajectory of the evolution of the APP protein family ends with the three well-studied members in mammals: APP, APLP1 and APLP2 (Fig. 3) (Zheng and Koo 2011). 
The evolutionary maintenance of a duplicated gene in the genome is influenced by the accumulation of genetic mutations affecting the function of the descendant duplicates. Three possible outcomes of duplication have been proposed: non-functionalization, neo(sub)functionalization or increased gene dosage (Innan and Kondrashov 2010). The non-functionalization scenario is the result of the accumulation of deleterious mutations leading to pseudogenization (Ohno 1970). In case of neo-functionalization, mutations confer new features to the duplicate which leads to the acquisition of new functions distinct from the ancestral ones (Force, Lynch et al. 1999). Subfunctionalization is a modified version of neofunctionalization in which the function of the ancestral gene becomes subdivided into subfunctions for each duplicate providing cells with proteins with more specialized functions (Innan and Kondrashov 2010). Finally without any functional innovation, duplication can provide cells with genetic robustness and redundancy by increasing the gene dosage for dosage sensitive genes (Conrad and Antonarakis 2007).

Which model of gene duplication and evolution can be applied to the APP family? While the prevalent vision stresses the "increased gene dosage", as I will discuss, more in depth interpretation of the data provide supporting evidence for neo or subfunctionalization of APP and APLPs as well.

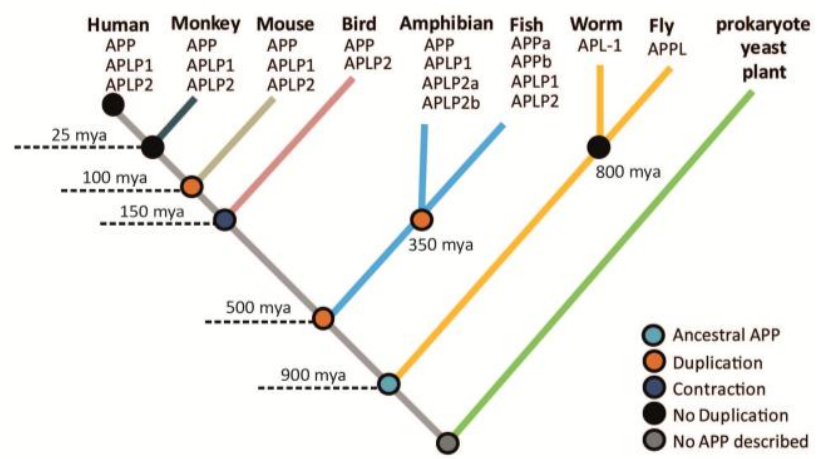

\section{Figure 3 Simplified dendrogram of APP protein family}

The tree illustrates the important events in the evolution of APP gene family. The duplication and contraction nodes are color coded. The lengths of the lines are not proportional to the evolutionary distance of species. For details of APP protein family evolution see the text. Mya: million years ago. 


\subsection{Proteolytic processing of Amyloid Precursor Proteins}

APP undergoes proteolytic processing by enzymatic activities of the membranes secretases known as: $\alpha$ - secretase, $\beta$-secretase, and $\gamma$-secretase (Fig. 1). The first cleavage of APP by $\alpha$-secretase or $\beta$-secretase releases soluble fragments and generates a membrane bound Cterminal stub which is the substrate of $\gamma$-secretase. In case of APP this proteolytic processing is classified into two pathways: amyloidogenic when $\beta$-secretase cleaves first and non-amyloidogenic when $\alpha$-secretase cleaves first. Only the former is linked to the pathogenesis of Alzheimer's disease because it produces $A \beta$ which is the main component of amyloid plaques in the brain of patients. Interestingly, the proteases $\alpha$-secretases, $\beta$ secretases and $\gamma$-secretases are largely conserved during evolution, together with the overall processing of the membrane bound APP paralogues resulting in the release of APP ectodomain and intracellular domain.

$\alpha$-secretase cleaves APP between Lys16 and Leu17 of the Abeta domain (Fig. 1) (Esch, Keim et al. 1990). Cleavage of APP by $\alpha$-secretase activity results in generation of a soluble fragment ( $\mathrm{SAPP} \alpha$ ) and an 83 amino acid C-terminal fragment (C83). In mammals, different members of the "A disintegrin and metalloprotease" (ADAM) family have been proposed as $\alpha$-secretases (Deuss, Reiss et al. 2008; Vingtdeux and Marambaud 2012). Over-expression of ADAM 9, 10, 17 in cell culture system can change the processing of APP (Deuss, Reiss et al. 2008; Vingtdeux and Marambaud 2012). In neurons, there is convincing evidence that Adam10 carries out the constitutive processing of APP (Jorissen, Prox et al. 2010; Kuhn, Wang et al. 2010). The secretion of sAPP $\alpha$ is reduced by $90 \%$ in Adam10 deficient neurons, reflecting the importance of Adam10 for constitutive processing of App. ADAM10 and ADAM17 can both cleave APLP2, but, similar to APP, ADAM10 was found to be a constitutive $\alpha$-secretase of APLP2 in neurons (Hogl, Kuhn et al. 2011). Although ADAM10 constitutively processes APP and APLP2, the induced processing of APP and APLP2 are regulated differently. Insulin growth factor 1(IGF1) has been shown to induce production of SAPP $\alpha$, sAPLP1 and sAPLP2 (Adlerz, Holback et al. 2007). Different $\alpha$-secretases mediate the effect of IGF1 induced secretion of soluble fragments of APP and APLPs (Jacobsen, Adlerz et al. 2010). ADAM10 inhibition blocks the effect of IGF1 induced shedding of APP. Likewise, APLP1 processing was blocked after inhibition of ADAM10, whereas APLP2 ectodomain shedding was decreased only after down-regulation of ADAM17 (Jacobsen, Adlerz et al. 2010). Thus, it is likely that ADAM17 mediates the induced processing of APLP2, whereas ADAM10 mediates its constitutive processing. 
In flies, a 130KD fragment that misses the carboxyl terminus of full-length APPL was identified and proposed as secreted form of APPL (Luo, Martin-Morris et al. 1990). Kuzbanian is the $\alpha$-secretase like protease of flies which was identified because of its role in regulation of Notch signaling and neurogenesis (Rooke, Pan et al. 1996). More recently it was shown that Kuzbanian can indeed also affect processing of flies' APPL (CarmineSimmen, Proctor et al. 2009). Therefore, despite small differences, $\alpha$-secretase cleavages are conserved in APLPs family reflecting the physiological importance of this pathway. The physiological importance of this pathway is supported by data showing that sApp $\alpha$ can rescue the phenotypes of App deficient mice (Ring, Weyer et al. 2007). One can speculate that $\alpha$-secretase generates soluble ectodomains of APP and APLPs which are active ligands for unknown receptors. It is not clear to what extent the biological activity of sAPP $\alpha$, sAPLP1 $\alpha$ and sAPLP $2 \alpha$ are different or similar. One example of similar activity of different soluble fragments of APP family is neurite outgrowth. It has been shown that the conditioned medium of $\mathrm{CHO}$ cells over-expressing APP, APLP1 or APLP2 similarly increase the length of the axons, suggesting similarity in the function of the soluble fragments of APP and APLPs in neurite outgrowth regulation (Young-Pearse, Chen et al. 2008).

$\beta$-secretase activity cleaves APP next to the N-terminal of the Abeta region generating sAPP $\beta$ and C99 (Fig. 1). Bace1 was identified as the major neuronal enzyme with $\beta$ secretase activity and its deficiency blocks Abeta secretion in neurons (Vassar, Bennett et al. 1999; Cai, Wang et al. 2001). The decreased level of Abeta is accompanied by reduced levels of $\beta$-CTF (Pastorino, Ikin et al. 2004). It has been shown that BACE1 can alter processing of APLPs when over-expressed in HEK293 cells (Li and Südhof 2004). Consistent with these data, Bace1 deficiency significantly decreased levels of soluble Aplp2 in the brain, whereas its over-expression had opposite effect (Pastorino, Ikin et al. 2004). Parallel to decreased soluble Aplp2 in brain, the $\beta$-CTF of Aplp2 was diminished in Bace1 ko brain reflecting the overall similarity between App and Aplp2 $\beta$-cleavage (Pastorino, Ikin et al. 2004). However, more recently it was shown that Bace1 ko did not alter the CTF production of App or Aplps raising the possibility of compensatory mechanisms for $\beta$-secretase activity (Sala Frigerio, Fadeeva et al. 2010). $\beta$-secretase activity has also been described in flies and interestingly $\mathrm{dBACE}$ can process APPL into neurotoxic A $\beta$ like peptide which can deposit in the brain similar to human APP (CarmineSimmen, Proctor et al. 2009). Therefore, similar to $\alpha$-cleavage, $\beta$-secretase activity is conserved in the APP protein family. As it will be discussed later (section 1.3.3), the 16 amino acid difference between $\operatorname{sAPP} \alpha$ and $\operatorname{sAPP} \beta$ have been proposed to contribute to striking differences in their functions, although this needs further mechanistic insight. 
In addition to ectodomain shedding, $\beta$-secretase proteolytic processing of APP results in the release of $A \beta$ with high propensity to aggregate. As this is a continuous process, the brain is constantly faced with the challenging task of controlling the concentration of $A \beta$ below the aggregation threshold. The A $\beta$ region is a novel feature of the APP paralogue and is not present as such in APLP1\&2 or in the APP-homologues in C. elegans (APL1) and D. melanogaster (APPL). For example, recently it was shown that sequential cleavage of APLP1 by $\beta$ - and $\gamma$-secretases generate APLP1 $\beta$ peptides of 25, 27 and 28 amino acids (to be compared with $\mathrm{A} \beta$ from APP that contains 38,40 and 42 amino acids) which do not aggregate in the brains (Yanagida, Okochi et al. 2009). Interestingly, the analogy between the processing of APP and APLP1 has raised the possibility of using APLP1 derived p28 in the cerebrospinal fluid as a surrogate marker to detect altered activity of $\gamma$-secretases in individuals with an increased risk of Alzheimer's disease (Yanagida, Okochi et al. 2009).

$\gamma$-secretase cleaves C99 and C83 generated by $\beta$-cleavage and $\alpha$-cleavage respectively (Fig. 1). $\gamma$-secretase is a multi-subunit complex that is composed of : Presenilins (PS1 and PS2), anterior pharynx-defective 1 (APH-1), Nicastrin, and Presenilin enhancer protein 2 (Pen2). A series of genetic and biochemical experiments showed that PS1 deficiency leads to the accumulation of APP CTF and blocks Abeta production in neurons showing that PS1 is the catalytic subunit of $\gamma$-secretase (De Strooper, Saftig et al. 1998; De Strooper, Annaert et al. 1999; Wolfe, Xia et al. 1999). Likewise, the CTFs of APLP1 and APLP2 are also cleaved by $\gamma$-secretase. One of the early hints showing that APLPs are also processed by $\gamma$-secretase came from accumulation of APLP1 CTF in PS1 deficient neurons (Naruse, Thinakaran et al. 1998). Further, CTFs of APLP1 and APLP2 were accidentally co-purified together with APP CTFs suggesting that APLP1 and APLP2 are also cleaved by $\gamma$-secretase (Gu, Misonou et al. 2001). Using both chemical inhibition and genetic deletion, there is now compelling evidence for $\gamma$-secretase processing of APLP1 and APLP2 (Walsh, Fadeeva et al. 2003; Eggert, Paliga et al. 2004; Yanagida, Okochi et al. 2009).

Processing of $\mathrm{C} 99$ or $\mathrm{C} 83$ by $\gamma$-secretase generates AICD, in other words AICD is the common product of both amyloidogenic and non-amyloidogenic pathways. As it was discussed, this fragment can potentially translocate to nuclei to regulate gene expression. This model postulates that APP works as a receptor that mediates signals from membrane to nucleus in a process known as Regulated Intramembrane Proteolysis (RIP) (Brown, Ye et al. 2000). For example, the extracellular domain of APP has been shown to bind to Tag1 in a ligand-receptor model and Tag1-APP binding can regulate neurogenesis. Enhanced neurogenesis of Tag1 deficient neuronal stem cells was reversed after expression of AICD. Instead, AICD with a mutation in the Fe65 binding site could not rescue the neurogenesis 
defect, supporting a signaling role for the AICD-Fe65 complex (Ma, Futagawa et al. 2008). Similar fragments of APLP1 and APLP2 (named ALID1 and ALID2) can also potentially contribute to gene expression regulation (Scheinfeld, Ghersi et al. 2002); however evidence for their role in neurogenesis and signaling function is lacking, and, as discussed above, we could not show a direct signaling role of the AICD (Hebert, Serneels et al. 2006).

\subsection{Temporally and tissue specific regulated expression of APP family proteins}

One of the determinants of the function of gene duplicates is the modification of their regulatory proximal elements which can lead to transcriptional divergence. In turn, transcriptional divergence is likely to result in diversification of the duplicates with refined functions instead of redundant functions. In particular, genetic differences in regulatory elements of genes that are expressed in the developing cortex have been proposed as a primary force influencing the emergence of mammalian brains (Johnson, Kawasawa et al. 2009; Zhang, Landback et al. 2011). Members of the APP family proteins are characterized by a specific tissue expression during different developmental stages which is important to keep in mind when discussing physiological functions.

The genomes of D.melanogaster and C. elegans each contain only one APP "like" gene. APl-1 of C.elegans is expressed in neurons mainly and also in a few other cell-types (Hornsten, Lieberthal et al. 2007). Expression of APPL in D.melanogaster is restricted to the nervous system (Rosen, Martin-Morris et al. 1989). In mammals Aplp1 shows a neuron specific expression whereas App and Aplp2 are expressed by various cell types. Until recently, App was assumed to be expressed by all cell types in the brain (Lorent, Overbergh et al. 1995). However, using a specific antibody to stain App, Guo et al showed that App is expressed predominantly in neurons in the adult brain (Guo, Li et al. 2012). At the transcript level, a complementary pattern has emerged from in situ hybridization analysis of APP and Aplps transcripts during development of the cortex. Lopez-Sanchez et al have demonstrated that Aplp1 expression is restricted to the post-mitotic cortical plate during cortical development while Aplp2 transcripts show a specific distribution in the proliferating neurons in the ventricular and/subventricular zone. App finally appears both in the ventricular zone neurons as well as in post-mitotic neurons of the cortical plate, thus 
showing partial overlapping expression with both Aplp1 and Aplp2 (López-Sánchez, Müller et al. 2005). The same expression pattern is demonstrated in publicly available atlases of the developing cortex, including Genepaint and Eurexpress (Visel, Thaller et al. 2004; Diez-Roux, Banfi et al. 2011). The region specific expression pattern of App, Aplp1 and Aplp2 suggests functional specialization of each member during different stages of neuronal development.

The genetic factors that contribute to the transcriptional divergence of APP duplicates are not well defined. However, analysis of the proximal element of APP and APP like proteins in different species reveal a CAGA box within the APP 5'-UTR which is not present in APP like proteins (Maloney, Ge et al. 2004). This CAGA box might regulate expression of APP in response to signaling pathways such as TGF $\beta$ (Maloney, Ge et al. 2004). More studies are needed to understand the contribution of the proximal element that control regulated expression of APP and APLPs.

\subsection{The interaction networks of APP, APLP1 and APLP2 show specificity}

Proteins are part of the dynamic networks of interactions that can show cell type and tissue specificity (Bossi and Lehner 2009). Evolutionary changes in specificity and strength of these interactions impact the function of the proteins and their networks (Robertson and Lovell 2009). Rewiring of the interaction network of paralogous protein is a clear sign for their functional refinement (Robertson and Lovell 2009).

Several binding partners have been proposed for APP with various functional implications. (Reinhard, Hebert et al. 2005; Zheng and Koo 2011; Guo, Wang et al. 2012). In general, the interactors of APP can be divided into two groups: extracellular binders with a possible ligand mode of action and intracellular binders with a possible signaling mode of action. Fspondin, Tag1, Reelin, Netrin, Lingo-1, Pancortins are among extra-cellular binders while Fe65, JIP, JNK, Mint1/X11, Dab1 are among intracellular binders of APP (Reinhard, Hebert et al. 2005; Zheng and Koo 2011; Rice, Townsend et al. 2012). If APP and APLPs share similar biological functions, then they are expected to be part of a similar protein network. However, a study by Bai et al challenges this idea by showing different networks of interaction for App and Aplps (Bai, Markham et al. 2008). Unexpectedly, a systematic comparison of in vivo brain interactome of App, Aplp1, and Aplp2 revealed different sets 
of interactors for each paralogue. A significant proportion of identified App interactors were consistent with previously published data supporting the reliability of candidate interactors. Surprisingly, the combined analysis of interactors shows only one interactor in common; Ras GAP-activating like Protein 1 which binds to both Aplp1 and Aplp2 (Bai, Markham et al. 2008). In this study, ER chaperones populated the interaction network of App. Over-representation of ER chaperone in the App interaction network suggest sensitivity of App folding, the distinct interaction of Aplp2 with Rho family of GTPases such as RhoA and RAC1 can link APLP2 to G-protein signaling pathway (Bai, Markham et al. 2008).

It is likely that the difference in the interaction networks of App and Aplps arises from different subcellular localization of each paralogue or from their differential expression pattern (Huminiecki and Wolfe 2004; Kaden, Voigt et al. 2009). Indeed, using fluorescent tagged version of APP and APLPs in HEK293 cells, Kaden et al showed that APLP1-YFP is primarily localized to the cell surface. Most of the APP-YFP was found in intracellular compartments such as the ER and endosomes and to a lesser extent in the Golgi apparatus. APLP2 was equally distributed at the cell surface and intracellular compartments showing partial overlapping localization with both APP and APLP2 (Kaden, Voigt et al. 2009). These findings suggest that in part specificity of interaction network of APP and its paralogues can be due to their differential subcellular localization. Regardless of the reason for different set of interactors, the specificity of interaction networks for APP duplicates can contribute to the separation of their role in different cellular contexts.

\subsection{Various roles of the APP members in the nervous system}

Loss of function studies is still the standard approach to deduce the physiological role of a gene. The APP family has been covered rather well in that regard with knock-outs (ko) in D. melanogaster, C. elegans and several combinations of gene ko in M. musculus. The data are somewhat divergent, but overall they suggest strongly a role of the APP family in the central nervous system.

\subsubsection{The extracellular domain in development of C. elegans}

In C. elegans, the single gene encoding for members of the APP family, is called apl-1. The encoded protein is very similar to the mammalian counterpart with a large 
extracellular and a short intracellular domain, while the Abeta sequence as such is lacking in APL-1 (Daigle and Li 1993). Loss of APL-1 leads to a molting defect resulting in developmental lethality (Hornsten, Lieberthal et al. 2007). In addition, the apl-1 null mutant worms are hypersensitive to the acetylcholinesterase inhibitor aldicarb supporting a role for APL-1 protein at synaptic junctions (Wiese, Antebi et al. 2010). Many reports stress the importance of the conserved intracellular domains of the APP family for its function, but, unexpectedly, the conserved carboxyl terminus fragment of APL-1 is not involved in the phenotype as demonstrated by rescuing the lethality of the apl-1 null mutant by c-terminus truncated version of APL-1 (Hornsten, Lieberthal et al. 2007). In contrast, the extracellular domain of APL-1 is sufficient to rescue both the lethality and hypersensitivity phenotypes. As this domain is soluble, these data suggest a receptor for APL-1 ectodomain, and indicate the importance of this domain in development (Hornsten, Lieberthal et al. 2007).

\subsubsection{D. melanogaster's APPL in axonal wiring and synaptic function}

Like C.elegans, D. melanogaster also carries one homologue of the APP gene, called Appl. Appl expression is first seen in developing neurons during axogenesis (Luo, Martin-Morris et al. 1990). Flies with an Appl null mutation are viable and fertile, but show subtle phenotypes. For instance at the neuromuscular junction Appl null mutant flies have a reduced number of neuromuscular buttons, whereas larvae over-expressing APPL show an increased number of buttons (Torroja, Packard et al. 1999). Interestingly, Torroja et al showed that APPL is transported to synaptic buttons and a highly conserved cytoplasmic YENPTY motif of APPL is required for promoting synapse formation (Torroja, Packard et al. 1999). This synaptogenic property might be mediated through interaction of Fasciclin II with APPL, while APPL is binding via its conserved cytoplasmic domain to APPBA1 at the synapse (Ashley, Packard et al. 2005). APPL has also been implicated in regulation of neurite arborization (Leyssen, Ayaz et al. 2005). Leyssen et al (Leyssen, Ayaz et al. 2005) showed that both APPL and its human homologue APP can promote post-developmental neurite arborization in D. melanogaster. Similar to its synaptogenic role, APPL requires the conserved cytoplasmic YENPTY for its effects on neurite arborization, but this time the signal is transduced through the Abelson tyrosine kinase (Abl) pathway (Leyssen, Ayaz et al. 2005). These data suggest a role for APP in the structural plasticity of neurons, whereas in pathological condition such as brain injury APPL might promote neurite arborization (Leyssen, Ayaz et al. 2005). Recently, it was shown that loss of APPL induced a developmental defect in the axonal outgrowth in mushroom bodies of D. melanogaster. 
Heterozygosity for Abl kinase significantly enhanced the axonal phenotype of Appl mutant flies. Mechanistically, APPL turned out to interact with core components of the planar polarity pathway (PCP) mediating the WNT5a induced phosphorylation of Disheveled. Thus, it was suggested that modulation of PCP pathway by neuronal APPL might regulate developmental axonal wiring in mushroom bodies (Soldano, Okray et al. 2013). Overall, the loss of function experiments in flies and worms suggest that the ancestral App like gene has evolved to serve in the nervous system, in particular in synapse formation and function. While the Drosophila counterpart is really a nervous system protein, the situation in C.elegans is not completely clear. Absence of APL-1 results in multiple developmental defects for instance decreased body size, and egg-laying rate (Ewald, Raps et al. 2012). It is uncertain whether these phenotypes are the result of defects in the neuronal system or indicate that APL-1 also operates in other cells, and that its function is context-dependent.

\subsubsection{The APP family in M. musculus}

The situation in mammals is even more complex. The different functions proposed for APP and its paralogues are not converging to a concrete model for APP family function. The single App KO mice are viable but show various subtle phenotypes such as 15-20\% reduced body weight, disturbed forelimb strength and reduced locomotor activity (Zheng, Jiang et al. 1995). The interpretation that App ko mice show subtle phenotypes because of compensation by other APP members is not supported by expression studies of the other members of the APP family: compensatory up-regulation of Aplp1 and Aplp2 transcripts were not observed in these mice (Zheng, Jiang et al. 1995).

The alterations in muscular strength and decreased locomotor activity in the App null mutant mice might reflect the synaptic role of App in the central nervous system. Immunocytochemical analysis of App null mice revealed age-dependent increased glial fibrillary acidic protein (Gfap) immunoreactivity indicating gliosis and reduced staining for synaptic marker markers such as synaptophysin, synapsin and MAP-2 (Dawson, Seabrook et al. 1999). In addition, the mice showed impaired LTP recording which was highly correlated with gliosis (Dawson, Seabrook et al. 1999). Consistent with a defect in LTP, App null mutants mice spend more time finding the hidden platform in the Morris water maze test (Dawson, Seabrook et al. 1999) further suggesting a role for App in spatial learning. The defect in LTP was associated with attenuation of GABA-mediated inhibitory post-synaptic currents (Seabrook, Smith et al. 1999). Increased expression of calcium channel, Cav1.2, was suggested as potential mechanism regulating GABAergic synaptic 
activity in inhibitory neurons (Yang, Wang et al. 2009). Further experiments will clarify the role of APP in synaptic plasticity of excitatory vs. inhibitory neurons.

Mixed results were obtained on the role of App in the formation of dendritic spines (Bittner, Fuhrmann et al. 2009; Lee, Moussa et al. 2010; Jung and Herms 2012). Bittner et al (Bittner, Fuhrmann et al. 2009) used in vivo two photon imaging to show that $\gamma$-secretase inhibition reduced spine density in an App dependent manner. In their study layer III and Layer V cortical neurons of App ko mice showed a two fold increase in the number of dendritic spines (Bittner, Fuhrmann et al. 2009). In contrast, Lee et al (Lee, Moussa et al. 2010) used primary rat hippocampal neurons to show that down-regulation of App decreases the number of spines, whereas over-expression of App has the opposite effect. App needs both its extracellular and intracellular domains to mediate these effects. Golgi staining of spines of CA1 pyramidal neurons and layer II/III cortical neurons revealed a significant decrease in density and length of spines in App null mutants, confirming the role of APP in spine formation in vivo (Lee, Moussa et al. 2010). More recently, Tyan et al (Tyan, Shih et al. 2012) reported decreased spine density in primary neuronal culture of App null mutant mice confirming further the role of App in promoting spine formation. The discrepancy may arise from different methodology used to image the spines (Golgi staining vs. in vivo two photon imaging) or analyzing different types of neurons, i.e. deep layer vs. upper layer pyramidal neurons of cortex or CA1 neurons of hippocampus. One can speculate that the effect of APP is cell type specific and age dependent, which remains intellectually an unsatisfying explanation, as it brings little insight into the real function of App. It is interesting however that the role of App in the regulation of neurite formation is reminiscent of the role of $D$. melanogaster APPL in regulation of arborization of neurites. Clearly, there would be some conservation of this role in evolution (Leyssen, Ayaz et al. 2005; Soldano, Okray et al. 2013).

It is noteworthy that the some of the phenotypes reported for App single ko mice are not observed in single Aplp1 and Aplp2 ko mice. Although both Aplp1 and Aplp2 single ko mice are much less extensively analyzed than the App knock-out, their phenotypes do not overlap (Heber, Herms et al. 2000). Aplp1 ko mice appear normal both in forelimb strength and in reduced locomotor activity (Heber, Herms et al. 2000). Similar analysis of dendritic spines of Aplp2 null mutant neurons did not reveal alterations of spines in those mice (Midthune, Tyan et al. 2012). A very different example of non-conserved function is the feroxidase activity in App which is mediated by the REXXE motif in the extracellular domain of App and is not found in Aplp1 and Aplp2 (Duce, Tsatsanis et al. 2010). Thus, although further work is needed, the different phenotypes of the single ko mice support the 
idea that App is specialized in its functions at the synaptic junction, which are likely not fully compensated by Aplp1 and Aplp2. Lack of overt phenotypes in Aplp1 and Aplp2 single $\mathrm{KO}$ mice does not exclude phenotypes that have escaped scrutiny at this moment.

Combinations of the genetic deletions of App/Aplps have been generated (Heber, Herms et al. 2000; Guo, Wang et al. 2012). Expression of Aplp2 alone is sufficient for survival of the mice meaning that double deletion of App and Aplpl is viable. However, in the absence of Aplp2, mice can survive only if they express both App and Aplp1. The viability of Aplp2 single ko might indicate that App and Aplp1 can work together to compensate for a function that is dominated by Aplp2. At first glance, compensation by App/Aplp1 together for Aplp2 deficiency is a possibility, however, no compensatory up-regulation of App or Aplp1 was detected after deletion of Aplp2 (Heber, Herms et al. 2000; Aydin, Filippov et al. 2011). Alternatively, it is equally possible that APP family independent mechanisms are compensating for the lack of Aplp2. Indeed, combination of Aplp1 ko with App or Aplp2 leads to different outcomes which is survival or lethality showing specificity in function of App and Aplp2 (Heber, Herms et al. 2000).

Several studies support a role for App at the neuromuscular junction. A phenotype emerges only when App deletion is analyzed in an Aplp2 ko background (App/Aplp2 dko). These mice show reduced vesicle density in presynaptic active zone, excessive nerve terminal sprouting and aberrant apposition of presynaptic and postsynaptic markers indicating a key role for proper formation of synaptic structures at the neuromuscular junction (Wang, Yang et al. 2005; Yang, Gong et al. 2005). Interestingly, proper development of the neuromuscular junction requires App and Aplp2 in the presynaptic motor neurons and the post-synaptic muscles suggesting a transynaptic homophilic or heterophilic interaction between App and Aplp2 (Wang, Wang et al. 2009). In contrast to the prominent role for soluble App in C.elegans, expression of soluble App $\beta$ (sApp $\beta$ ) in the App/Aplp2 dko mice (App/Aplp2 sApp $\beta^{k i k i}$ ) did not rescue the lethality or neuromuscular defects of App/Aplp2 dko mice (Li, Wang et al. 2010). Strikingly, expression of soluble App $\alpha$ (sApp $\alpha$ ) rescued the lethality of the App/Aplp2 dko mice (App/Aplp2 sAppo ${ }^{k i k i}$ ) (Weyer, Klevanski et al. 2011) indicating that a few amino acid between $\alpha$ and $\beta$ cleavage are instrumental in the biological function of sApp. However, App/Aplp2 sAppo ${ }^{k i k i}$ showed a widened end plate, impaired neuromuscular transmitter release, and structural abnormalities at the neuromuscular synapses correlating with decreased grip strength. In the central nervous system, the mice showed impaired LTP accompanied with impaired spatial memory (Weyer, Klevanski et al. 2011). Thus, sApp $\alpha$ was not able to rescue several neurological 
phenotypes, implying that full length APP is needed. Interestingly, App/Aplp2 sApp $\alpha^{k i / k i}$ mice did not have any spine or morphological defects in cortical or hippocampal neurons.

It is very likely that the developmental function of App at the neuromuscular junction is mediated through its highly conserved YENPTY motif in its carboxyl terminus domain since expression of App with a single Tyr(682) to Gly (682), Y682G, mutation in an Aplp2 null background, leads to the lethality and neuromuscular defects similar to App/Aplp2 dko mice (Barbagallo, Wang et al. 2011). This conserved Tyr (682) residue is both a docking site for several cytoplasmic partners and regulates processing of App. For example, a significant 15 fold increase in $\mathrm{sApp}-\alpha$ together with a 3.5 fold decrease in $\mathrm{sApp}-\beta$ was detected in brain tissue from $A p p^{Y 682 G / Y 682 G}$ mice, highlighting the importance of this residue in regulating App processing (Barbagallo, Weldon et al. 2010). NGF-TrkA signaling was proposed as the pathway responsible for regulating the phosphorylation of Tyr(682) of App. Tyrosine phosphorylation of APP was induced after NGF treatment of primary hippocampal neurons. The tyrosine kinase activity of TrkA receptor may mediate the NGF induced tyrosine phosphorylation of App (Matrone, Barbagallo et al. 2011). Further, it was shown that $\mathrm{Y} 682 \mathrm{G}$ mutant neurons are insensitive to trophic activity of NGF, suggesting that phosphorylation of $\operatorname{Tyr}(682)$ can work down-stream of NGF-TrkA signaling to mediate the trophic effect of NGF. A nearby conserved phosphorylated $\operatorname{Thr}(668)$, part of pSer/Thr-Pro motif, is a docking site for Pin1 and this interaction can down regulate production of A $\beta$ peptide from APP (Balastik, Lim et al. 2007). Pin1 is a unique peptidyl-prolyl cis/trans isomerase that can catalyse cis/trans isomerization of pSer/Thr-Pro motifs (Lu 2004). Binding of Pin1 to the pThr 668-Pro motif in c-terminus of App was shown to accelerate its isomerization leading to conformational changes in the cterminus of App (Pastorino, Ikin et al. 2004). In contrast to the instrumental role of $\operatorname{Tyr}(682)$ for survival of the mice during development, mutation in $\operatorname{Thr}(668)$ of App (T668A), in an Aplp2 null background, does not cause lethality or neuromuscular defects (Barbagallo, Wang et al. 2011) highlighting further the importance of tyrosine phosphorylation of APP during development.

The fact that several loss of function App phenotypes emerge in an Aplp2 null background is evidence for genetic interaction but does not directly address the question whether there is really functional redundancy between these different paralogues. Further thorough analyses of the single mutant mice should be more informative to identify pathways in which the specific effects of Aplps become apparent. Indeed the question remains whether double mutants generate more severe phenotypes either because of complete loss of a redundant function or because of disruption of multiple independent pathways. 
Transcriptional profiling of the different single mutant mice supports the second possibility. The transcriptomes of App and Aplp2 single ko mice reveal different sets of genes (Aydin, Filippov et al. 2011). From the 1061 genes that are up or down regulated after deletion of Aplp2, only 181 are also found altered in App mutant mice (Yang, Turner et al. 1998; Aydin, Filippov et al. 2011). For instance, signalling molecules that regulate early response to synaptic activity such as KCNH6 (Erg2), Fos and Arc are significantly down-regulated in App mutant mice, but not in Aplp2 mutant mice, strengthening the evidence for APP function in synaptic plasticity. p21 is such an example that is down regulated in both APP and APLP2 ko mice cortices. p21 is a cyclin-dependent kinase inhibitor that regulate cell-cycle progression during G1 phase of cell cycle. Deficiency of p21 decrease cell cycle exit and enhances proliferation of neural stem cells by regulating the expression of pluripotency factor Sox2 (Kippin, Martens et al. 2005; MarquésTorrejón, Porlan et al. 2013). Thus, down-regulation of p21 in both App and Aplp2 null mutants may enhance the proliferation of neural stem cells. This is consistent with data from Lopez-Sanchez et al (López-Sánchez, Müller et al. 2005) that demonstrate Aplp2 transcripts is predominantly enriched in the proliferative zone of the developing cortex while App show a partial overlapping expression with Aplp2 in this area. Soluble fragment of APP and Aplp2 can promote proliferation of EGF expressing progenitors of subventricular zone (Caillé, Allinquant et al. 2004). Thus, overall it appears that App and Aplp2 indeed are partially redundant in neurogenic niches. Nevertheless, it should be noted that next to shared pathways between APP and APLP2, significant differences in the transcriptional response of App or Aplp2 deletion suggest that there are distinct pathways that are regulated by either App or Aplp2. It also of note that it is not yet clear whether expression changes in App and Aplp2 ko mice is due to direct transcriptional activity of intracellular domain of this protein or an indirect effect of loss of those proteins (Cao and Südhof 2001; Hebert, Serneels et al. 2006; Aydin, Filippov et al. 2011).

\subsection{A role of APP and APLPs in cortical development?}

The mammalian cortex has expanded rapidly across different species and this is associated with the evolution of neocortical related behaviour such as perception and cognition (Kriegstein, Noctor et al. 2006). The expansion of cortical surface is believed to underlie the transition from a smooth cortex (lissencephaly) to a highly folded cortex (gyrencephalic). Indeed, changes in the proliferative pattern of ventricular zone resident neural stem cells have been titled as " a giant leap for mankind " referring to the expanded surface of the human cortex due to more proliferative radial units (Rakic 1995). However, 
neural progenitors outside the ventricular zone, for example the intermediate progenitors in subventricular zone, might be as well important players in the evolutionary expansion of the cortex (Kriegstein, Noctor et al. 2006; Fietz and Huttner 2011). In mice, APP and APLP2 are expressed in both ventricular and subventricular neurogenic niches of the developing cortex, and the question whether they play there a role in the development and evolution of the cortex is attractive (Lorent, Overbergh et al. 1995; López-Sánchez, Müller et al. 2005). Recently, several studies support such a role of the APP protein family in both migration and differentiation of neuronal precursor and progenitors during cortical development.

A

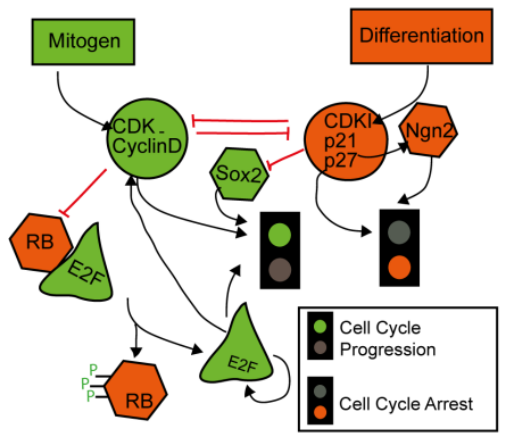

B

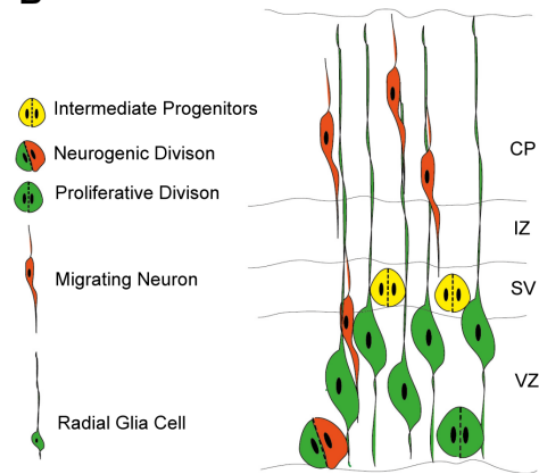

Figure 4. Cell cycle network and schematic representation of the developing cortex.

A) Part of the network that regulates the proliferation/differentiation balance of neural stem cells. Proteins that promote proliferation are depicted in green and differentiation promoting factors in red. B) The cells that compose the cortex are generated outside the cortex and reach their final destination by migration. For example, excitatory neurons are born in the proliferative regions of the developing cortex and reside in the cortical plate. The activity of neural stem cells is tightly regulated to ensure the balanced production of different neuronal subtypes. The two principle classes of neuronal progenitors are radial glia cells and intermediate progenitors which reside in $\mathrm{VZ}$ and SVZ respectively. The mitotic activity is induced when the radial glia cells approach and contact the ventricular lumen. This division can lead to generation of neurons which use the scaffold of radial glia cells to migrate and position in the cortical plate.

\subsubsection{Cell cycle of neural stem cells}

Two major neurogenic niches exist during cortical development; the ventricular zone (VZ) largely populated by the radial glia cells, and the subventricular zone (SVZ), populated by 
the intermediate progenitors (Fig. 4B). More recently an additional class of progenitors is described in the outer subventricular zone OSVZ (OSVZ) of human, as well as of ferret and mouse (Fietz, Kelava et al. 2010; Hansen, Lui et al. 2010; Fietz and Huttner 2011). Initially neural stem cells mainly divide symmetrically to expand the pool of neural stem cells (E9.5-E11.5). This phase is followed by gradual increase of neurogenic divisions (E11.5-E17.5) (Dehay and Kennedy 2007; Farkas and Huttner 2008). Neurons can arise directly from radial glial cells or indirectly through intermediate progenitors which undergo symmetric final mitosis to produce two neurons (Dehay and Kennedy 2007; Farkas and Huttner 2008) (Fig. 4B). Before migration starts, the neuronal precursors need to exit the cell cycle. It is noteworthy that progression through the cell cycle and fate specification is highly coordinated (Dehay and Kennedy 2007; Farkas and Huttner 2008). Entry and exit from the cell cycle is regulated during the G1 phase of the cell cycle. Progression through the G1 is tightly regulated by Cyclin Dependent Kinases (CDK2/4/6) whose activity depends on their interaction with their activating cyclins subunits (E/D). When the activity of the G1 CDK-Cyclin is low, retinoblastoma tumour suppressor protein (RB) binds to E2F transcription factors suppressing the transcription of the genes required for cell cycle entry (Fig 4A). In response to mitogen in early G1, CDK4/6-CyclinD Phosphorylates RB resulting in its hyperphosphorylation. Hyperphosphorylated RB is inactive and dissociates from $\mathrm{E} 2 \mathrm{~F}$ transcription factors leading to the transcription of the genes necessary for transition to $S$ phase of the cell cycle (Figure 4A). Consistent with an anti-proliferative role for $\mathrm{RB}$, telencephalon specific deletion of $\mathrm{RB}$ enhances the proliferation of the neural progenitors and an increase in the size of the telencephalon (Ferguson, Vanderluit et al. 2002). Active E2F1 promotes the expression of CDK2/CylinE which triggers the G1-S transition in late stages of the G1. The activity of the CDKs is negatively regulated by CDK inhibitors (CDKIs). There are two classes of the CDKIs: the INK4 family (p15, p16,p18 and p19) and the CIP/KIP (p21, p27, p57). In neural stem cells of the adult brain loss of $\mathrm{p} 21$ results in increased proliferation of stem cells followed by their exhaustion. These data show that the cell cycle inhibitor p21 is necessary to maintain the pool of neual stem cells in the adult brain by regulating their quiescence (Kippin, Martens et al. 2005). More recently, it was shown that P21 regulate the pool of neural stem cells by suppressing the expression of Sox 2 which is necessary transcription factor for selfrenewal of neural stem cells (Marqués-Torrejón, Porlan et al. 2013). It is interesting that p21 not only regulate the activity of the G1 CDK but also link the cell cycle progression to cell fate decisions mechanisms. p27 is another CDKI which control activity of the CDK2/Cyclin E during G1-S transition. Interestingly, p27 deficiency promotes neuronal differentiation by stabilizing Neurogenin2 (Ngn2) in a cell cycle independent manner (Nguyen, Besson et al. 2006). Together, these findings suggest that cell cycle and 
cell fate mechanism are interconnected with some proteins regulating both proliferation and differentiation (Fig 4A).

Early studies of cortical neurogenesis proposed a model in which the length of the cell cycle determines the output of the division. Takahashi et al used S-Phase labelling of dividing neural stem cell to show that the length of the cell cycle increases during cortical development. This increase in the cell cycle length is accompanied by increased rate of neurogenesis meaning that early short cycles expand the pool of neural stem cell, whereas longer cycles in later stages of cortical development produce more neurons (Takahashi, Nowakowski et al. 1995; Takahashi, Nowakowski et al. 1996). Currently, converging evidence suggest that the progressive increase in neurogenesis is mainly due to the lengthening of the G1 phase of the cell cycle. Based on this model, differentiative divisions have longer G1, and the reverse is true for proliferative divisions (Calegari and Huttner 2003; Dehay and Kennedy 2007). Calegari and Huttner used specific inhibitor of CDK2 (Olomoucine) to show that lengthening of G1 progression increases the number of neuron generating divisions (Calegari and Huttner 2003). On the contrary over-expression of CDK4/Cyclin D1 shortens the G1 leading to increased number of proliferative divisions (Lange, Huttner et al. 2009; Pilaz, Patti et al. 2009). Over-expression of cdk4/cyclin D1 did not affect cell size or the cleavage angle of the division, but increased the number of divisions that produce basal progenitors confirming the idea that G1 cdk activity is a major determinant of the differentaitive vs. proliferative division (Lange, Huttner et al. 2009). Similar to developmental neurogenesis, over-expression of cdk4/cyclin D1 in the adult hippocampus expand the pool of adult neural stem cells suggesting conservation of this developmental pathway in adult neurogenesis (Artegiani, Lindemann et al. 2011). Based on these finding, the "cell cycle length" model proposes that the speed of G1 determines the fate of the daughter cells, perhaps by regulating their exposure to extrinsic differentiation factors (Calegari and Huttner 2003; Caviness, Nowakowski et al. 2009).

\subsubsection{Radial migration and the role of APP proteins}

Post-mitotic neurons born in neurogenic niches migrate towards the cortical plate using the fibers provided by the radial glia cells (Fig. 4B). This mode of migration is called glia guided migration. The glia guided migration stops at a cellular layer populated by CajalRetzius (CR) cells. CR cells produce Reelin which binds to ApoER2 and Vldlr receptor to signal via Dab1 to control the end stage of neuronal migration by promoting glia independent somal translocation (Franco, Martinez-Garay et al. 2011). Triple deletion of App, Aplp1 and Aplp2 result in reduced number of CR cells and accumulation of neurons 
that over-migrate to the marginal zones of the developing cortex (Herms, Anliker et al. 2004). Likewise, deficiency of presenilin-1 decreases the number of CR cells and cause an ectopic accumulation of neurons in the marginal zones of the developing cortex (Hartmann, Strooper et al. 1999), suggesting the importance of APP processing in CR cell function. In contrast to the over-migration phenotype, Young-Pearse et al (Young-Pearse, Bai et al. 2007) showed that single knock-down of APP in wt brain inhibits migration of cortical neurons and APP over-expression promoted the migration of neurons which again depends on the conserved YENPTY in the carboxyl terminus. It is noteworthy that endogenous expression of Aplp1 and Aplp2 could not rescue the effect of shRNA, but their overexpression rescued the migration phenotypes, indicating that regulated expression of App and Aplps is critical for their function (Young-Pearse, Bai et al. 2007). Down-stream, DISC1 is another interactor of APP with key roles during progenitor proliferation and neuronal migration (Bradshaw and Porteous 2012). Over-expression of DISC1 can significantly rescue the migration effect observed after Dab1 and APP down-regulation (Young-Pearse, Suth et al. 2010). Upstream, binding of different isoforms of Pancortins mediate different effects on processing of APP. Using an unbiased assay for identification of ectodomain binders of APP, Rice et al showed that pancortins can bind to APP and binding of Pancortin 1 and 2 (B-domain containing pancortins) can significantly decrease Abeta processing of APP (Rice, Townsend et al. 2012). Down-regulation of Pancortin 1 or over-expression of Pancortin 4 resulted in similar migration defects observed after downregulation of APP in developing cortex suggesting opposite roles for different isoforms of the Pancortins (Rice, Townsend et al. 2012). Expression of Pancortin 1 or APP could rescue the delayed migration of pancortin 4 over-expressing migratory neurons (Rice, Townsend et al. 2012). Similar to Pancortins, Reelin interacts with the extracellular domain of APP in primary hippocampal neurons (Hoe, Lee et al. 2009) and Dab1 interacts with the highly conserved YENPTY motif in the carboxyterminus of APP. This interaction most likely depends on the phosphorylation of tyrosine highlighting further the importance of this residue for developmental functions of APP proteins (Howell, Lanier et al. 1999). Extracellular interaction of APP with Reelin and intracellular binding to Dab1 shows that APP might work together with ApoER2/Vldlr as (co)receptor to mediate the Reelin effect during migration of neurons. Indeed, Dab1 over-expression could rescue the blocked migration induced by APP shRNA in the developing cortex, further suggesting that Dab1 might act down-stream of APP and Reelin complex (Young-Pearse, Bai et al. 2007). From these findings, a model emerges in which the ectodomain of APP binds to Reelin and Pancortins at the cell surface which leads to signal transduction through down-stream effectors such as Disc1 and Dab1 to regulate neuronal migration. It is very likely that phosphorylation of YENPTY motif at the C-terminus plays a central role in the regulation 
of cortical migration. However, this model does not explain the reduction of CR cell in triple ko mice (Herms, Anliker et al. 2004), unless Reelin affects the survival of CR cells in a cell-autonomous way. It is likely that early neurogenesis is affected by APP proteins because CR cells are among the first neurons that are born during development.

It might be that Reelin has a dual site of action in the developing cortex. Similar to postmitotic migratory neurons, Reelin-Dab1 can directly signal to radial glial cells regulating their morphology and rate of neurogenesis (Hartfuss, Förster et al. 2003; Lakomá, GarciaAlonso et al. 2011; Pérez-Martínez, Luque-Río et al. 2012). Regarding the dual site of action of Reelin, it is likely that during cortical development App and Aplp2 can regulate Reelin signalling both in migrating neuron and proliferating neural stem cells. Moreover, the YENPTY motif is also present in App like proteins raising the possibility that Reelin can also signals through Aplps to control migration and differentiation of cortical precursors and progenitors.

Altogether, the current findings do not converge to a concrete model for APP protein family function during cortical development. Moreover, it is not clear to what extent App and Aplps have specialized function in different neuronal events such as migration and differentiation. 


\section{Chapter II: Rationale, Aims and Approach}

Expression of amyloid precursor protein (APP) and its two paralogues, APLP1 and APLP2 during brain development coincides with key cellular events such as neuronal differentiation and migration. However, the neurodevelopmental roles of APP and APLPs remain controversial. When analyzing the function of APP and APLPs, a primary assumption made by many investigators is that the APP proteins are redundant. However, the early embryonic lethality of triple ko mice precludes the generation of sufficient number of mice for careful analysis of neurons (less than $6.25 \%$ theoretical chance of triple ko embryos from viable parents)(Bergmans, Shariati et al. 2010) . Previously, we approached these problems by generation of an embryonic stem cell line with triple deletion of App/Aplp1/Aplp2. The triple ko ES cells were differentiated to neurons in vitro and were analysed for different parameters such as migration and synaptic activity (Bergmans, Shariati et al. 2010). However, we did not find any obvious phenotype. This prompted us to further investigate the role of the APP gene family in vivo. We started by the generation of the chimeric mice with tKO neurons incorporated in a wt background brain using a morula aggregation technique. Using this technique, we showed that triple ko neurons can be generated in vivo and can migrate to the cortex (Bergmans, Shariati et al. 2010). However, we could not generate sufficient numbers of mice for in depth analysis of neurons and neuronal precursors in vivo.

The enrichment of Aplp2 expression in the proliferative zones of the developing cortex is compatible with a role of this protein in early proliferation and differentiation of neuronal precursors prior to migration. Moreover, among the different combinatorial genetic deletions of App/Aplps in mice, only App/Aplp1 double ko is a viable genotype, supporting a crucial and distinct developmental role for Aplp2 (Herms, Anliker et al. 2004). Therefore, we down-regulated Aplp2 by shRNA in wt mice as well as in App/Aplp1 dko mice. We avoided lethality by down-regulating Aplp2 only in a subpopulation of cells in the ventral telencephalon. This was done by in utero electroporation of shRNA against Aplp2. We investigated the effect of the loss of Aplp2 function in the proliferation and differentiation of progenitors, and migration and final positioning of cortical excitatory neurons using specific promotors to drive cell specific expression of the shRNA. 


\section{Chapter III: Methods and Materials}

The following chapters partly correspond to the following research article:

S. Ali M. Shariati et al, APLP2 regulates neuronal stem cell differentiation during cortical development, Journal of Cell Science, 126, 2013.

\subsection{DNA constructs}

We used two different approaches to down-regulate expression of the APLP2. First, we have used a type III RNA polymerase promoter (U6) to express APLP2 shRNA. The hairpin itself is composed of the $29 \mathrm{nt}$ followed by $7 \mathrm{nt}$ loop structure and $29 \mathrm{nt}$ reverse complement sequence. Trancription of shRNA by U6 promoter produces shRNAs that are recognized by miRNA processing enzyme to generate targeting sequence (Rossi 2008). In the second approach, the shRNA is flanked by the genomic sequence of a naturally present miRNA, in this case Let7f2. The let7f2 based shRNA is expressed from an intron of the GFP allowing cell specific expression by using RNA polymerase II expression (Chang, Elledge et al. 2006).

The APLP2 ShRNA1 (GI562807) (sequence: 5' CGATTACAATGAGGAGAATCCAACCGAAC-3'), the APLP2 shRNA2 (GI562808) (Sequence 5'-ATGAAGGCTCTGGAATGGCAGAACAAGAC-3') and control shRNA (scrambled sequence: 5'-GCACTACCAGAGCT AACTCAGATAGTACT-3') driven by the U6 promoter were obtained from Origene (Rockville, USA).

The $p C A G$-EGFPintron-let-7f based shRNA expression system was constructed as followed. The synthetic intron found in the psicheck2 plasmid (Promega, Leiden, The Netherlands) was PCR amplified using Promega IntronF (5'CGAAGGTAAGTATCAAGGTTACAAGACAG-3') and R (5'GACGTAGCCTGTGGAGAGAAAGGCAAAGTG-3') primers. The intron was then inserted into EGFP by overlap-PCR using two inner primers for 5' (5'TGATACTTACCTTCG GGCATGGCGGACTTGAAG-3') and 3'arms (5'TCTCTCCACAGGCTACGTCCAGG AGCGCACCATCTTCTTC-3') of EGFP and two outer primers for 5' (5'-GCCACCGGTCGATCCACGCCACCATGGTGAGCAAGGGCG AGGAG-3') and 3' (5'-GATTGTCGACTTACTTGTACAGCTCGTCCATGCCG-3') arms. Next, XhoI and EcoRI restriction sites were added to the intron by PCR using Intron Xhol-EcoRI-F GAATTCCAATCTCGAGCTATTGGTCTTACTGACATCCACTTTGC-3') and Intron XhoI-EcoRI-R TCTTCTCTG-3') primers (pCAG-EGFP intron). The let-7f2 genomic sequence was 
amplified from human genomic DNA using LET-7Fhu-MfeI (5'TCATCAATTGTAACTCTCCTTCCCTTTCTCCCTTCTTAC-3') and LET-7Fhu-SalI (5'-TCATGTCGACCATCAAAGGACCAGCCACTT-3') primers and cloned into the pCAG-EGFP intron vector digested by XhoI and EcoRI. This intermediate construct contains the genomic sequence of human let- $7 \mathrm{f} 2$ precursor including the mature let- $7 \mathrm{f}$ sequence. In order to remove this mature sequence and facilitate cloning of shRNAs, the 5' and 3' arms of the let-7f scaffold were amplified using two inner primers: 5'arm (5'GGCGCGCCCTCGAGCCATCTTCAGCCTATGTGGG-3') and 3'arm (5'GGCGCGCCG AATTCTCTTCTCCGACTGGCTCTGTTC-3') scaffold and two outer primers: Let7F-XhoI (5'-CAATCTCGAGGTGCTCTGTGGGAT-3') and Let7F-EcoRI (5'-CAATGAATTCGT ACCACCGTGGGA-3'). The PCR product was cloned into the intermediate construct resulting in the pCAG-EGFPintron-let-7f plasmid. For shRNA cloning, overlapping DNA oligonucleotides were designed to embed the shRNA into the let-7f scaffold sequence. The shRNAs for APLP2 and mCherry were obtained after annealing the following oligonucleotides: APLP2-let7-I (5'CTCGAGGTGCTCTGTGGGATCGCTGCTGGGT TCGGTTGGATtTAGGGTCATACCCCATCTTG-3'); APLP2-let7-II (5'GAATTCGTAC CACCGTGGGACGCCACTGGGTTCGGTTGGATATCTCCAAGATGGGGTATGAC$\left.3^{\prime}\right)$; mCherry-let7-I

\section{CTCGAGGTGCTCTGTGGGATGATGTTGACGTTGTAGGCGCCTT}

AGGGTCATACCCCATCTTG-3'); mCherry-Let7-II (5'-GAATTCGTACCACCG TGGGAGATACTGACGTTGTAGGCGCCATCTCCAAGATGGGGTATGAC-3') and PCR amplified using pre-Let7F and pre-Let7R universal primers. The resulting shRNAs were digested and cloned into the pCAG-EGFPintron-let-7f plasmid using XhoI and EcoRI restriction sites.

BLBP-shRNA mir: For cell-specific expression into radial glia cells, the BLBP promoter was amplified from mouse genomic DNA using BLBP-F (5'-CAATGTCGACAG CACAGCAGAAAGGGAAAA-3') and BLBP-R GGTGGGCGCGCCAGGCAGGAACT GGAGGAACTC-3') primers and cloned into the pCAG-EGFPintron-let-7f digested by SalI and AscI, thus replacing the CAG promoter by the mouse BLBP promoter.

$T \alpha$-shRNAmir: The tubulin alpha promoter was chosen to drive neuronal expression and amplified from mouse genomic DNA using T $\alpha$-F (5'-ACCTACTAGTGTATTAGAA GGGATGGCTCA-3') and T $\alpha-\mathrm{R}$ (5'-ACCTACCGGTGGTTGCTGCTTCGCGGCTGCC3') primers and cloned into the pCAG-EGFPintron-let-7f digested by SpeI and AscI. For in 
utero electroporation, DNA preparations, included endotoxin removal treatment, were obtained using Qiagen EndoFree Plasmid Maxi Kit (Qiagen, Venlo, Nethelands), with final concentration between 2-3 $\mu \mathrm{g} / \mu \mathrm{l}$ plasmid DNA.

\subsection{Western blot}

Total cell lysates of cortical neuron cultures or HEK293 were prepared in cell lysate buffer (1\% Triton-X100, with protease inhibitors in PBS). $20 \mu \mathrm{g}$ of protein was separated on a NuPAGE $4 \%-12 \%$ (Invitrogen), transferred to nitrocellulose and membranes were incubated overnight at $4{ }^{\circ} \mathrm{C}$ with the following primary antibodies: APLP2 (CT12 a kind gift from Dr. Thinakaran), V5 antibody (1:10000-mouse, Invitrogen Gent, Belgium), APP antibody (B63-1:5000, custom made rabbit antibody), GAPDH (1:5000-mouse, HyTest), Actin (1:1000-mouse, Sigma-Aldrich, Diegem, Belgium) and detected with HRP conjugated secondary antibodies using a ECL chemiluminescence detection kit (PerkinElmer Life Sciences, Zaventem, Belgium). The density of bands was quantified by densitometry using Aida Image Analyser 4.27 (Raytest, Straubenhardt, Germany) and linearity of the signal was tested using different dilution of total cell lysate.

\subsection{Cell cultures}

Mouse embryonic cortical neurons were prepared as described previously (Banker \& Goslin, 1988) and plated at a density of 100000 cells per $\mathrm{cm}^{2}$ on poly-L-lysine (PLL) coated dishes. Neurons were transfected before plating using nucleofection (Amaxa, Cologne, Germany). HEK293 cells over-expressing V5 tagged APLP2 were grown in DMEM/F12 with $10 \%$ Fetal Calf serum (FCS) and were transfected with shRNA expressing construct using TransIT®-LT1 transfection reagent (Mirus, Madison, USA).

\subsection{Matrigel assay for migration}

E14 embryonic cortices were dissected and digested by papain for $20 \mathrm{~min}$ at $37{ }^{\circ} \mathrm{C}$. After subsequent mechanical dissociation, cells were transfected by nucleofection (Amaxa) followed by overnight shaking (350rpm) at $37^{\circ} \mathrm{C}$ to form aggregates. The aggregates were embedded in Matrigel (BD Biosciences, Erembodegem, Belgium) on coverslips and fixed in $4 \%$ paraformaldehyde (PFA) after 3 to 4 days. For live imaging from one day after plating onwards, coverslips were mounted in a closed metal chamber and images were acquired at 20 min intervals for up to $24 \mathrm{~h}$ using an inverted Olympus Cell ${ }^{\mathrm{R}}$ microscope. 


\subsection{Knock-out mice}

APP/APLP1 double knock-out mice were described previously and generated by genomic deletion of the promoter and initiation codon of APP and APLP1 loci (Heber, Herms et al. 2000; Herms, Anliker et al. 2004). Wt embryos were from C57/B16 background.

\subsection{In utero electroporation}

All animal experiments were approved by the Ethics Committee of the K.U.Leuven. Pregnant mice were anesthetized by intramuscular injections of $88 \mu \mathrm{g}$ ketamine and $132 \mu \mathrm{g}$ xylazine per gram of body weight. The uterine horns were exposed and the plasmids (1$2 \mu \mathrm{g} / \mu \mathrm{l})$ mixed with Fast Green (Sigma) were microinjected in the lateral ventricles of E14.5 mouse embryos. Five current pulses (50 ms pulse/ $950 \mathrm{~ms}$ interval) were delivered across the head of the embryos $(36 \mathrm{~V})$ targeting the dorsal-medial part of the cortex. After 2-4 days, embryos were collected and perfused with PBS and $4 \%$ PFA and the brains postfixed for $6-10 \mathrm{~h}$ in $4 \%$ PFA at $4{ }^{\circ} \mathrm{C}$.

\subsection{Immunocytochemistry}

Coronal vibratome sections of the fixed embryonic brains were prepared with $100 \mu \mathrm{m}$ thickness. Subsequently, the sections were permeabilized and blocked at RT for $1 \mathrm{~h}$ in PBS/ $0.3 \%$ Triton-X100/ $3 \%$ BSA/ $5 \%$ goat or donkey normal serum, incubated with the primary antibody at $4{ }^{\circ} \mathrm{C}$ overnight followed by the secondary Alexa conjugated antibodies for $2 \mathrm{~h}$ at room temperature (Invitrogen). For BrdU detection, slices were pretreated with $1 \mathrm{M} \mathrm{HCl}\left(10 \min 4{ }^{\circ} \mathrm{C}\right)$ and $2 \mathrm{M} \mathrm{HCl}\left(10 \mathrm{~min} \mathrm{RT}\right.$ and $\left.20 \min 37^{\circ} \mathrm{C}\right)$ with subsequent washes in $0.1 \mathrm{M}$ borate buffer.

The following primary antibodies were used: chicken anti-EGFP (1:500; Aves labs, Oregon, USA), rabbit anti-Ki67 (1:300; Novacastra, Diegem, Belgium), rabbit anti-Tbr2 (1:1000; Abcam, Cambridge, UK), rabbit anti-PH3 (1:300; Cell signalling, Leiden, The Netherlands), rabbit anti- $\beta$ III-tubulin (1:1000, Abcam), mouse anti-BrdU (1:200; Roche, Vilvoorde, Belgium), rabbit anti-Cux1 (1:500; Santa-Cruz, Heidelberg, Germany), goat anti-Sox2 (1:150; Santa-Cruz). Nuclei were visualized with DAPI.

\subsection{Cell cycle exit}

One day after in utero electroporation, pregnant mice were injected intraperitoneally with BrdU (75 mg/kg, Sigma-Aldrich). After another $24 \mathrm{~h}$ the brains were collected, fixed and immuno-stained using anti-EGFP, anti-BrdU and anti-Ki67 antibodies. The cell cycle exit rate was calculated as the ratio of $\mathrm{EGFP}^{+} / \mathrm{BrdU}^{+} / \mathrm{Ki}^{-}$cells (cells which are not in the cell cycle) divided by the number of $\mathrm{EGFP}^{+} / \mathrm{BrdU}^{+}$cells (total number of dividing and nondividing cells). 


\subsection{Confocal imaging and quantification}

Confocal images were captured on a Nikon microscope (Eclipse; Ti A1) using an Apo 10x A/1.40 N.A. objective lens. The images were acquired by Nis-Element software and the imaging parameters were kept constant during imaging. Ten to fifteen consecutive Zsections were obtained per brain slice. All images were processed using the ImageJ software (NIH).

For cortical positioning: The entire length of cortical walls was divided into ten equal bins and the frequency of cells per bin was calculated by counting the cell bodies of EGFPPositive cells in each bin, divided by the total number of EGFP positive cells.

For cell cycle exit: All the images were thresholded and BrdU+/EGFP+ cells were detected by the AND function of Image Calculator (ImageJ software). Next, the same function was used to find BrdU/EGFP double positive cells that are positive or negative for Ki67.

\subsection{Statistics}

Corresponding bins were compared using Student's $t$-test. The population distribution of two groups of neurons was compared using a non-parametric Mann-Whitney $\mathrm{U}$ test $(\mathrm{P}<$ 0.05 as significance level). All statistical analysis and graph preparation were done by using GraphPad Prism5. 


\section{Chapter IV: Results}

To study the role of Aplp2 in neuronal development, we tested the effect of Aplp2 downregulation on cortical position of neurons. To this end, we performed the following experiments:

- Identification of functional and specific shRNAs

- Down-regulation of Aplp2 in wt cortices using in utero electroporation

- Down-regulation of Aplp2 in dko cortices using in utero electroporation

- Morphological studies of neurons and neuronal precursors

- Cell specific interference with Aplp2 functions

- Analysis of cell cycle variables

In these experiments, we electroporated Aplp2 shRNA at E14 and removed the brain at E18 for migration and morphological studies. The neurons born on E14 are expected to reside in the upper layers of the developing cortical plate 4 days after electroporation (E18.5) (Figure 5).

To analyze the cell cycle, differentiation and mitosis, we collected samples at E16.5 when many electroporated cells are still residing in the VZ/SVZ (Figure 5). 
E14.5
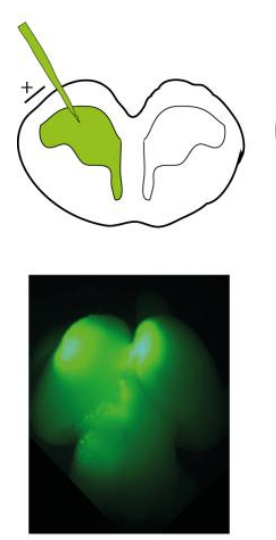

E16.5
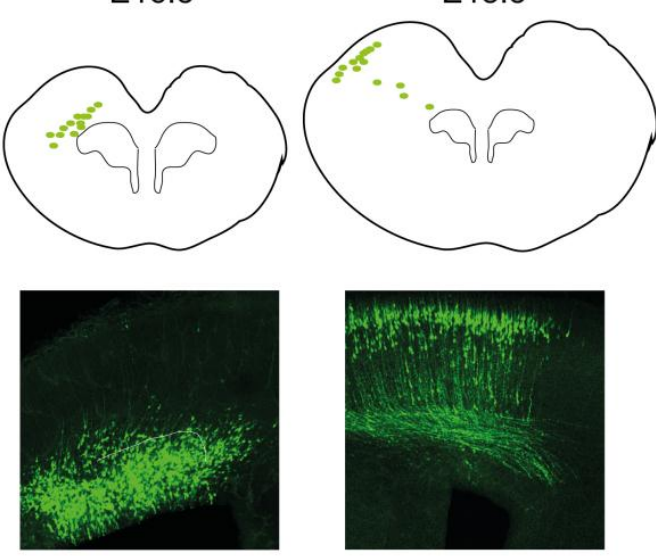

Cell cycle Exit Mitotic index Differentiation
E18.5

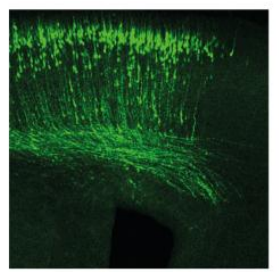

Cortical positioning Morphological analysis

Figure 5. The experimental approaches used to study different neuronal processes.

The DNA constructs expressing Aplp2 shRNA were electroporated at E14.5 Two days after electroporation, most of the cells are still residing in the proliferative zones of the developing cortex. We chose E16.5 (when many of the electroporated cells are still in the proliferative zones) to test the cell cycle exit, mitotic index and differentiation of neuronal precursor. Four days after electroporation, most of the targeted cells end up in the upper layers of the developing cortex. We performed the migration, morphological studies and cortical positioning analysis at E18.5.

\subsection{Identification of functional and specific shRNAs targeting Aplp2}

To examine the role of Aplp2 in cortical development, we tested the effect of four U6 driven shRNAs on the expression of endogenous Aplp2 in mouse embryonic fibroblasts. We selected two different U6 driven shRNAs constructs (shRNA1 and 2) targeting different regions of the coding sequence of the Aplp2 transcript. To control the effect, we used a scrambled control shRNA construct that does not align significantly with any published NCBI mouse transcript sequence. Western-blot analysis of Aplp2-V5 overexpressing HEK293 cells which were transfected with one of those shRNA constructs confirmed the down-regulation of Aplp2 protein (APLP2 shRNA1 more than $95 \%$ knockdown and Aplp2 shRNA 2 more than $80 \%$ knock-down: Fig. 6A). Since Aplp2 shRNA1 was more efficient for the down-regulation of Aplp2 protein, we used in most of our analysis this shRNA construct (in the further text named Aplp2 shRNA) and utilized the 
second construct in initial experiments in order to validate the phenotype and exclude the possibility of off-target effects. Also in cultures of cortical neurons from E14 mice (Fig. 13D) endogenous Aplp2 expression was clearly down-regulated by Aplp2 shRNA1 three days after transfection. Next, we tested the selectivity of the Aplp2 shRNAs by assessing their effect on highly related Aplp1 transcripts. Western blot analysis showed that Aplp2 shRNAs do not change significantly the level of Aplp1 supporting the specificity of selected shRNAs (Fig. 6B).
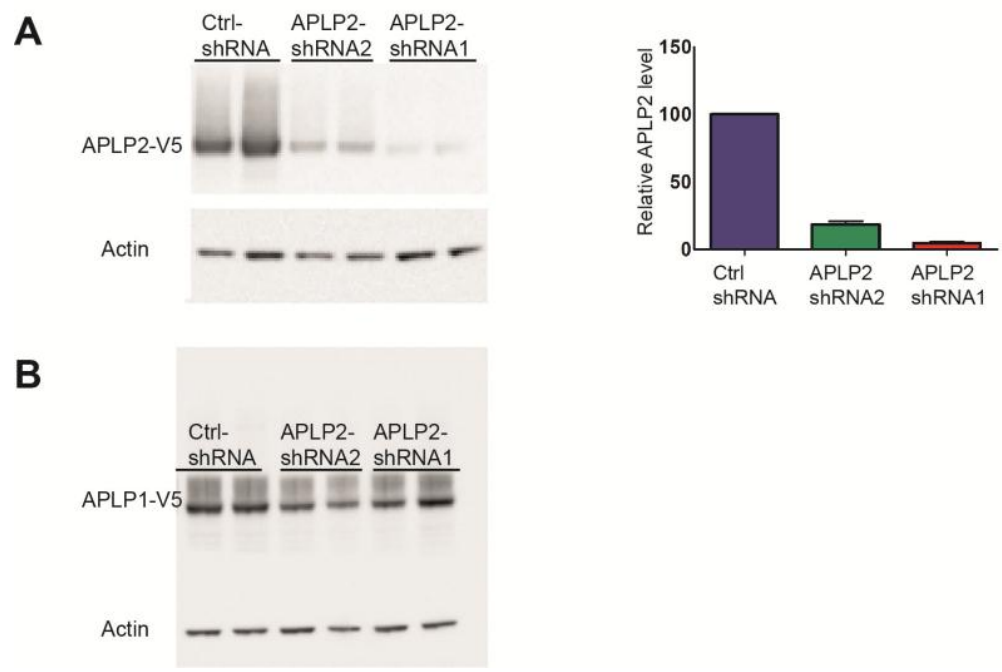

\section{Figure 6. Western blot analysis of Aplp2 shRNA effect}

A) The selected shRNA1 and shRNA2 significantly down-regulate expression of Aplp2 -V5 that is overexpressed in Hek293 cells. On the left, the expression of Aplp2-V5 was assessed using a mouse antibody against the V5 tag and on the right the quantification of the APLP2 band normalized to actin loading control $(\mathrm{n}=2)$ is shown B) APLP2 shRNAs does not change significantly Aplp1 level. The expression of Aplp1-V5 was assessed using a mouse antibody against the V5 tag.

\subsection{Down-regulation of Aplp2 in wt cortices does not change cortical positioning}

To address Aplp2 function, we expressed the Aplp2 shRNA constructs in cortical progenitors of wt mice at E14.5 by using in utero electroporation. Aplp2 is highly expressed in the developing cortex at E14.5 (Lorent, Overbergh et al. 1995; López- 
Sánchez, Müller et al. 2005) when upper layer neurons are generated (Molyneaux, Arlotta et al. 2007). In order to visualize electroporated cells, EGFP was co-expressed. As control, we used a scrambled control shRNA that does not align significantly with any NCBI mouse transcript sequence. Four days after electroporation, the time point when transfected precursors are expected to have differentiated into neurons and are residing in the upper layers of the cortical plate (Fig. 7A), we fixed the brains and analysed the position of labelled cells in coronal sections. For this purpose we divided the cortex into 10 equal bins and counted the relative number of EGFP-positive cells in each bin (Fig. 7A/B, see Material and Methods). Moreover, we analysed the difference of the entire population distribution (Fig. 7B, inset). Both types of analysis did not reveal any difference in the behaviour of Aplp2 shRNA expressing cells in respect to control shRNA cells (Fig. 7A/B). In both cases, EGFP-positive cells were mostly positioned in the upper layers of the cortex, which is marked by Cux1 (Cut like homeobox 1 )antibody (Fig. 7B).

A

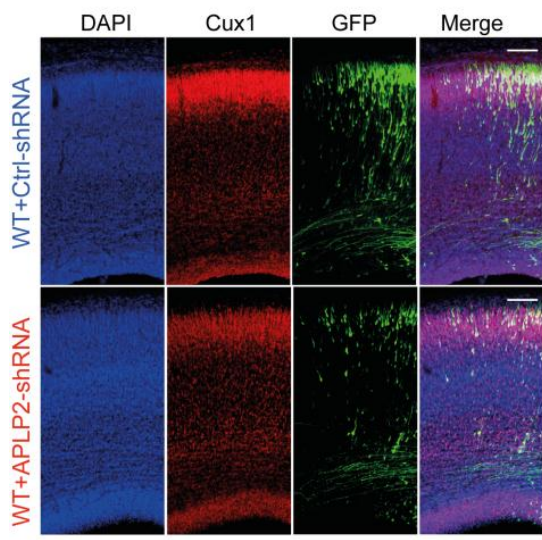

B

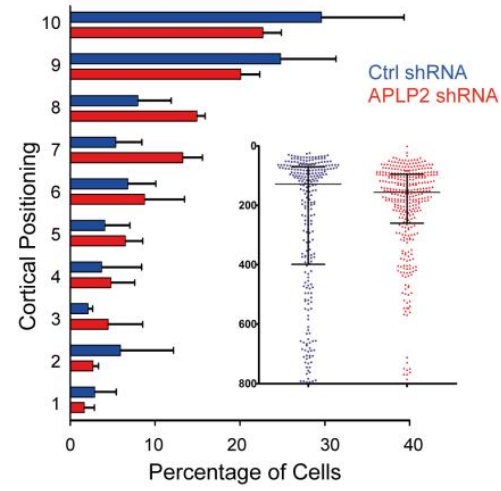

Figure 7. APLP2 down-regulation in wt cortices does not change cortical positioning of neurons.

A) Confocal images of coronal slices of wt brains electroporated with constructs expressing Aplp2 shRNA or Ctrl shRNA together with GFP, 4 days after electroporation (E14.5-E18.5). Aplp2 shRNA expression does not lead to developmental differences respect ctrl conditions. B) Quantification of GFP+ cells of A. Bar graphs represent frequency distribution of GFP positive cells in ten equally divided bins from ventricle (10) to the pial surface (1) of the cortical wall. Values represent the mean \pm STDV $(n=5$; $t$-test). The inset scatter plot compares the population distribution of GFP+ cells. ( $\mathrm{n}=3,300-400$ cells only are shown for clarity of graph; Values represent the median \pm interquartile Mann Whitney test). 


\subsection{Down-regulation of Aplp2 in App/Aplp1 dko cortices affects cortical positioning}

Next, we considered the possibility that the overlapping function of App, Aplp1 and Aplp2 throughout development (Heber, Herms et al. 2000) could have led to a compensation for the loss of Aplp2 function. To test this, we expressed Aplp2 shRNA in cortical progenitors from App/Aplp1 dko mice. Aplp2 down-regulation in App/Aplp1 dko resulted in a large number of EGFP positive-cells (54\%) residing in the Cux1 negative region, i.e. predominantly in the VZ/SVZ of the developing cortex (Fig. 8A/B). Similar to wt mice, the majority of neurons electroporated with the control shRNA construct (App/Aplpl dko) migrated to the upper layer of the cortical plate (Cux1-positive layer, Fig. 8A). This indicates that Aplp2 is an important component of the machinery responsible for proper neuronal progression towards the cortical plate. To guard against possible off-target of the Aplp2 shRNA construct, we used a second shRNA (i.e. shRNA2) to target Aplp2 in the developing cortex. Again, we find only a change in the cortical positioning of cells transfected with Aplp2 shRNA2 in App/Aplp1 dko mice (Fig. 9 A,B). Moreover, the inability of both Aplp2 shRNA constructs to induce any phenotype in wt cortices (Fig. 7A,B and Fig. 9A,B) argues for the specificity of our approach. 
A

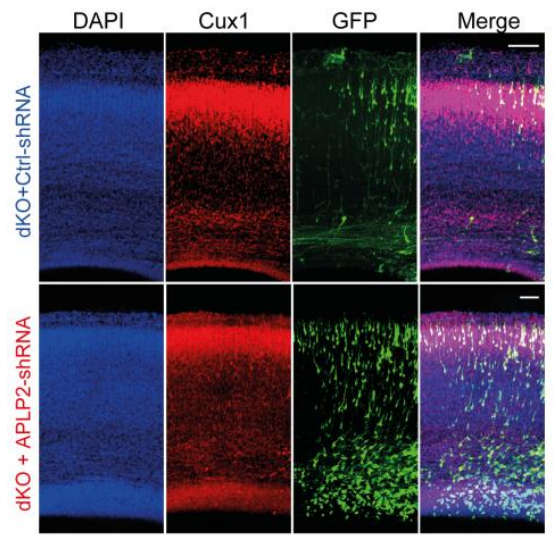

B

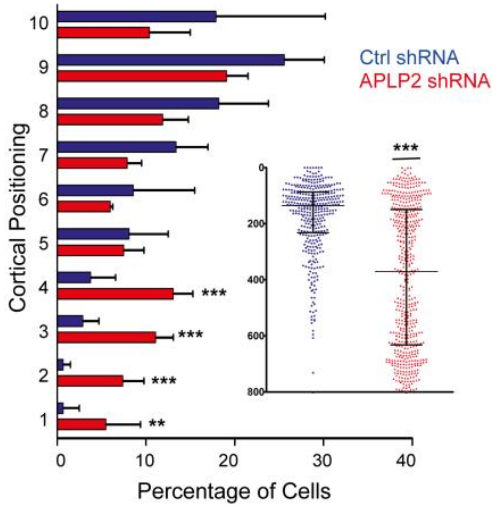

Figure 8. APLP2 down-regulation in dko cortices change cortical positioning of neurons.

A) Confocal images of coronal slices of dko brains electroporated with constructs expressing Aplp2 shRNA or Ctrl shRNA together with GFP, 4 days after electroporation (E14.5-E18.5). Aplp2 shRNA expression leads to developmental differences respect wt and ctrl conditions. B) Quantification of GFP+ cells of A. Bar graphs represent frequency distribution of GFP positive cells in ten equally divided bins from ventricle (10) to the pial surface (1) of the cortical wall. Values represent the mean \pm STDV $(n=5$; t-test). The inset scatter plot compares the population distribution of GFP+ cells. ( $n=3,300-400$ cells only are shown for clarity of graph; Values represent the median \pm interquartile Mann Whitney test).

A

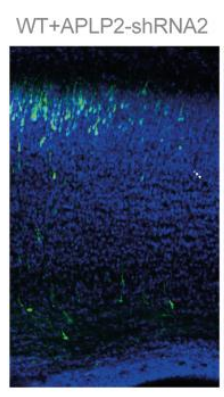

B

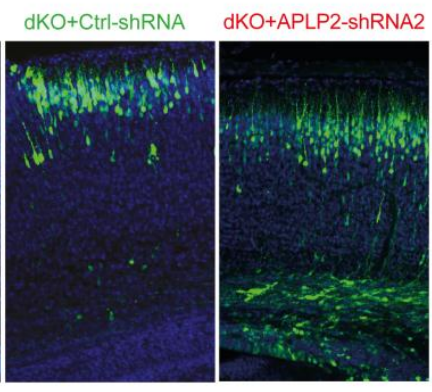

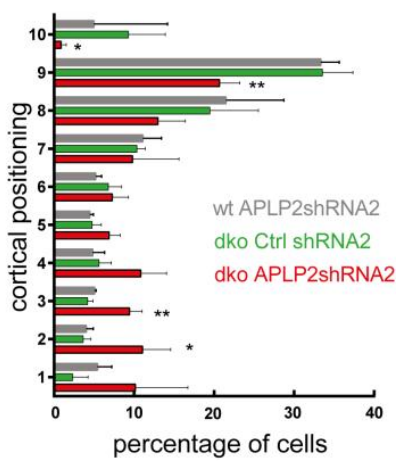

Figure 9. Confocal images (left) and quantification (right) of the effect of a second Aplp2 ShRNA.

See the text and legend of figure 7 and 8 for full description. 


\subsection{Morphology and migratory behaviour of "Triple knock-out" cells remain unchanged}

Next, we asked whether the morphology of neurons that are moving towards the cortical plate is different in dko vs. "triple ko" neurons ("triple ko" refers to APP/APLP1dko cells expressing APLP2shRNA). Neurons born in the proliferative zones of the cortex acquire a multipolar morphology in the lower part of the intermediate zone. As they migrate towards cortical plate, the neurons change from multipolar to bipolar morphology with a thick leading process and a thin trailing process. The transition from multipolar to bipolar morphology is essential for proper positioning of the neurons in the cortical plate. A defect in acquiring the bipolar morphology could explain the observed changes in cortical positioning of the cells (Jossin and Cooper 2011). Careful microscopic analysis revealed that this is not the case: neurons in both groups displayed the typical bipolar morphology of migrating neurons with a thickened leading edge and a thinner trailing process (Fig. 10A), indicating that Aplp2 is not essential for the acquisition of the morphological polarization required for proper migration. To assess directly neuronal migration, we monitored the migration speed and distance of dko neurons either expressing the control shRNA or the Aplp2 shRNA through the use of an in vitro migration assay in Matrigel (Calderon de Anda, Gartner et al. 2008). We did not detect any differences in the distance that double or "triple ko neurons" migrate away from the explants (Fig. 2B). Moreover, live imaging of migrating neurons did not reveal differences in the speed of neuronal migration nor in the morphology nor in the behaviour of the migrating neurons (Fig. 10B). Thus, neither a morphological defect nor the migratory behaviour of neurons is the cause of altered cortical positioning. 


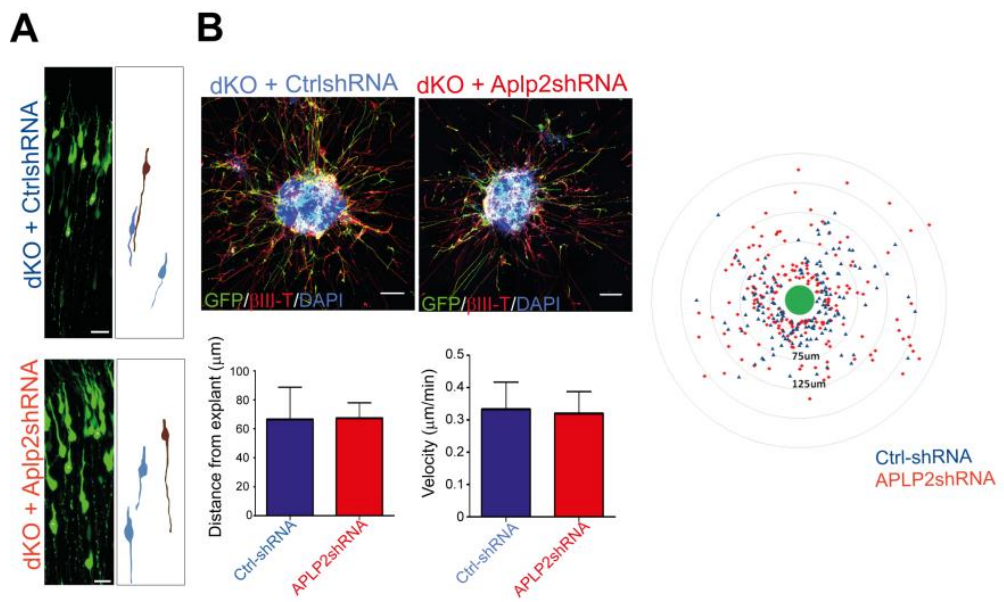

Figure 10. Morphology and in vitro migration of migrating neurons are not altered

A) Confocal images of 20-25 $(0.8 \mu \mathrm{m})$ consecutive z-sections illustrating morphology of dko migrating neurons transfected with Aplp2 shRNA or control shRNA. Drawings on the right depict the morphology of two migrating neurons (blue) and one positioned in the CP. The morphology of neurons in both groups is comparable. Scale bars: $25 \mu \mathrm{m}$. B) Images of control shRNA or Aplp2 shRNA transfected neuronal explants embedded in Matrigel 3 days after plating. The first upper graph shows the mean distance of EGFP+ cells from the margin of explants which does not change in "triple ko" neurons. Values represent the mean \pm s.d. (n=3 different experiments, Control: 161 cells from 16 explants; shRNA: 182 cells from 18 explants, Student's $t$-test). The second upper graph, on the right, shows the overall distribution of neurons in both groups in respect to the margins of the aggregates. The lower graph shows that the velocity of neuronal movement does not change with expression of Aplp2 shRNA ( $n=2$ independent experiments, 29 cells for Aplp2 shRNA and 26 cells for control shRNA). Scale bars: $50 \mu \mathrm{m}$.

To test whether the migration delay was due to a change in the morphological differentiation of radial glia cells, which provide the scaffold for radially migrating neurons, we analysed the morphology of EGFP-labelled radial glia cells in E16.5 dko slices of mice with down-regulated Aplp2 from E14.5. The morphology of radial glia was similar in Aplp2 shRNA and control plasmid electroporated dko cortices: they were radially oriented, well aligned and spanned the entire cortical wall with branched basal end feet and apical connections (Fig. 11) (Chanas-Sacre, Rogister et al. 2000). 

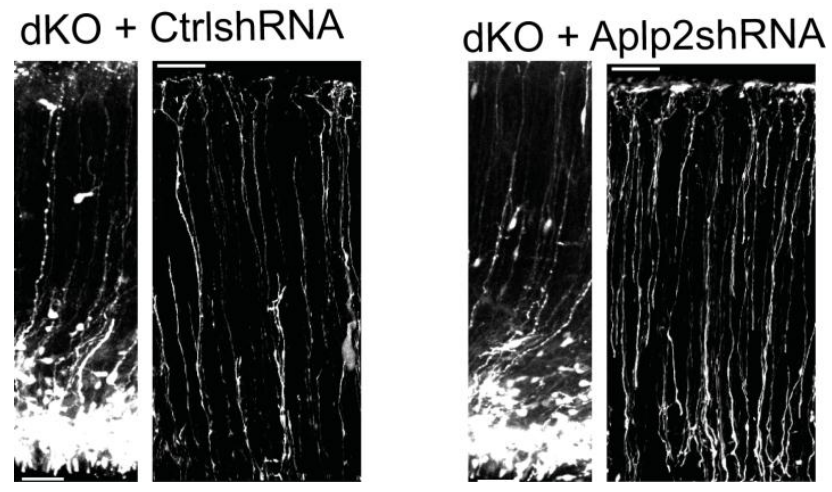

Figure 11.The morphology of radial glia cells remains unchanged.

Confocal projection images of $20-25$ consecutive z-sections $(0.8 \mu \mathrm{m})$ of radial glia cells illustrating their ascending fibers (left) and end feet (right) in App/Aplp1 double knock-out cortices transfected with Aplp2 shRNA or Control-shRNA. In both groups the fibers span the entire cortical wall with branched end feet that are attached to the pial surface. Scale bars: $50 \mu \mathrm{m}$ (left), $25 \mu \mathrm{m}$ (right).

\section{5 "Triple knock-out" cells remain in a proliferative progenitor state}

Apart from the defective cortical positioning of "triple knock-out" neurons described above, we also detected retention of "triple knock-out" cells in the VZ/SVZ (Fig. 8A,B). To determine whether the cells arrested in the VZ/SVZ are progenitors which remain longer in a proliferative state, or neurons which fail to migrate away from the proliferative zones, we labelled the brain slices with the basal progenitor marker Tbr2 ( $\mathrm{T}$ box brain protein 2) (Fig. 12A). In dko cortices electroporated with the control shRNA a small number of EGFP positive cells were located in the VZ/SVZ and only $7 \%$ ( \pm s.d. 2,4\%, $\mathrm{n}=3$ ) were Tbr2 positive, demonstrating that four days after electroporation, most of the cells became post-mitotic and migrated to the cortical plate (Fig. 12A). In contrast, in dko cortices electroporated with the Aplp2 shRNA, a large number of cells remained in the VZ/SVZ of which $29 \%$ ( \pm s.d. $3.5 \%, n=3$ ) expressed Tbr2 suggesting that they failed to differentiate into post-mitotic neurons (Fig. 12A). In addition, a Tbr2 negative population in the ventricular zone, most likely radial glia progenitors (Fig. 19), was still present (Fig. 12A,B) and some cells (Fig. 12B) were still expressing phosphor-histone 3 (PH3), a marker tightly associated to chromosome condensation during mitosis (Goto, Tomono et al. 1999), showing that they were undergoing mitosis. In contrast, in dko cortices electroporated with 
the control shRNA, we very rarely found mitotic PH3/EGFP-positive cells and only observed a very small number of radial glia cell progenitors.

Altogether, these data suggest that Aplp2 plays a role in the normal progression of the neuronal differentiation program from precursors to post-mitotic neurons.

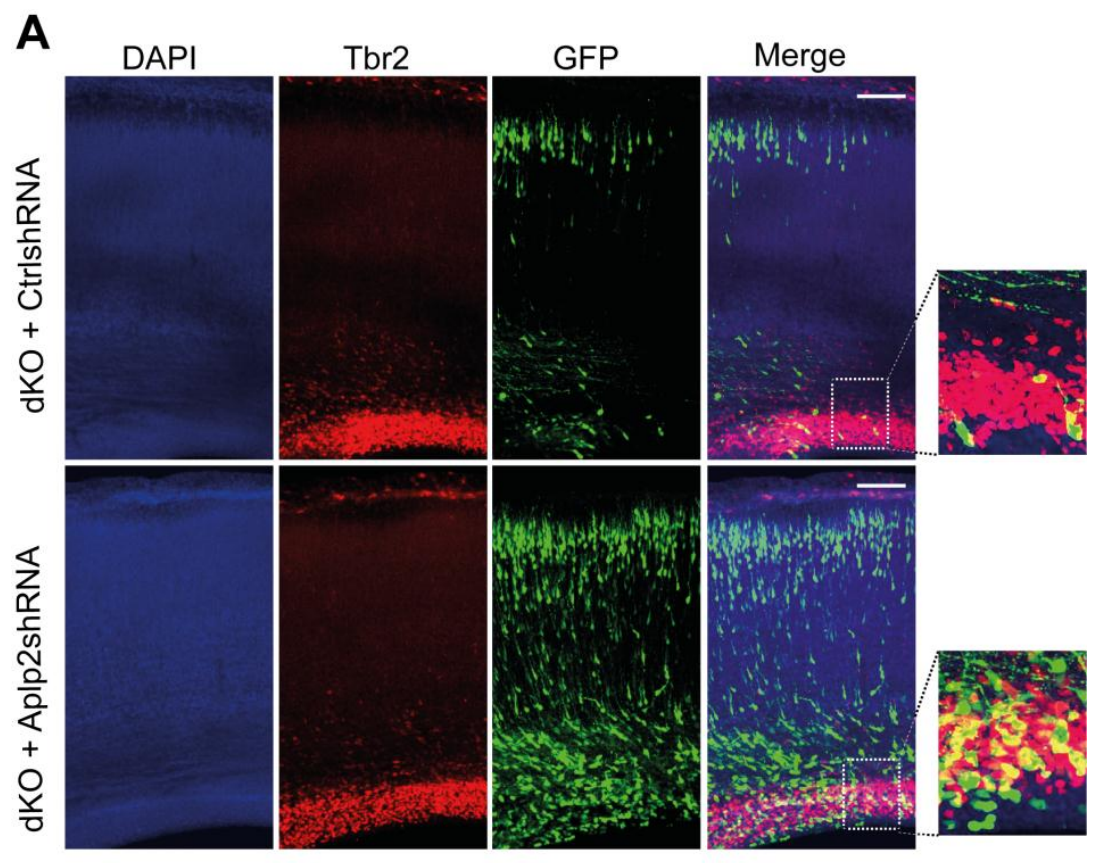

B

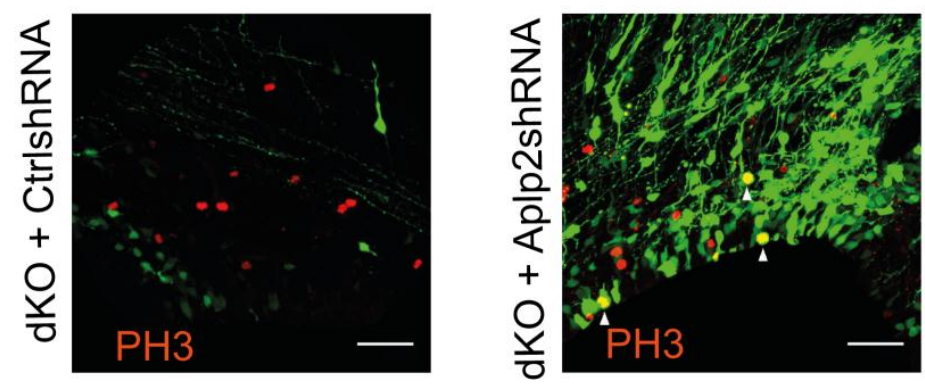

Figure 12. The arrested "'triple ko"' EGFP positive cells express progenitor and mitotic marker.

A) Confocal images of coronal cortical sections labelled with Tbr2 antibody four days after electroporation show progenitors in the VZ/SVZ of Aplp2 shRNA treated cortices. Scale bars: $100 \mu \mathrm{m}$. B) App/Aplp1 double knock-out cortices transfected with Aplp2 shRNA or control shRNA labelled with the mitotic PH3 marker show mitotic Aplp2 shRNA transfected cells (filled arrows). Scale bars: $50 \mu \mathrm{m}$. 


\subsection{Aplp2 has a progenitor specific function and is dispensable for radial migration}

To substantiate the above hypothesis, we designed a construct to achieve cell-specific expression of the Aplp2 shRNA, based on the use of a let-7 microRNA embedded shRNA that can be expressed from cell-type specific promoters (Chang, Elledge et al. 2006) (Fig. 13A). In our hand, the let-7 microRNA based shRNA was more effective in downregulation of cherry fluorescent molecule compared to the commonly used miR-30 microRNA system in Hek293 cells (Fig. 13B). Its functionality for Aplp2 down-regulation was shown by western blot analysis of HEK293 cells expressing a V5 tagged Aplp2 cDNA and transfected with a shRNAmir construct (Fig. 13C). Similar to the U6-Aplp2 shRNA constructs (Fig. 6A), the Aplp2 shRNAmir construct reduced Aplp2 protein expression by about $90 \%$. Moreover, E14 cortical cultures transfected with Aplp2 shRNAmir, showed comparable down-regulation of endogenous Aplp2 to the U6-driven-shRNA (Fig. 13D). In addition, in utero electroporation of Aplp2 shRNAmir using the ubiquitous CAG promoter recapitulated the phenotype (14A) that was obtained by the U6 driven Aplp2 downregulation in dko mice (Fig. 8 A,B).
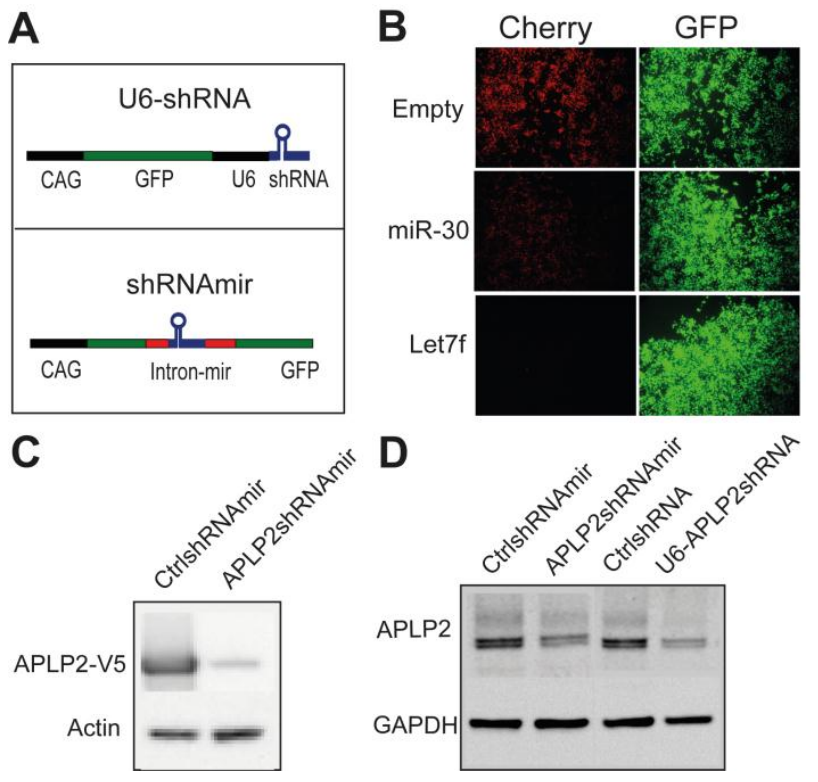

Figure 13. Cell specific construct for Aplp2 down-regulation

A) Schematic comparison of U6-shRNA and microRNA-based shRNA. U6 is a type III RNA polymerase promoter that is expressed ubiquitously, whereas microRNA based shRNA can be expressed from cell specific type II RNA polymerase promoters B) Down-regulation of the 
cherry fluorescent molecule using miR30 or Let7f2 based shRNA GFP construct in Hek293 cells. Let7f2 construct appeared more powerful in down-regulating Cherry when compared to miR30 system. C) Western blot showing protein levels of Aplp2-V5 and actin (loading control) of HEK cells expressing Aplp2-V5 transfected with Aplp2 shRNAmir or control shRNAmir. The down-regulation obtained by the microRNA construct was about $90 \%$ and comparable to the efficiency of the U6 shRNA1 construct (see Fig. 6A) D) Aplp2 and GAPDH (loading control) western blot of cortical cells transfected by shRNAmir or U6 shRNA directed against Aplp2. Comparable down-regulation was obtained by both constructs.

This system allowed us to investigate the result of a cell specific loss of Aplp2 function by driving the expression of Aplp2 shRNA in neural progenitors and post-mitotic neurons using the Brain lipid-binding protein (BLBP) and Tubulin- $\alpha(\mathrm{T} \alpha)$ promoters respectively (Feng, Hatten et al. 1994; Gloster, Wu et al. 1994; Coksaygan, Magnus et al. 2006; Hashimoto-Torii, Torii et al. 2008). Differential expression of T $\alpha$ and BLBP promoters was confirmed by co-electroporation of T $\alpha$-mCherry with BLBP-EGFP in utero (Fig. 14B).

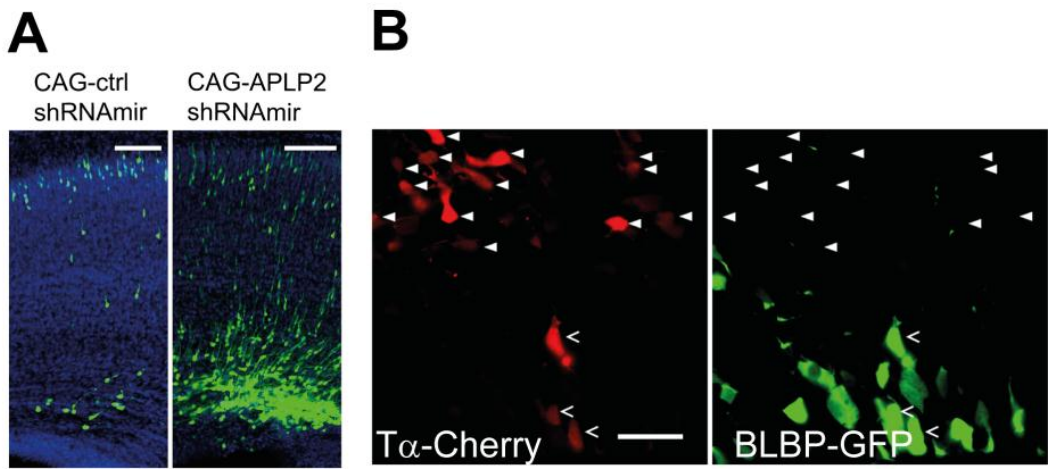

Figure 14. Down-regulation of Aplp2 by shRNAmir change the cortical positioning

A) Confocal images of coronal slices of dko brains electroporated with constructs expressing Aplp2 shRNAmir or Ctrl shRNA from Let7 construct, 4 days after electroporation (E14.5E18.5). Aplp2 shRNAmir expression lead to the similar developmental defect as U6 driven shRNA. B) Confocal images (projection of 10-15 consecutive z-sections) of dko cortical slices transfected with Aplp2 shRNAmir or control shRNAmir under the control of T $\alpha$ promoter. Neuronal down-regulation of Aplp2 does not change cortical positioning. Scale bars: $100 \mu \mathrm{m}$.

Expression of Aplp2 shRNAmir under the control of neuronal T $\alpha$ promoter in dko postmitotic cells did not result in any changes in the cortical positioning of EGFP-positive cells when compared with control shRNA (Fig. 15A,B). 
A

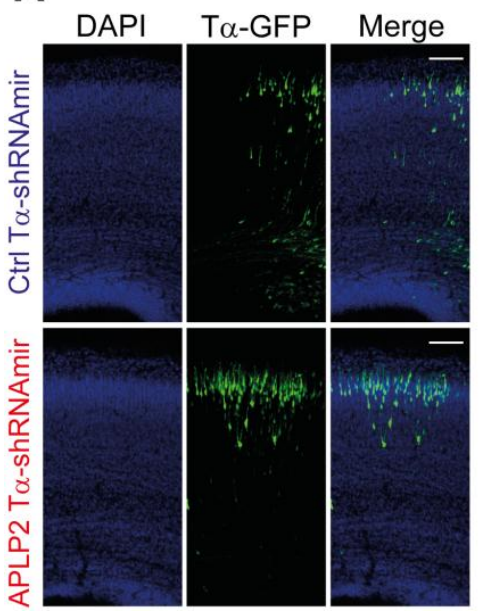

B

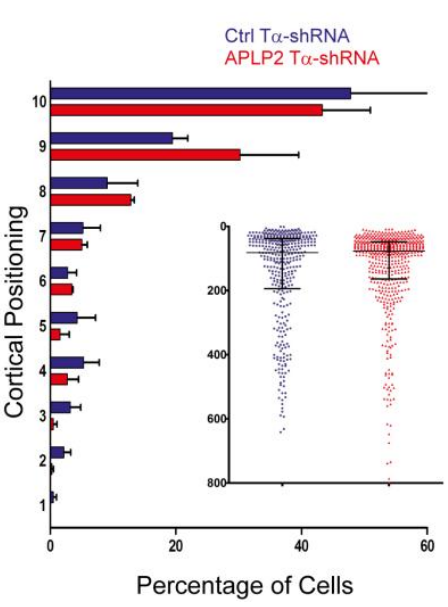

Figure 15. Neuronal Aplp2 shRNAmir does not alter cortical positioning

A) Confocal images (projection of 10-15 consecutive z-sections) of dko cortical slices transfected with Aplp2 shRNAmir or control shRNAmir under the control of T $\alpha$ promoter. Neuronal down-regulation of Aplp2 does not change cortical positioning. Scale bars: $100 \mu \mathrm{m} . \mathrm{B}$ ) Quantification of EGFP+ cells of D. Bar graphs represent frequency distribution of EGFP positive cells in ten equally divided bins from ventricle (1) to the pial surface (10) of the cortical wall. Values represent the mean \pm s.d. ( $\mathrm{n}=3$; Student's $t$-test). The inset scatter plot compares the population distribution of EGFP+ cells. $(n=3,300-400$ cells for clarity of graph; Values represent the median \pm interquartile range, Mann Whitney test).

In contrast, progenitor specific expression of Aplp2 shRNAmir caused the accumulation of cells in the VZ/SVZ similar to the phenotype that we observed using the U6 promoter (Fig. 16A,B compare to Fig. 8A/B). In order to visualize the progeny of cells electroporated with BLBP Aplp2 shRNAmir after the BLBP promoter is switched off in young neurons, we coelectroporated a mCherry expressing construct with the ubiquitous CAG promoter. Four days after electroporation we detected BLBP-EGFP positive cells only in the Aplp2 shRNAmir expressing cortices (Fig. 16A). This supports a progenitor specific function of Aplp2 and the delay in the exit from the progenitor stage, further highlighting the importance of Aplp2 in neural differentiation of cortical progenitors. 
A

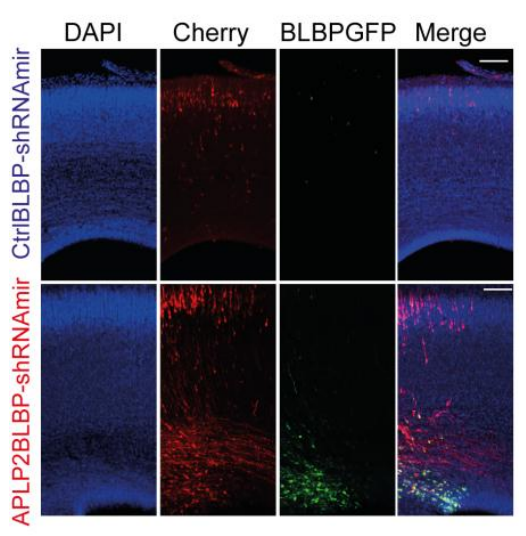

B

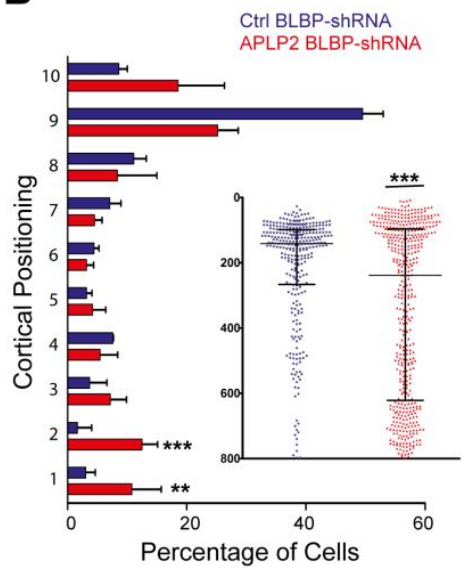

Figure 16. Progenitor specific expression of Aplp2 shRNA is sufficient to retain cells in the proliferative zone of the developing cortex.

A) Confocal images (projection of 10-15 consecutive z-sections) of dko cortical slices transfected with Aplp2 shRNAmir or control shRNAmir under the control of BLBP promoter. Progenitor specific expression of shRNA leads to retention of cells in the VZ/SVZ. Scale bars: $100 \mu \mathrm{m}$. B) Quantification of EGFP+ cells of F. Bar graphs represent the frequency distribution of EGFP positive cells in ten equally divided bins from ventricle (1) to the pial surface (10) of the cortical wall. Values represent the mean \pm s.d. $(\mathrm{n}=3$; ** $p<0.01 ; * * * p<0.001$, Student's $t$ test). The inset scatter plot compares the population distribution of EGFP+ cells. $(n=3,300-400$ cells; Values represent the median \pm interquartile range, $* * * p<0.001$, Mann Whitney test).

\subsection{Cell cycle variables are regulated by Aplp2}

In order to understand the role of Aplp2 during precursor proliferation in more detail, we chose to analyse in utero electroporated brains two days after electroporation instead of four days. After two days, a substantial number of progenitors can still be found in the proliferative zone of the developing cortex even under control conditions (Tabata and Nakajima 2001; Tabata and Nakajima 2008), allowing us to compare the proliferative fraction of cells under different conditions, whilst after four days most of the progeny deriving from in utero electroporated progenitors has been differentiated into neurons (Fig. 7A,B).

Initially, we analysed the position of Aplp2 shRNAmir expressing cells and found a higher number of cells compared to control transfected cells many of which were located closer to the ventricle (Fig. 17A). This initial observation suggested that Aplp2 may be involved in the regulation of progenitor proliferation. Alternatively, the higher number of cells simply 
might reflect differences in electroporation efficiencies. To distinguish between these possibilities, we analysed the fraction of EGFP positive cells which were still proliferating under control and "triple ko" conditions. To determine which fraction of the progenitor pool remains in the proliferative state, we examined cell cycle exit rates of EGFP-positive cells after in utero electroporation of E14 cortices and BrdU pulse labelling of S-phase cells $24 \mathrm{~h}$ before collecting the brains at E16.5. This was followed by Ki67 staining, which is expressed throughout the cell cycle and thus labels all proliferating cells (Chenn and Walsh 2002). Hence, the cells which integrate BrdU and express Ki67 after 24h correspond to the proliferative pool, while Ki67 negative but BrdU positive cells correspond to the pool of cells that have recently exited mitosis, and consequently are young neurons (Fig 17B). The rate of cell cycle exit was calculated as the ratio between EGFP+/BrdU+/Ki67cells and the total EGFP+/BrdU+ population. This ratio was significantly decreased from $74 \%$ in ctrl shRNAmir expressing cells to $45 \%$ in APLP2 shRNAmir dko cells, demonstrating essential functions of Aplp2 in the regulation of neuronal differentiation (Fig. 17B). In light of these findings, the observed decrease in neuronal progression and resulting changes in cortical positioning of "triple ko" cells likely results from delay in the cell cycle exit rate and a delayed entry into the neuronal differentiation program. 
A
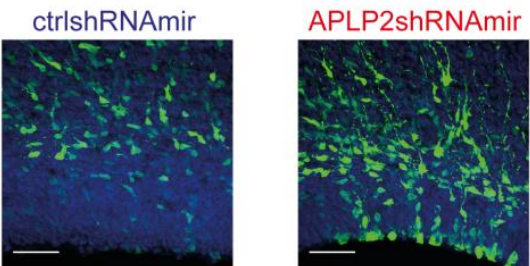

DAPI / GFP

B

Cell Cycle Exit Scheme
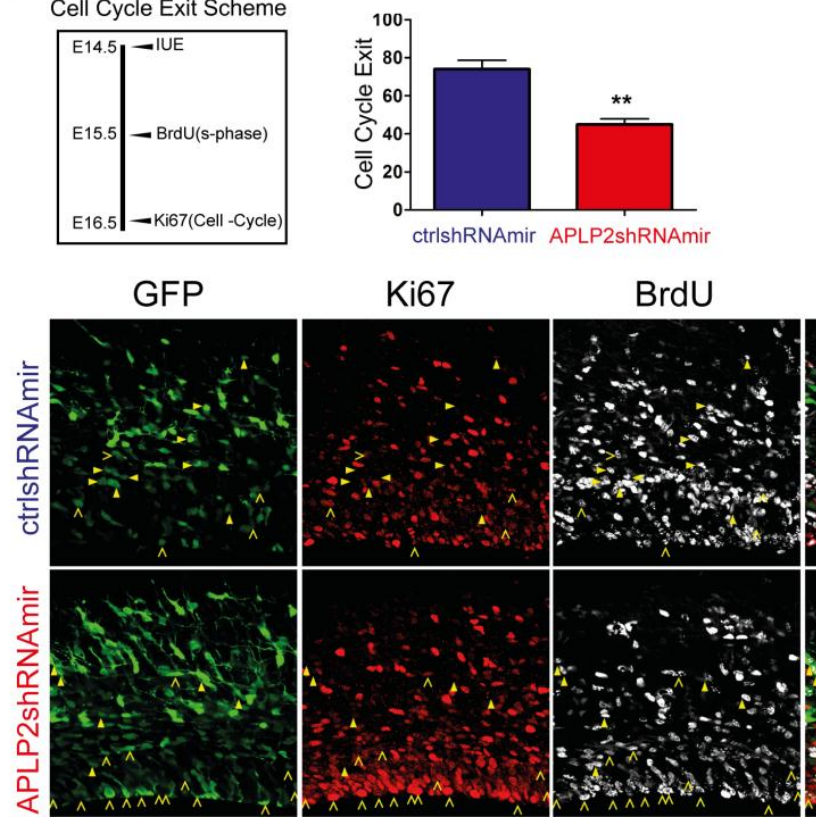

Merge

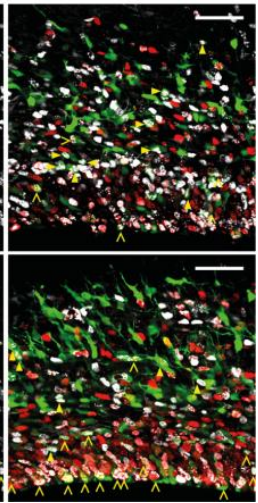

Figure 17. Decreased cell cycle exit rate after Aplp2 down-regulation

A) Confocal images (projection of 10-15 consecutive z-sections) of E16 dko cortical slices cotransfected with Aplp2 shRNAmir or control shRNAmir at E14. Two days after electroporation more cells are found close to the VZ of the developing cortex in Aplp2 shRNA expressing cortices. Scale bars: $50 \mu \mathrm{m}$. B) Confocal images of dko cortices transfected by Aplp2 or control shRNA at E14.5 followed by BrdU injection at E15.5 and then triple stained for EGFP, BrdU and Ki67 at E16.5 (see scheme of the cell cycle exit assay). The graph shows the decreased cycle exit of Aplp2 shRNA expressing progenitors that is calculated by the ratio of EGFP+/BrdU+/Ki67- cells (filled arrows) divided by the total EGFP+/BrdU+. Open arrows indicate the cells that did not leave the cell cycle. Values represent the mean \pm s.d. $(\mathrm{n}=5 ; * * p<$ 0.01 ; Student's $t$-test). Scale bar: $100 \mu \mathrm{m}$.

We reasoned that a reduced cell cycle exit rate can result in more mitotic cells in "triple ko" conditions. To test this hypothesis, we labelled specifically mitotic cells using an antibody against phosphorylated histone 3 (Ser10). Two days after electroporation a two- 
fold increase in the number of mitotic cells was observed in VZ/SVZ of dko cortices electroporated with Aplp2 shRNAmir when compared to control shRNAmir (Fig. 18).

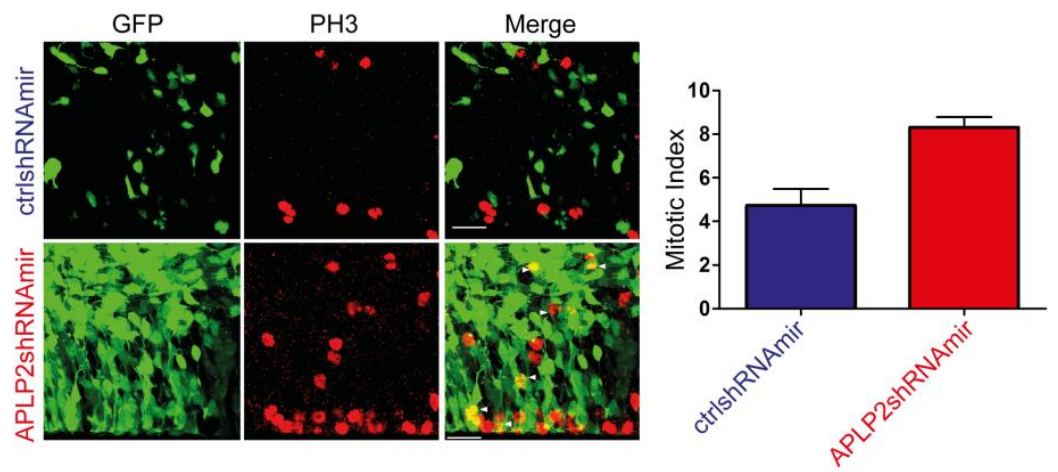

Figure 18. Aplp2 down-regulation increases mitotic index.

Confocal images cells labelled with the mitotic PH3 marker. Two days after Aplp2 downregulation the number of mitotic cells increased (filled arrows). Graph: mitotic index is calculated by the ratio of $\mathrm{PH} 3+$ cells divided by the total number of EGFP+ cells (values represent the mean \pm s.d. $(\mathrm{n}=3 ; * * p<0.01$, Student's $t$-test). Scale bar: $25 \mu \mathrm{m}$.

The observed changes in progenitor proliferation raised the question of whether this had resulted in a different distribution of the progenitor and neuronal pools. The balance between progenitors and post-mitotic neurons depends on the ratio of neurogenic vs. proliferative radial glia cell division. A proliferative division can be self-renewing or leading to the generation of a radial glia cell and intermediate progenitor cells. These two principle classes of progenitors can be distinguished by specific molecular markers: Sox 2 for radial glia and Tbr2 for intermediate progenitor cells. We therefore used doublestaining of Sox 2 and Tbr2 to evaluate the balance between proliferative and neurogenic division of radial glia cells after Aplp2 down-regulation. Aplp2 down-regulation in dko cortices significantly increased both Sox 2 and Tbr2 EGFP-positive cells with a corresponding relative paucity of post-mitotic neurons (Fig. 4D). This result shows that lack of Aplp2 shifts radial glia cells towards proliferative division, implying that Aplp2 is involved in neurogenic division. 


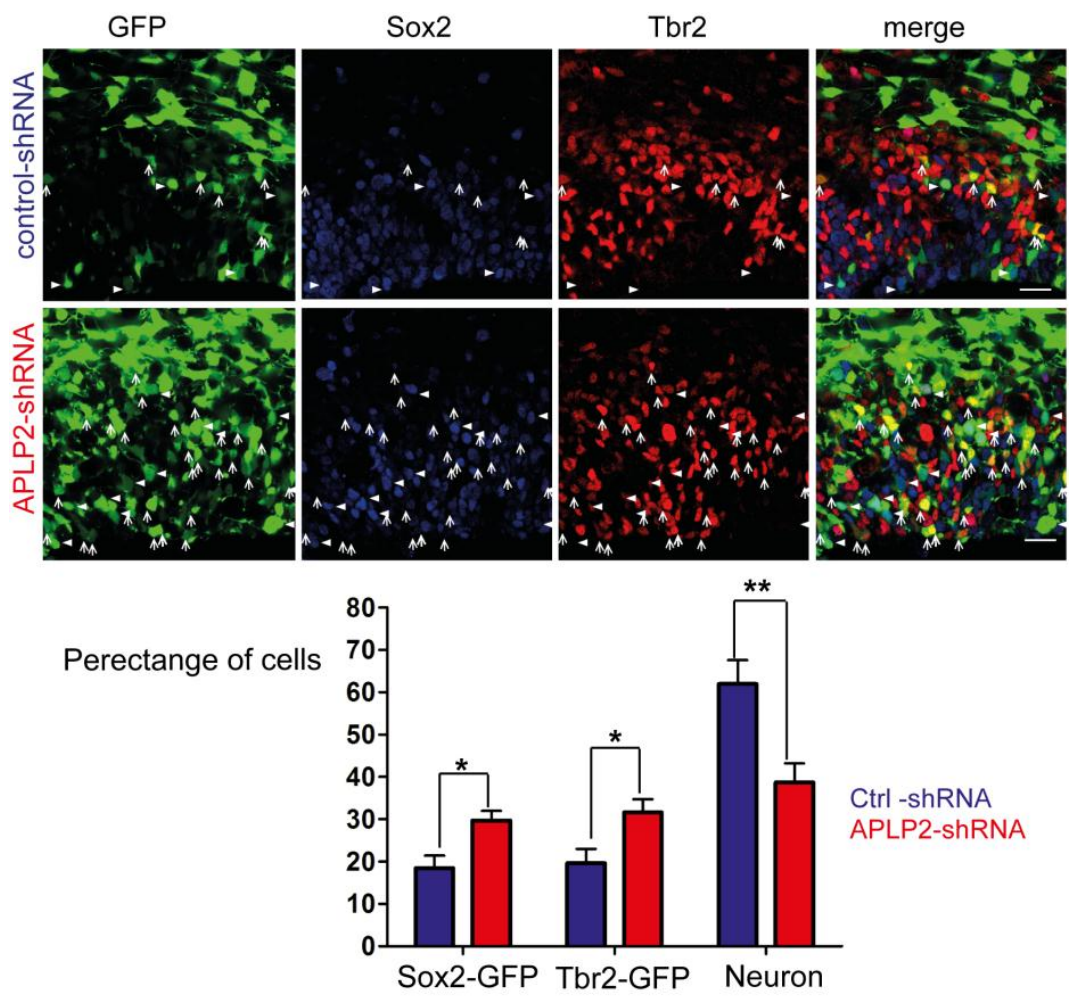

Figure 19. Aplp2 down-regulation increases the proportion of two major classes of cortical progenitors.

Confocal images of Sox2-Tbr2 double stained slices transfected with Aplp2 shRNA or control shRNA. EGFP/Sox2 double positive progenitors: filled arrows; EGFP/Tbr2 double positive progenitors: open arrows. The graph shows that both classes of progenitors are increased after Aplp2 down-regulation (values represent the mean \pm s.d. $(\mathrm{n}=3 ; * p<0.05$, **p $<0.01$, Student's $t$-test). Scale bars: $20 \mu \mathrm{m}$. 


\section{Chapter V: General discussion and perspectives}

Our data are consistent with the view that Aplp2 plays a key role in the differentiation of a neuronal progenitor into a neuron. The control of this step is essential during cortical development since there is a close link between the timing of the cell cycle exit and the determination of the laminar fate of the generated neurons (McConnell and Kaznowski 1991). Hence, prospective cortical architecture is already determined at early developmental stages.

We could unravel this function of Aplp2 by combining in utero electroporation with cellspecific approaches. In this section, I propose different hypotheses that can explain how Aplp2 can regulate neural stem cell differentiation. Next, I take the example of APP gene family to discuss the advantages and disadvantages of the in utero electroporation approach. I end the discussion by explaining the discrepant observations on the different roles for App and Aplp2 in neuronal differentiation and migration and I will speculate on the future direction of research with regard to the physiological function of App proteins during cortical development.

\subsection{Hypotheses on Aplp2 regulation of neural stem cell differentiation}

We show that reduced levels of Aplp2 in App/Aplp1 dko progenitors leads to slower cell cycle exit and preservation of progenitors in their proliferative stage (Fig. 19). Aplp2 is a transmembrane protein with a large extracellular multidomain region and an intracellular domain and thus could regulate the proliferation of progenitors functioning either as a receptor, a cell adhesion molecule or a signal transducer. The intracellular YENPTY domain of Aplp2 can bind to several adapter molecules which are involved in the control of neurogenesis such as Dab1 (Homayouni, Rice et al. 1999; Lakomá, Garcia-Alonso et al. 2011), Numb (Roncarati, Šestan et al. 2002) and Fe65 (Ma, Futagawa et al. 2008). Numb could regulate the decision to stop proliferation and promote differentiation as it represses Notch activity (Roncarati, Šestan et al. 2002). Active Notch is promoting the self-renewal of radial glia progenitors (Yoon, Nery et al. 2004), the population which is also increased after Aplp2 down-regulation in progenitors of dko mice(Figs. 3F, 4D). Therefore, one can hypothesize that Aplp2 promotes the neuronal differentiation by directly or indirectly relaxing Notch activity.

Aplp2 might regulate the neural stem cell proliferation by interacting with components of the cell cycle. Interestingly, the conformation and thus binding properties of the Aplp2 
YENPTY interaction domain can be influenced by phosphorylation of $\mathrm{Thr}^{668}$ by a Cdk1 kinase which couples Aplp2 function and metabolism to the cell cycle (Suzuki, Ando et al. 1997). Similar to Aplp2, Cdk1 expression is also concentrated in the VZ/SVZ of the developing cortex (Visel, Thaller et al. 2004; Diez-Roux, Banfi et al. 2011) suggesting that Cdk1 could be involved in the regulation of neuronal development through Aplp2. Supporting a signalling role for Aplp2 in cell cycle, an analysis of proteins interacting with Aplp2, and not App and Aplp1, revealed members of RhoGTPase such as Rac1 and RhoA (Bai, Markham et al. 2008), which can potentially influence cell cycle progression (Vidaki, Tivodar et al. 2012; Yang, Wang et al. 2012). Moreover, a recent DNA microarray transcriptome profiling of the adult prefrontal cortex showed that the expression of genes involved in neurogenesis is altered in Aplp2 ko brains (Aydin, Filippov et al. 2011). In this study one interesting candidate was Cdk inhibitor p21 which was down-regulated in Aplp2 ko mice. p21 down-regulation was found to enhance progenitor proliferation in the adult hippocampus (Pechnick, Zonis et al. 2008). More recently, it was shown that p21 negatively regulates the expression of Sox2, a key regulator of neural stem cell proliferation (Marqués-Torrejón, Porlan et al. 2013). These data can link Aplp2 to components of cell cycle and it will be interesting to determine whether similar mechanisms are relevant for embryonic neurogenesis regulation.

Finally, Aplp2 can influence cell cycle progression by regulating cell-cell and cellextracellular matrix interactions (Soba, Eggert et al. 2005; Müller and Zheng 2012) could directly regulate the decision between progenitor proliferation and differentiation into neurons, which is strongly dependent on specific membrane associated factors (Temple and Davis 1994). Indeed at the neuromuscular junction, APP family proteins are proposed as novel synaptic adhesion molecules (Wang, Wang et al. 2009) and it will be of interest to investigate a similar role in the context of neuronal progenitor differentiation.

\subsection{In utero electroporation to study neurodevelopmental processes: the example of APP proteins}

Previously, we approached the function of APP protein family by using in vitro differentiation of mouse embryonic stem cells. With this approach, we managed to analyse sufficient numbers of App triple ko neurons and neuronal progenitors in vitro. We did not find, however, any phenotype in triple ko neurons produced in vitro. This prompted us to 
further analyse the role of App proteins in vivo by generation of chimeric mice using the morula aggregation technique. We succeeded in generating chimeric brains where triple ko neurons were randomly integrated into the wt brain. This technique allowed us to study triple ko neurons in the brain while avoiding lethality of the full triple ko mice. Nevertheless, the yield of the technique was not high. In fact, we obtained only 2 mice with brain chimerism, even though we used more than 1200 morulas in over 30 different experiments (Bergmans, Shariati et al. 2010). In contrast, in this study we used in utero electroporation to down-regulate Aplp2 in neurons and neuronal progenitors with a high yield. In our hands, more than $60 \%$ of embryos survived the operation and expressed the reporter gene in the brain. Using in utero electroporation, we circumvented the lethality of the triple ko mice by down-regulating Aplp2 in a subpopulation of cells in the ventral telencephalon (Fig. 8A). The cells are indeed viable under those conditions as shown by their even increased proliferation rate and their normal morphology (Figs. 10, 11,12). In addition, we performed the experiment in both WT and App/Aplp1 dko mice which provided us with a system to study "triple ko" neurons and neuronal precursors. Although our studies demonstrate that Aplp2 down-regulation alone is not sufficient to elicit developmental defects (Fig. 7A,B), the expression pattern of Aplp2 suggests a central role in neurogenesis; Aplp2 is specifically distributed in the proliferative VZ and SVZ of the developing cortex. In contrast, Aplp1 is restricted to the $\mathrm{CP}$ where differentiated neurons reside while App is distributed in both VZ/SVZ and CP (López-Sánchez, Müller et al. 2005). Thus, App residing in the VZ/SVZ could be responsible for a compensating effect on proliferation in the single Aplp2KO mice.

In utero electroporation is applicable in studies in which the cell autonomous functions of proteins are investigated. This technique allows studying the effect of genetic manipulation of cells in the subpopulation of cells in the wt brains. It is difficult to evaluate exactly the electroporation efficiency but we estimate that in our hand 5-10\% of the cells in the targeted region were EGFP positive (after conservative dissection of the targeted region under the dissection microscope). This mosaicism allows to compare transfected cells with the neighbourhood cells that are unaffected and thus to investigate the cell-autonomous function of Aplp2. However, we cannot exclude the possibility of missing some phenotypes that are regulated by soluble fragments of Aplp2. One should also consider the possibility of non-autonomous effects on the cells that are not electroporated.

We could also approach the cell-specific function of App and Aplps by combining in utero electroporation with a microRNA based system for shRNA expression. This combination allowed us to narrow down the function of Aplp2 specifically to neural stem cells. 
Nevertheless, it should be taken into account that the choice of microRNA is critical for the functionality of shRNA. For example, in our hands the commonly used miR-30 scaffold did not work efficiently in the developing cortex. In fact, it has been shown that downregulation efficiency by miR-30 varies among different cell types (Liu, Xu et al. 2010). This might be due to the variability in the post-transcriptional processing of precursor transcripts of microRNAs. We chose Let7F scaffold for two reasons: First, it is enriched in the developing cortex; second, it is naturally expressed from an intron. We embedded the Let7F in a synthetic intron to avoid interfering with untranslated regions of the transcripts which are important for translation efficiency and stability of the transcripts.

We used in utero electroporation to target the dorso-medial part of the developing cortex. Other groups have targeted other regions of the brains such as the prefrontal cortex or the ganglionic eminence to study tangential migration of inhibitory neurons (LoTurco, Manent et al. 2009). This can be done by changing the position of electrodes. In our experience, however, the precise control of which region is targeted was difficult because movements of the embryos during electroporation. Therefore, a high level of technical proficiency is required to spatially target different regions of the developing brain reproducibly. It is also reported that the long term effect of genetic manipulation by in utero electroporation can be studied postnatally. Two technical notes should be mentioned on the application of in utero electroporation for long-term analysis of the effect of genetic manipulation. First, the survival of the newborn mice depends on the maternal instinct of the mice which varies from strain to strain. Cross-fostering, gentle handling of the animals and a quiet mice room can improve the survival of the newborn pups. Second, the developmental activity of the DNA construct may decrease during the maturation of the neurons. The choice of promoter is one of the primary factors that need to be considered when designing long-term experiments.

\subsection{Controversies on the role of APP proteins in cortical development}

To our surprise, we did not observe migration phenotypes in App/Aplp1 dko neurons nor did we detect a migration phenotype in neurons expressing Aplp2 shRNA or "triple ko" neurons. This was consistent with our previous findings using triple ko neurons derived from ES cells (Bergmans, Shariati et al. 2010). In fact, our study had shown that Aplps and App appeared largely dispensable for the radial migration of cortical excitatory neurons. Cortical neuron positioning in App/Aplp1 double knock-out mice or in APLP2 knock-down 
cells was indistinguishable from that in wt mice (Fig. 7A,B). Using in vitro assays, we showed that Aplp2 down-regulation does not change migratory behaviour of neurons (Fig. 10). The absence of a migration defect contrasts with other findings showing abnormalities in neuronal migration during cortical development. Yet, the findings of these previous studies were not conclusive, one study showing a complete inhibition of cortical plate entry and the other an ectopic accumulation of neurons in the marginal zone (Herms, Anliker et al. 2004; Young-Pearse, Bai et al. 2007).

However this delay in cortical neuron progression towards the CP is likely a consequence of a primary defect in progenitor function: First, we could not detect any differences in migration speed of isolated "triple ko" neurons and wt neurons using an in vitro assay (Fig. $10 \mathrm{~A}, \mathrm{~B})$; second, we could phenocopy the accumulation of cells close to the VZ/SVZ by expressing Aplp2 shRNA only in progenitors of dko mice (Fig. 16 A,B). Indeed the effect of APP proteins on progenitor function could be a possible alternative or additional explanation for the observed cortical positioning defects in previous publications. This provides an interpretation that is different from what was proposed in the previous papers which considered migration defects as the primary cause. It should be noticed that those previous studies did not directly study migration. Timelapse microscopy could give insight in this particular question. With regard to these discrepancies, one should also consider that acute down-regulation of APP in a wt background may not have the same outcome as a germline deletion of APP which can trigger early developmental adaption.

Taken together, the current data support a model in which App is functional in both progenitors and post-mitotic migrating neurons, whilst Aplp2 is playing a specific role in regulating progenitor proliferation and differentiation.

\subsection{Perspective on biological function of APP protein family during cortical development.}

The current findings indicate that App and Aplps are essential for correct completion of neurodevelopmental processes such as differentiation, migration, synaptogenesis and circuit formation. One of the first essential decisions for proper formation of the cortex is the exit from the cell cycle and the differentiation into postmitotic neurons. In fact, the prospective identity of a neuron is determined when its progenitor undergoes the last mitosis. The link between Aplp2 and cell cycle during cortical development opens avenues towards the understanding of new functions of App proteins during cortical development. However, the picture remains unclear. One remarkable question remains how Aplp2 
signalling is integrated in the global signalling process and how it is responding to external cues that promote cell cycle progression and neuronal differentiation. It is possible that Aplp2 functions as a cell surface receptor responsible for the correct completion of the neurogenic program. Identification of the putative ligand would be possible by using crosslinking and proteomics approaches. Along the same line, in vitro culture of neural stem cells is a valuable strategy to test the function of soluble signalling factors that promotes neuronal differentiation after down-regulation of Aplp2. Although this model presupposes a signalling role for Aplp2, one should not neglect the cell adhesion properties of Aplp2. Cell biological studies of Aplp2 subcellular localization and identification of the site of adhesion (apical or basal) are required to understand the link between the Aplp2 adhesion properties and cell cycle progression of cortical progenitors.

It becomes clear that while investigating the biological function of App and Aplps, we lack deeper mechanistic insight. In this regard, defining the molecular interaction network of App and Aplps in different subregions and cell types of the developing cortex is of primary importance. It would be interesting to categorize shared and distinct interactors of App and Aplps. Sometimes APP is dubbed "All Purpose Protein" to indicate the confusing many different signaling pathways and protein interactions in which APP has been implicated. Maybe this information has to be re-evaluated taking into account temporary and cell type expression patterns of APP family and the interacting proteins. It is indeed likely that App and Aplps rewire their interaction network according to the cell type to serve different functions. This will call attention to the cell specific function of App and Aplps. For example, the primary attention has been on understanding the neuronal function of App and Aplps. However, it is now clear that development of the circuits requires the interaction of neurons with each other as well as with glia. Until now, the function of App and Aplps in inhibitory neurons, astrocyte and microglia is not well-studied. Therefore, with the development of the conditional mouse models, it will become feasible to untangle cell specific functions of the APP protein family.

Proposing App and Aplps as cell receptors may lead to a static view on their signaling role without considering their processing and its products. Although, we focused our studies on understanding the cell-autonomous functions of Aplp2, the regulated processing of Aplp2, and App, can mediate non-autonomous functions. This model hypothesizes the existence of a receptor for the soluble fragments of App and Aplps. Therefore, an effort in the field should also focus on the identification of the receptor for App and Aplps and the physiological importance of this interaction. 
Finally, generation of specific inhibitor of enzymes involved in amyloidogenic processing of APP such as the BACE1 and $\gamma$-Secretase are viable approaches for treatment of Alzheimer's disease. Such compounds would ideally lower the Abeta burden without affecting processing of other substrates. No matter how challenging this might be, changing the metabolism of APP inevitably interferes with the physiological functions of APP raising the possibility of mechanism based side effects. At first glance, developmental functions of APP and APLPs appear a remote link to Alzheimer's disease. However, many neurodevelopmental processes continue to be active in the adult brain in processes such as adult neurogenesis. In fact, generation of neurons continues in two distinct neurogenic niches of the adult brain, i.e. in the subgranular zone of the hippocampus and the subventricular zone of lateral ventricles. Interestingly, hippocampus circuitry that is involved in memory formation is one of the primary regions affected in Alzheimer's disease. Whether and how APP proteins can contribute to generation of neurons in the adult brain and during aging remain unclear. Therefore, a clear understanding of the function of APP will be complementary to the pharmaceutical efforts to treat Alzheimer's disease. 


\section{References:}

Adlerz, L., S. Holback, et al. (2007). "IGF-1-induced Processing of the Amyloid Precursor Protein Family Is Mediated by Different Signaling Pathways." Journal of Biological Chemistry 282(14): 10203-10209.

Artegiani, B., D. Lindemann, et al. (2011). "Overexpression of cdk4 and cyclinD1 triggers greater expansion of neural stem cells in the adult mouse brain." The Journal of Experimental Medicine 208(5): 937-948.

Ashley, J., M. Packard, et al. (2005). "Fasciclin II Signals New Synapse Formation through Amyloid Precursor Protein and the Scaffolding Protein dX11/Mint." The Journal of Neuroscience 25(25): 5943-5955.

Aydin, D., M. A. Filippov, et al. (2011). "Comparative transcriptome profiling of amyloid precursor protein family members in the adult cortex." BMC Genomics 12: 160.

Bai, Y., K. Markham, et al. (2008). "The in Vivo Brain Interactome of the Amyloid Precursor Protein." Molecular \& Cellular Proteomics 7(1): 15-34.

Balastik, M., J. Lim, et al. (2007). "Pin1 in Alzheimer's disease: Multiple substrates, one regulatory mechanism?" Biochimica et Biophysica Acta (BBA) - Molecular Basis of Disease 1772(4): 422-429.

Barbagallo, A. P., Z. Wang, et al. (2011). "The intracellular threonine of amyloid precursor protein that is essential for docking of Pin1 is dispensable for developmental function." PLoS One 6(3): e18006.

Barbagallo, A. P., R. Weldon, et al. (2010). "Tyr(682) in the intracellular domain of APP regulates amyloidogenic APP processing in vivo." PLoS One 5(11): e15503.

Barbagallo, A. P. M., Z. Wang, et al. (2011). "A Single Tyrosine Residue in the Amyloid Precursor Protein Intracellular Domain Is Essential for Developmental Function." Journal of Biological Chemistry 286(11): 8717-8721.

Barnham, K. J., W. J. McKinstry, et al. (2003). "Structure of the Alzheimer's Disease Amyloid Precursor Protein Copper Binding Domain: A REGULATOR OF NEURONAL COPPER HOMEOSTASIS." Journal of Biological Chemistry 278(19): 17401-17407.

Bergmans, B. A., S. A. M. Shariati, et al. (2010). "Neurons Generated from APP/APLP1/APLP2 Triple Knockout Embryonic Stem Cells Behave Normally in Vitro and in Vivo: Lack of Evidence for a Cell Autonomous Role of the Amyloid Precursor Protein in Neuronal Differentiation." STEM CELLS 28(3): 399-406.

Bittner, T., M. Fuhrmann, et al. (2009). " $\gamma$-Secretase Inhibition Reduces Spine Density In Vivo via an Amyloid Precursor Protein-Dependent Pathway." The Journal of Neuroscience 29(33): 10405-10409.

Bossi, A. and B. Lehner (2009). "Tissue specificity and the human protein interaction network." Mol Syst Biol 5.

Bradshaw, N. J. and D. J. Porteous (2012). "DISC1-binding proteins in neural development, signalling and schizophrenia." Neuropharmacology 62(3): 1230-1241.

Brown, M. S., J. Ye, et al. (2000). "Regulated Intramembrane Proteolysis: A Control Mechanism Conserved from Bacteria to Humans." Cell 100(4): 391-398.

Cai, H., Y. Wang, et al. (2001). "BACE1 is the major beta-secretase for generation of Abeta peptides by neurons." Nat Neurosci 4(3): 233-234.

Caillé, I., B. Allinquant, et al. (2004). "Soluble form of amyloid precursor protein regulates proliferation of progenitors in the adult subventricular zone." Development 131(9): 2173-2181.

Calderon de Anda, F., A. Gartner, et al. (2008). "Pyramidal neuron polarity axis is defined at the bipolar stage." J Cell Sci 121(Pt 2): 178-185.

Calegari, F. and W. B. Huttner (2003). "An inhibition of cyclin-dependent kinases that lengthens, but does not arrest, neuroepithelial cell cycle induces premature neurogenesis." Journal of Cell Science 116(24): 4947-4955.

Cao, X. and T. C. Südhof (2001). "A Transcriptively Active Complex of APP with Fe65 and Histone Acetyltransferase Tip60." Science 293(5527): 115-120.

Carmine-Simmen, K., T. Proctor, et al. (2009). "Neurotoxic effects induced by the Drosophila amyloid- $\beta$ peptide suggest a conserved toxic function." Neurobiology of Disease 33(2): 274-281. 
Caviness, V. S., R. S. Nowakowski, et al. (2009). "Neocortical neurogenesis: morphogenetic gradients and beyond." Trends in Neurosciences 32(8): 443-450.

Chanas-Sacre, G., B. Rogister, et al. (2000). "Radial glia phenotype: origin, regulation, and transdifferentiation." J Neurosci Res 61(4): 357-363.

Chang, K., S. J. Elledge, et al. (2006). "Lessons from Nature: microRNA-based shRNA libraries." Nat Meth 3(9): 707-714.

Chenn, A. and C. A. Walsh (2002). "Regulation of cerebral cortical size by control of cell cycle exit in neural precursors." Science 297(5580): 365-369.

Coksaygan, T., T. Magnus, et al. (2006). "Neurogenesis in Talpha-1 tubulin transgenic mice during development and after injury." Exp Neurol 197(2): 475-485.

Conrad, B. and S. E. Antonarakis (2007). "Gene Duplication: A Drive for Phenotypic Diversity and Cause of Human Disease." Annual Review of Genomics and Human Genetics 8(1): 17-35.

Coulson, E. J., K. Paliga, et al. (2000). "What the evolution of the amyloid protein precursor supergene family tells us about its function." Neurochemistry International 36(3): 175-184.

Cupers, P., I. Orlans, et al. (2001). "The amyloid precursor protein (APP)-cytoplasmic fragment generated by $\gamma$-secretase is rapidly degraded but distributes partially in a nuclear fraction of neurones in culture." Journal of Neurochemistry 78(5): 1168-1178.

Dahms, S. O., S. Hoefgen, et al. (2010). "Structure and biochemical analysis of the heparininduced E1 dimer of the amyloid precursor protein." Proceedings of the National Academy of Sciences 107(12): 5381-5386.

Daigle, I. and C. Li (1993). "apl-1, a Caenorhabditis elegans gene encoding a protein related to the human beta-amyloid protein precursor." Proceedings of the National Academy of Sciences 90(24): 12045-12049.

Dawson, G. R., G. R. Seabrook, et al. (1999). "Age-related cognitive deficits, impaired longterm potentiation and reduction in synaptic marker density in mice lacking the $\beta$ amyloid precursor protein." Neuroscience 90(1): 1-13.

De Strooper, B., W. Annaert, et al. (1999). "A presenilin-1-dependent [gamma]-secretase-like protease mediates release of Notch intracellular domain." Nature 398(6727): 518-522.

De Strooper, B., P. Saftig, et al. (1998). "Deficiency of presenilin-1 inhibits the normal cleavage of amyloid precursor protein." Nature 391(6665): 387-390.

Dehay, C. and H. Kennedy (2007). "Cell-cycle control and cortical development." Nat Rev Neurosci 8(6): 438-450.

Deuss, M., K. Reiss, et al. (2008). "Part-time alpha-secretases: the functional biology of ADAM 9, 10 and 17." Curr Alzheimer Res 5(2): 187-201.

Diez-Roux, G., S. Banfi, et al. (2011). "A high-resolution anatomical atlas of the transcriptome in the mouse embryo." PLoS Biol 9(1): e1000582.

Duce, J. A., A. Tsatsanis, et al. (2010). "Iron-Export Ferroxidase Activity of $\beta$-Amyloid Precursor Protein Is Inhibited by Zinc in Alzheimer's Disease." Cell 142(6): 857-867.

Eggert, S., K. Paliga, et al. (2004). "The Proteolytic Processing of the Amyloid Precursor Protein Gene Family Members APLP-1 and APLP-2 Involves $\alpha-\beta-, \gamma$, and $\epsilon$-Like Cleavages: MODULATION OF APLP-1 PROCESSING BY NGLYCOSYLATION." Journal of Biological Chemistry 279(18): 18146-18156.

Emes, R. D. and S. G. N. Grant (2012). "Evolution of Synapse Complexity and Diversity." Annual Review of Neuroscience 35(1): 111-131.

Emes, R. D., A. J. Pocklington, et al. (2008). "Evolutionary expansion and anatomical specialization of synapse proteome complexity." Nat Neurosci 11(7): 799-806.

Esch, F. S., P. S. Keim, et al. (1990). "Cleavage of amyloid beta peptide during constitutive processing of its precursor." Science 248(4959): 1122-1124.

Ewald, C. Y., D. A. Raps, et al. (2012). "APL-1, the Alzheimer's Amyloid Precursor Protein in Caenorhabditis elegans, Modulates Multiple Metabolic Pathways Throughout Development." Genetics 191(2): 493-507.

Farkas, L. M. and W. B. Huttner (2008). "The cell biology of neural stem and progenitor cells and its significance for their proliferation versus differentiation during mammalian brain development." Current Opinion in Cell Biology 20(6): 707-715.

Feng, L., M. E. Hatten, et al. (1994). "Brain lipid-binding protein (BLBP): a novel signaling system in the developing mammalian CNS." Neuron 12(4): 895-908. 
Ferguson, K. L., J. L. Vanderluit, et al. (2002). "Telencephalon-specific Rb knockouts reveal enhanced neurogenesis, survival and abnormal cortical development." EMBO J 21(13): 3337-3346.

Fietz, S. A. and W. B. Huttner (2011). "Cortical progenitor expansion, self-renewal and neurogenesis - a polarized perspective." Current Opinion in Neurobiology 21(1): 2335 .

Fietz, S. A., I. Kelava, et al. (2010). "OSVZ progenitors of human and ferret neocortex are epithelial-like and expand by integrin signaling." Nat Neurosci 13(6): 690-699.

Force, A., M. Lynch, et al. (1999). "Preservation of Duplicate Genes by Complementary, Degenerative Mutations." Genetics 151(4): 1531-1545.

Franco, S. J., I. Martinez-Garay, et al. (2011). "Reelin Regulates Cadherin Function via Dab1/Rap1 to Control Neuronal Migration and Lamination in the Neocortex." Neuron 69(3): 482-497.

Gloster, A., W. Wu, et al. (1994). "The T alpha 1 alpha-tubulin promoter specifies gene expression as a function of neuronal growth and regeneration in transgenic mice." $\mathrm{J}$ Neurosci 14(12): 7319-7330.

Goldgaber, D., M. I. Lerman, et al. (1987). "Characterization and chromosomal localization of a cDNA encoding brain amyloid of Alzheimer's disease." Science 235(4791): 877-880.

Goto, H., Y. Tomono, et al. (1999). "Identification of a novel phosphorylation site on histone H3 coupled with mitotic chromosome condensation." J Biol Chem 274(36): 2554325549.

Gu, Y., H. Misonou, et al. (2001). "Distinct Intramembrane Cleavage of the $\beta$-Amyloid Precursor Protein Family Resembling $\gamma$-Secretase-like Cleavage of Notch." Journal of Biological Chemistry 276(38): 35235-35238.

Guo, Q., H. Li, et al. (2012). "Amyloid Precursor Protein Revisited: neuron-specific expression and highly stable nature of soluble derivatives." Journal of Biological Chemistry 287(4): 2437-2445.

Guo, Q., Z. Wang, et al. (2012). "APP physiological and pathophysiological functions: insights from animal models." Cell Res 22(1): 78-89.

Hansen, D. V., J. H. Lui, et al. (2010). "Neurogenic radial glia in the outer subventricular zone of human neocortex." Nature 464(7288): 554-561.

Hartfuss, E., E. Förster, et al. (2003). "Reelin signaling directly affects radial glia morphology and biochemical maturation." Development 130(19): 4597-4609.

Hartmann, D., B. D. Strooper, et al. (1999). "Presenilin-1 deficiency leads to loss of Cajal Retzius neurons and cortical dysplasia similar to human type 2 lissencephaly." Current biology: CB 9(14): 719-727.

Hashimoto-Torii, K., M. Torii, et al. (2008). "Interaction between Reelin and Notch signaling regulates neuronal migration in the cerebral cortex." Neuron 60(2): 273-284.

Heber, S., J. Herms, et al. (2000). "Mice with Combined Gene Knock-Outs Reveal Essential and Partially Redundant Functions of Amyloid Precursor Protein Family Members." The Journal of Neuroscience 20(21): 7951-7963.

Hebert, S. S., L. Serneels, et al. (2006). "Regulated intramembrane proteolysis of amyloid precursor protein and regulation of expression of putative target genes." EMBO Rep 7(7): 739-745.

Herms, J., B. Anliker, et al. (2004). "Cortical dysplasia resembling human type 2 lissencephaly in mice lacking all three APP family members." EMBO J 23(20): 4106-4115.

Hoe, H.-S., K. J. Lee, et al. (2009). "Interaction of Reelin with Amyloid Precursor Protein Promotes Neurite Outgrowth." The Journal of Neuroscience 29(23): 7459-7473.

Hogl, S., P. H. Kuhn, et al. (2011). "Determination of the proteolytic cleavage sites of the amyloid precursor-like protein 2 by the proteases ADAM10, BACE1 and gammasecretase." PLoS One 6(6): e21337.

Homayouni, R., D. S. Rice, et al. (1999). "Disabled-1 Binds to the Cytoplasmic Domain of Amyloid Precursor-Like Protein 1." The Journal of Neuroscience 19(17): 7507-7515.

Hornsten, A., J. Lieberthal, et al. (2007). "APL-1, a Caenorhabditis elegans protein related to the human $\beta$-amyloid precursor protein, is essential for viability." Proceedings of the National Academy of Sciences 104(6): 1971-1976. 
Howell, B. W., L. M. Lanier, et al. (1999). "The Disabled 1 Phosphotyrosine-Binding Domain Binds to the Internalization Signals of Transmembrane Glycoproteins and to Phospholipids." Molecular and Cellular Biology 19(7): 5179-5188.

Huminiecki, L. and K. H. Wolfe (2004). "Divergence of spatial gene expression profiles following species-specific gene duplications in human and mouse." Genome Res 14(10A): 1870-1879.

Huysseune, S., P. Kienlen-Campard, et al. (2009). "Epigenetic control of aquaporin 1 expression by the amyloid precursor protein." The FASEB Journal 23(12): 4158-4167.

Innan, H. and F. Kondrashov (2010). "The evolution of gene duplications: classifying and distinguishing between models." Nat Rev Genet 11(2): 97-108.

Jacobsen, K. T., L. Adlerz, et al. (2010). "Insulin-like Growth Factor-1 (IGF-1)-induced Processing of Amyloid- $\beta$ Precursor Protein (APP) and APP-like Protein 2 Is Mediated by Different Metalloproteinases." Journal of Biological Chemistry 285(14): 10223-10231.

Jin, L., H. Ninomiya, et al. (1994). "Peptides containing the RERMS sequence of amyloid beta/A4 protein precursor bind cell surface and promote neurite extension." The Journal of Neuroscience 14(9): 5461-5470.

Johnson, M. B., Y. I. Kawasawa, et al. (2009). "Functional and Evolutionary Insights into Human Brain Development through Global Transcriptome Analysis." Neuron 62(4): 494-509.

Jorissen, E., J. Prox, et al. (2010). "The Disintegrin/Metalloproteinase ADAM10 Is Essential for the Establishment of the Brain Cortex." The Journal of Neuroscience 30(14): 48334844.

Jossin, Y. and J. A. Cooper (2011). "Reelin, Rap1 and N-cadherin orient the migration of multipolar neurons in the developing neocortex." Nat Neurosci 14(6): 697-703.

Jung, C. E. and J. Herms (2012). "Role of APP for dendritic spine formation and stability." Experimental Brain Research 217(3-4): 463-470.

Kaden, D., L.-M. Munter, et al. (2008). "Homophilic Interactions of the Amyloid Precursor Protein (APP) Ectodomain Are Regulated by the Loop Region and Affect $\beta$-Secretase Cleavage of APP." Journal of Biological Chemistry 283(11): 7271-7279.

Kaden, D., P. Voigt, et al. (2009). "Subcellular localization and dimerization of APLP1 are strikingly different from APP and APLP2." Journal of Cell Science 122(3): 368-377.

Kang, J., H.-G. Lemaire, et al. (1987). "The precursor of Alzheimer's disease amyloid A4 protein resembles a cell-surface receptor." Nature 325(6106): 733-736.

Khalifa, N. B., J. Van Hees, et al. (2010). "What is the role of amyloid precursor protein dimerization?" Cell Adh Migr 4(2): 268-272.

Kienlen-Campard, P., B. Tasiaux, et al. (2008). "Amyloidogenic Processing but Not Amyloid Precursor Protein (APP) Intracellular C-terminal Domain Production Requires a Precisely Oriented APP Dimer Assembled by Transmembrane GXXXG Motifs." Journal of Biological Chemistry 283(12): 7733-7744.

Kippin, T. E., D. J. Martens, et al. (2005). "p21 loss compromises the relative quiescence of forebrain stem cell proliferation leading to exhaustion of their proliferation capacity." Genes \& Development 19(6): 756-767.

Kong, G. K. W., J. J. Adams, et al. (2007). "Structural Studies of the Alzheimer's Amyloid Precursor Protein Copper-binding Domain Reveal How it Binds Copper Ions." Journal of Molecular Biology 367(1): 148-161.

Kriegstein, A., S. Noctor, et al. (2006). "Patterns of neural stem and progenitor cell division may underlie evolutionary cortical expansion." Nat Rev Neurosci 7(11): 883-890.

Kuhn, P.-H., H. Wang, et al. (2010). "ADAM10 is the physiologically relevant, constitutive [alpha]-secretase of the amyloid precursor protein in primary neurons." EMBO J 29(17): 3020-3032.

Lakomá, J., L. Garcia-Alonso, et al. (2011). "Reelin sets the pace of neocortical neurogenesis." Development 138(23): 5223-5234.

Lange, C., W. B. Huttner, et al. (2009). "Cdk4/CyclinD1 Overexpression in Neural Stem Cells Shortens G1, Delays Neurogenesis, and Promotes the Generation and Expansion of Basal Progenitors." Cell Stem Cell 5(3): 320-331. 
Lee, K. J., C. E. H. Moussa, et al. (2010). "Beta amyloid-independent role of amyloid precursor protein in generation and maintenance of dendritic spines." Neuroscience 169(1): 344-356.

Lee, S., Y. Xue, et al. (2011). "The E2 Domains of APP and APLP1 Share a Conserved Mode of Dimerization." Biochemistry 50(24): 5453-5464.

Leyssen, M., D. Ayaz, et al. (2005). "Amyloid precursor protein promotes post-developmental neurite arborization in the Drosophila brain." EMBO J 24(16): 2944-2955.

Li, H., B. Wang, et al. (2010). "Soluble amyloid precursor protein (APP) regulates transthyretin and Klotho gene expression without rescuing the essential function of APP." Proceedings of the National Academy of Sciences 107(40): 17362-17367.

Li, Q. and T. C. Südhof (2004). "Cleavage of Amyloid- $\beta$ Precursor Protein and Amyloid- $\beta$ Precursor-like Protein by BACE 1." Journal of Biological Chemistry 279(11): 1054210550.

Liu, B., H. Xu, et al. (2010). "Cell- and region-specific miR30-based gene knock-down with temporal control in the rat brain." BMC Molecular Biology 11(1): 93.

López-Sánchez, N., U. Müller, et al. (2005). "Lengthening of G2/mitosis in cortical precursors from mice lacking $\beta$-amyloid precursor protein." Neuroscience 130(1): 51-60.

Lorent, K., L. Overbergh, et al. (1995). "Expression in mouse embryos and in adult mouse brain of three members of the amyloid precursor protein family, of the alpha-2macroglobulin receptor/low density lipoprotein receptor-related protein and of its ligands apolipoprotein E, lipoprotein lipase, alpha-2-macroglobulin and the 40,000 molecular weight receptor-associated protein." Neuroscience 65(4): 1009-1025.

LoTurco, J., J.-B. Manent, et al. (2009). "New and Improved Tools for In Utero Electroporation Studies of Developing Cerebral Cortex." Cerebral Cortex 19(suppl 1): i120-i125.

Lu, K. P. (2004). "Pinning down cell signaling, cancer and Alzheimer's disease." Trends in Biochemical Sciences 29(4): 200-209.

Luo, L., L. Martin-Morris, et al. (1990). "Identification, secretion, and neural expression of APPL, a Drosophila protein similar to human amyloid protein precursor." The Journal of Neuroscience 10(12): 3849-3861.

Ma, Q.-H., T. Futagawa, et al. (2008). "A TAG1-APP signalling pathway through Fe65 negatively modulates neurogenesis." Nat Cell Biol 10(3): 283-294.

Ma, Q. H., T. Futagawa, et al. (2008). "A TAG1-APP signalling pathway through Fe65 negatively modulates neurogenesis." Nat Cell Biol 10(3): 283-294.

Maloney, B., Y.-W. Ge, et al. (2004). "Presence of a "CAGA box" in the APP gene unique to amyloid plaque-forming species and absent in all APLP-1/2 genes: implications in Alzheimer's disease." The FASEB Journal.

Marqués-Torrejón, M. Á., E. Porlan, et al. (2013). "Cyclin-Dependent Kinase Inhibitor p21 Controls Adult Neural Stem Cell Expansion by Regulating Sox2 Gene Expression." Cell Stem Cell 12(1): 88-100.

Matrone, C., A. P. M. Barbagallo, et al. (2011). "APP is Phosphorylated by TrkA and Regulates NGF/TrkA Signaling." The Journal of Neuroscience 31(33): 11756-11761.

McConnell, S. K. and C. E. Kaznowski (1991). "Cell cycle dependence of laminar determination in developing neocortex." Science 254(5029): 282-285.

Midthune, B., S.-H. Tyan, et al. (2012). "Deletion of the amyloid precursor-like protein 2 (APLP2) does not affect hippocampal neuron morphology or function." Molecular and Cellular Neuroscience 49(4): 448-455.

Molyneaux, B. J., P. Arlotta, et al. (2007). "Neuronal subtype specification in the cerebral cortex." Nat Rev Neurosci 8(6): 427-437.

Müller, U. C. and H. Zheng (2012). "Physiological Functions of APP Family Proteins." Cold Spring Harbor Perspectives in Medicine 2(2).

Nalivaeva, N. N. and A. J. Turner (2013). "The amyloid precursor protein: A biochemical enigma in brain development, function and disease." FEBS letters 587(13): 20462054.

Naruse, S., G. Thinakaran, et al. (1998). "Effects of PS1 Deficiency on Membrane Protein Trafficking in Neurons." Neuron 21(5): 1213-1221.

Nguyen, L., A. Besson, et al. (2006). "p27kip1 independently promotes neuronal differentiation and migration in the cerebral cortex." Genes \& Development 20(11): 1511-1524. 
Ninomiya, H., J. M. Roch, et al. (1994). "Secreted Form of Amyloid $\beta /$ A4 Protein Precursor (APP) Binds to Two Distinct APP Binding Sites on Rat B103 Neuron-Like Cells Through Two Different Domains, but Only One Site Is Involved in Neuritotropic Activity." Journal of Neurochemistry 63(2): 495-500.

Ninomiya, H., J. M. Roch, et al. (1993). "Amino acid sequence RERMS represents the active domain of amyloid beta/A4 protein precursor that promotes fibroblast growth." J Cell Biol 121(4): 879-886.

Ohno, S. (1970). Evolution by gene duplication, London: George Alien \& Unwin Ltd. Berlin, Heidelberg and New York: Springer-Verlag.

Pastorino, L., A. F. Ikin, et al. (2004). "BACE ( $\beta$-secretase) modulates the processing of APLP2 in vivo." Molecular and Cellular Neuroscience 25(4): 642-649.

Pechnick, R. N., S. Zonis, et al. (2008). "p21Cip1 restricts neuronal proliferation in the subgranular zone of the dentate gyrus of the hippocampus." Proc Natl Acad Sci U S A 105(4): 1358-1363.

Pérez-Martínez, F. J., Á. Luque-Río, et al. (2012). "Reelin-dependent ApoER2 downregulation uncouples newborn neurons from progenitor cells." Biology Open 1(12): 1258-1263.

Pilaz, L.-J., D. Patti, et al. (2009). "Forced G1-phase reduction alters mode of division, neuron number, and laminar phenotype in the cerebral cortex." Proceedings of the National Academy of Sciences 106(51): 21924-21929.

Rakic, P. (1995). "A small step for the cell, a giant leap for mankind: a hypothesis of neocortical expansion during evolution." Trends in Neurosciences 18(9): 383-388.

Reinhard, C., S. S. Hebert, et al. (2005). "The amyloid-beta precursor protein: integrating structure with biological function." Embo J 24(23): 3996-4006.

Rice, H. C., M. Townsend, et al. (2012). "Pancortins interact with amyloid precursor protein and modulate cortical cell migration." Development 139(21): 3986-3996.

Ring, S., S. W. Weyer, et al. (2007). "The Secreted $\beta$-Amyloid Precursor Protein Ectodomain APPs $\alpha$ Is Sufficient to Rescue the Anatomical, Behavioral, and Electrophysiological Abnormalities of APP-Deficient Mice." The Journal of Neuroscience 27(29): 78177826.

Robertson, D. L. and S. C. Lovell (2009). "Evolution in protein interaction networks: coevolution, rewiring and the role of duplication." Biochem Soc Trans 37(Pt 4): 768771.

Roncarati, R., N. Šestan, et al. (2002). "The $\gamma$-secretase-generated intracellular domain of $\beta$ amyloid precursor protein binds Numb and inhibits Notch signaling." Proceedings of the National Academy of Sciences 99(10): 7102-7107.

Rooke, J., D. Pan, et al. (1996). "KUZ, a conserved metalloprotease-disintegrin protein with two roles in Drosophila neurogenesis." Science 273(5279): 1227-1231.

Rosen, D. R., L. Martin-Morris, et al. (1989). "A Drosophila gene encoding a protein resembling the human beta-amyloid protein precursor." Proceedings of the National Academy of Sciences 86(7): 2478-2482.

Rossi, J. J. (2008). "Expression strategies for short hairpin RNA interference triggers." Gene Ther 19(4): 313-317.

Rossjohn, J., R. Cappai, et al. (1999). "Crystal structure of the N-terminal, growth factor-like domain of Alzheimer amyloid precursor protein." Nat Struct Biol 6: 327 - 331.

Ryan, T. J. and S. G. N. Grant (2009). "The origin and evolution of synapses." Nat Rev Neurosci 10(10): 701-712.

Sala Frigerio, C., J. V. Fadeeva, et al. (2010). " $\beta$-Secretase cleavage is not required for generation of the intracellular C-terminal domain of the amyloid precursor family of proteins." FEBS Journal 277(6): 1503-1518.

Sato, T., T.-c. Tang, et al. (2009). "A helix-to-coil transition at the $\varepsilon$-cut site in the transmembrane dimer of the amyloid precursor protein is required for proteolysis." Proceedings of the National Academy of Sciences 106(5): 1421-1426.

Scheinfeld, M., E. Ghersi, et al. (2002). "Processing of beta-amyloid precursor-like protein-1 and -2 by gamma-secretase regulates transcription." J Biol Chem 277: 44195 - 44201.

Seabrook, G. R., D. W. Smith, et al. (1999). "Mechanisms contributing to the deficits in hippocampal synaptic plasticity in mice lacking amyloid precursor protein." Neuropharmacology 38(3): 349-359. 
Small, D., V. Nurcombe, et al. (1994). "A heparin-binding domain in the amyloid protein precursor of Alzheimer's disease is involved in the regulation of neurite outgrowth." The Journal of Neuroscience 14(4): 2117-2127.

Soba, P., S. Eggert, et al. (2005). "Homo- and heterodimerization of APP family members promotes intercellular adhesion." EMBO J 24(20): 3624-3634.

Soldano, A., Z. Okray, et al. (2013). "The Drosophila Homologue of the Amyloid Precursor Protein Is a Conserved Modulator of Wnt PCP Signaling." PLOS BIOLOGY 11(5).

Suzuki, T., K. Ando, et al. (1997). "Phosphorylation of Alzheimer beta-amyloid precursor-like proteins." Biochemistry 36(15): 4643-4649.

Tabata, H. and K. Nakajima (2001). "Efficient in utero gene transfer system to the developing mouse brain using electroporation: visualization of neuronal migration in the developing cortex." Neuroscience 103(4): 865-872.

Tabata, H. and K. Nakajima (2008). "Labeling embryonic mouse central nervous system cells by in utero electroporation." Dev Growth Differ 50(6): 507-511.

Takahashi, T., R. Nowakowski, et al. (1995). "The cell cycle of the pseudostratified ventricular epithelium of the embryonic murine cerebral wall." The Journal of Neuroscience 15(9): 6046-6057.

Takahashi, T., R. S. Nowakowski, et al. (1996). "The Leaving or Q Fraction of the Murine Cerebral Proliferative Epithelium: A General Model of Neocortical Neuronogenesis." The Journal of Neuroscience 16(19): 6183-6196.

Tanzi, R., J. Gusella, et al. (1987). "Amyloid beta protein gene: cDNA, mRNA distribution, and genetic linkage near the Alzheimer locus." Science 235(4791): 880-884.

Temple, S. and A. A. Davis (1994). "Isolated rat cortical progenitor cells are maintained in division in vitro by membrane-associated factors." Development 120(4): 999-1008.

Torroja, L., M. Packard, et al. (1999). "The Drosophila $\beta$-Amyloid Precursor Protein Homolog Promotes Synapse Differentiation at the Neuromuscular Junction." The Journal of Neuroscience 19(18): 7793-7803.

Tyan, S.-H., A. Y.-J. Shih, et al. (2012). "Amyloid precursor protein (APP) regulates synaptic structure and function." Molecular and Cellular Neuroscience 51(1-2): 43-52.

Vassar, R., B. D. Bennett, et al. (1999). " $\beta$-Secretase Cleavage of Alzheimer's Amyloid Precursor Protein by the Transmembrane Aspartic Protease BACE." Science 286(5440): 735-741.

Vidaki, M., S. Tivodar, et al. (2012). "Rac1-Dependent Cell Cycle Exit of MGE Precursors and GABAergic Interneuron Migration to the Cortex." Cerebral Cortex 22(3): 680-692.

Vingtdeux, V. and P. Marambaud (2012). "Identification and biology of $\alpha$-secretase." Journal of Neurochemistry 120: $34-45$.

Visel, A., C. Thaller, et al. (2004). "GenePaint.org: an atlas of gene expression patterns in the mouse embryo." Nucleic Acids Res 32(Database issue): D552-556.

Waldron, E., S. Isbert, et al. (2008). "Increased AICD generation does not result in increased nuclear translocation or activation of target gene transcription." Exp Cell Res 314(13): 2419-2433.

Walsh, D. M., J. V. Fadeeva, et al. (2003). " $\gamma$-Secretase Cleavage and Binding to FE65 Regulate the Nuclear Translocation of the Intracellular C-Terminal Domain (ICD) of the APP Family of Proteins $\uparrow . "$ Biochemistry 42(22): 6664-6673.

Wang, P., G. Yang, et al. (2005). "Defective Neuromuscular Synapses in Mice Lacking Amyloid Precursor Protein (APP) and APP-Like Protein 2." The Journal of Neuroscience 25(5): 1219-1225.

Wang, Y. and Y. Ha (2004). "The X-Ray Structure of an Antiparallel Dimer of the Human Amyloid Precursor Protein E2 Domain." Molecular Cell 15(3): 343-353.

Wang, Z., B. Wang, et al. (2009). "Presynaptic and Postsynaptic Interaction of the Amyloid Precursor Protein Promotes Peripheral and Central Synaptogenesis." The Journal of Neuroscience 29(35): 10788-10801.

Weyer, S. W., M. Klevanski, et al. (2011). "APP and APLP2 are essential at PNS and CNS synapses for transmission, spatial learning and LTP." EMBO J 30(11): 2266-2280.

White, A. R., G. Multhaup, et al. (1999). "The Alzheimer's Disease Amyloid Precursor Protein Modulates Copper-Induced Toxicity and Oxidative Stress in Primary Neuronal Cultures." The Journal of Neuroscience 19(21): 9170-9179. 
Wiese, M., A. Antebi, et al. (2010). "Intracellular trafficking and synaptic function of APL-1 in Caenorhabditis elegans." PLoS One 5(9).

Wolfe, M. S., W. Xia, et al. (1999). "Two transmembrane aspartates in presenilin-1 required for presenilin endoproteolysis and [gamma]-secretase activity." Nature 398(6727): 513517.

$\mathrm{Xu}, \mathrm{X}$., H. Zhou, et al. (2011). "Mediator is a transducer of amyloid-precursor-protein-dependent nuclear signalling." EMBO Rep 12(3): 216-222.

Xue, Y., S. Lee, et al. (2011). "Crystal structure of amyloid precursor-like protein 1 and heparin complex suggests a dual role of heparin in E2 dimerization." Proceedings of the National Academy of Sciences 108(39): 16229-16234.

Yamamoto, K., T. Miyoshi, et al. (1994). "The survival of rat cerebral cortical neurons in the presence of trophic APP peptides." J Neurobiol 25(5): 585-594.

Yanagida, K., M. Okochi, et al. (2009). "The 28-amino acid form of an APLP1-derived A $\beta$-like peptide is a surrogate marker for A $\beta 42$ production in the central nervous system." EMBO Molecular Medicine 1(4): 223-235.

Yang, G., Y.-D. Gong, et al. (2005). "Reduced synaptic vesicle density and active zone size in mice lacking amyloid precursor protein (APP) and APP-like protein 2." Neuroscience Letters 384(1-2): 66-71.

Yang, L., Z. Wang, et al. (2009). "Amyloid Precursor Protein Regulates Cav1.2 L-type Calcium Channel Levels and Function to Influence GABAergic Short-Term Plasticity." The Journal of Neuroscience 29(50): 15660-15668.

Yang, Y., R. S. Turner, et al. (1998). "The Chaperone BiP/GRP78 Binds to Amyloid Precursor Protein and Decreases A $\beta 40$ and A $\beta 42$ Secretion." Journal of Biological Chemistry 273(40): 25552-25555.

Yang, Y. T., C. L. Wang, et al. (2012). "DOCK7 interacts with TACC3 to regulate interkinetic nuclear migration and cortical neurogenesis." Nat Neurosci 15(9): 1201-1210.

Yoon, K., S. Nery, et al. (2004). "Fibroblast growth factor receptor signaling promotes radial glial identity and interacts with Notch1 signaling in telencephalic progenitors." $\underline{\mathbf{J}}$ Neurosci 24(43): 9497-9506.

Young-Pearse, T., A. Chen, et al. (2008). "Secreted APP regulates the function of full-length APP in neurite outgrowth through interaction with integrin beta1." Neural Development 3(1): 15.

Young-Pearse, T. L., J. Bai, et al. (2007). "A Critical Function for $\beta$-Amyloid Precursor Protein in Neuronal Migration Revealed by In Utero RNA Interference." The Journal of Neuroscience 27(52): 14459-14469.

Young-Pearse, T. L., S. Suth, et al. (2010). "Biochemical and Functional Interaction of Disrupted-in-Schizophrenia 1 and Amyloid Precursor Protein Regulates Neuronal Migration during Mammalian Cortical Development." The Journal of Neuroscience 30(31): 10431-10440.

Zhang, Y. E., P. Landback, et al. (2011). "Accelerated recruitment of new brain development genes into the human genome." PLoS Biol 9(10): e1001179.

Zheng, H., M. Jiang, et al. (1995). " $\beta$-amyloid precursor protein-deficient mice show reactive gliosis and decreased locomotor activity." Cell 81(4): 525-531.

Zheng, H. and E. H. Koo (2011). "Biology and pathophysiology of the amyloid precursor protein." Mol Neurodegener 6(1): 27. 


\section{SEYED ALI MOHAMMAD SHARIATI}

ljzerenmolenstraat 117, Heverlee, 3001, Belgium | sam.shariati@gmail.com

\section{EDUCATION}

PhD, KU Leuven, Leuven, Belgium

$2010-2013$

Molecular and Developmental Genetics,

Thesis Title: APLP regulates neuronal stem cell differentiation during cortical development.

Mentor: Professor Bart De Strooper

Predoctoral studies, KU Leuven, Leuven, Belgium

$2008-2010$ Molecular and Developmental Genetics,

Thesis Title: Cell autonomous functions of APP proteins in vivo and in vitro using APP triple knockout mouse of embryonic stem cells.

Mentor: Professor Bart De Strooper

M.Sc. Genetics Tarbiat Modares University, Tehran, Iran,

Thesis focus: Genetic polymorphism of NRG1 gene in patients with schizophrenia Mentor: Professor. Mehrdad Behmanesh

\section{TEACHING EXPERIENCE}

Teacher Assistant, KU Leuven,

$2012-2013$

Hot topics in cell biology, Master of Biomedical Sciences.

Teacher Assistant, KU Leuven,

2012-2013

Molecular pathogenesis of neurodegenerative diseases, Medical Students.

\section{PUBLICATIONS AND PAPERS}

1. Shariati SA and De Strooper B. Redundancy and divergence in the Amyloid Precursor Protein family. FEBS Letters, 2013.

2. Shariati SA, Lau P, Hassan BA, M“ uller U, Dotti CG, De Strooper B, G" artner A. APLP2 regulates neuronal stem cell differentiation during cortical development. Cell Sci, 2013. Citation: 4

3. Arefian E, Kiani J, Soleimani M, Shariati SA, Aghaee-Bakhtiari SH, Atashi A, Gheisari Y, Ahmadbeigi N, Banaei-Moghaddam AM, Naderi M, Namvarasl N, Good $\mathrm{L}$, Faridani OR. Analysis of microRNA signatures using size-coded ligation mediated PCR. Nucleic Acids Res, 2011. Citation: 4

4. Ahmadbeigi N, Soleimani M, Gheisari $Y$, Vasei M, Amanpour S, Bagherizadehl, Shariati SA, Azadmanesh K, Amini S, Shafiee A, Arabkari V, Nardi N. Dormant phase and multinuclear cells: two key phenomena in early culture of murine bone marrow mesenchymal stem cells. Stem Cells Dev, 2011. Citation: 6

5. Bergmans BA, Shariati SA, Habets RL, Versreken P, Schoonjans L, Muller U, Dotti CG, De Strooper. Neurons generated from APP/APLP1/APLP2 triple knockout embryonic stem cells behave normally in vitro and in vivo: lack of evidence for a 
cell autonomous role of the amyloid precursor protein in neuronal differentiation. Stem Cells, 2010. Citation: 23

6. Shariati S.A, Mehrdad Behmanesh, Hamid Galehdari. Multiplex Tetra-Primer Amplification Refractory Mutation System PCR to genotype SNP8NRG221533 of NRG1 gene. Iranian Journal of Biotechnology, 2008. Citation: 1

\section{SKILLS}

Languages:

- $\quad$ Farsi (Persian)-Native

- $\quad$ English (TOEFL IBT:107, IELTS:7)

- $\quad$ French (Basic)

Laboratory:

Confocal and live cell imaging, In utero gene transfer to the brain, Birthdating and cell cycle analysis, Western blot, Immunostaining, Embryonic and neuronal stem cell culture, Primary neuron culture, Cloning, DNA and (micro)RNA extraction, Real Time (RT)PCR.

\section{REFERENCES}

1. Professor Dr. Bart De Strooper, Center for the Biology of Disease, VIB and Katholieke Universiteit Leuven, Belgium, bart.destrooper@cme.vib-kuleuven.be

2. Professor Dr. Carlos Dotti, Center for the Biology of Disease, VIB and Katholieke Universiteit Leuven, carlos.dotti@cme.vib-kuleuven.be

3. Professor Dr. Bassem Hassan, Center for the Biology of Disease, VIB and Katholieke Universiteit Leuven, bassem.hassan@cme.vibkuleuven.be

4. Professor Dr. Amantha Thathiah, Center for the Biology of Disease, VIB and Katholieke Universiteit Leuven, Belgium, amantha.thathiah@cme.vibkuleuven.be 